\author{
UNIVERSIDADE DE SÃO PAULO \\ Faculdade de Filosofia, Ciências e Letras de Ribeirão Preto \\ Departamento de Física
}

THAYS BERRETTA KÄSEMODEL

Avaliação da Correção de Atenuação e Espalhamento em Imagens de SPECT em Protocolo Cerebral.

Versão Corrigida

Ribeirão Preto - SP 
THAYS BERRETTA KÄSEMODEL

Avaliação da Correção de Atenuação e Espalhamento em Imagens de SPECT em Protocolo Cerebral.

Dissertação submetida ao Programa de Pós-
Graduação em Física Aplicada à Medicina e
Biologia, da Faculdade de Filosofia, Ciências e
Letras de Ribeirão Preto, da Universidade de
São Paulo, como parte dos requisitos para a
obtenção do título de Mestre em Ciências, Area
de concentração: Física Aplicada à Medicina e
Biologia.

Orientador: Prof. Dr. Eder Rezende Moraes.

Ribeirão Preto - SP 
THAYS BERRETTA KÄSEMODEL

\title{
Avaliação da Correção de Atenuação e Espalhamento em Imagens de SPECT
} em Protocolo Cerebral.

\author{
Dissertação submetida ao Programa de Pós- \\ Graduação em Física Aplicada à Medicina e \\ Biologia, da Faculdade de Filosofia, Ciências e \\ Letras de Ribeirão Preto, da Universidade de \\ São Paulo, como parte dos requisitos para a \\ obtenção do título de Mestre em Ciências.
}

Área de concentração:

Física Aplicada à Medicina e Biologia.

Orientador:

Prof. Dr. Eder Rezende Moraes.

Ribeirão Preto - SP 


\section{AUTORIZO A REPRODUÇÃO TOTAL OU PARCIAL DESTE}

TRABALHO, POR QUALQUER MEIO CONVENCIONAL OU ELETRÔNICO,

PARA FINS DE ESTUDO E PESQUISA, DESDE QUE CITADA A FONTE.

\section{FICHA CATALOGRÁFICA}

Käsemodel, Thays Berretta

Avaliação da correção de atenuação e espalhamento em imagens SPECT em protocolo cerebral / Thays Berretta Käsemodel; orientador Eder Rezende Moraes. Ribeirão Preto - SP, 2013.

85f.:il.

Dissertação (Mestrado - Programa de Pós-graduação em Físicaaplicada à Medicina e Biologia) - Faculdade de Filosofia, Ciências e Letras de Ribeirão Preto da Universidade de São Paulo, 2013.

1. Correção de Atenuação. 2. Correção de Espalhamento. 3. SPECT-CT. 4. Tripla Janela de Energia5. Correção Uniforme de Atenuação 
Nome: KÄSEMODEL, Thays Berretta.

Título: Avaliação da Correção de Atenuação e Espalhamento em imagens de SPECT em Protocolo Cerebral.

Dissertação apresentada à Faculdade de Filosofia, Ciências e Letras de Ribeirão Preto para obtenção do título de Mestre em Ciências.

Aprovado em:

Banca Examinadora

Prof. Dr.

Julgamento:

Prof. Dr.

Julgamento:

Prof. Dr.

Julgamento:
Instituição:

Assinatura:

Instituição:

Assinatura:

Instituição:

Assinatura: 
Dedicatória

Aos meus pais Rubens e Deise, ao meu irmão Rodrigo, à minha tia Nádia e aos irmãos de coração Alex, Marcelo e Caroline. 


\section{AGRADECIMENTOS}

Ao orientador Eder Rezende Moraes, pelo conhecimento transmitido e construído, paciência e confiança.

À CAPES pelo apoio financeiro através de bolsa e auxílios à pesquisa.

Ao professor Dr.Lauro WichertAnapela paciência, conhecimentos transmitidos e me apresentar à rotina clínica de um setor de Medicina Nuclear

À minha família por todo o apoio, amor e compreensão pelo tempo e distância.

Aos amigos que fiz durante esta trajetória e aos que trouxe de longa data pelo apoio, carinho e companheirismo.

À secretária da pós graduação Nilza pela sua eficiência. 


\section{RESUMO}

\section{KÄSEMODEL, T. B. Avaliação da Correção de Atenuação e Espalhamento em}

Imagens de SPECT em Protocolo Cerebral. 2014.Dissertação (Mestrado. Faculdade de Filosofia, Ciências e Letras de Ribeirão Preto, Universidade de São Paulo, Ribeirão Preto - SP, 2014.

A tomografia computadorizada por emissão de fóton único (SPECT) é uma das modalidades de diagnóstico na Medicina Nuclear em que se detecta a radiação emitida por um radiofármaco previamente administrado ao paciente. Visto que osfótons emitidos sofrem interações com o corpo do paciente, fazem-se necessárias as correções de atenuação e de espalhamento a fim de melhor representar a distribuição do radiofármaco, e assimresultar em imagens mais precisas.

O objetivo deste trabalho é avaliar os parâmetros anotados como padrão para reconstruções de imagens tomográficas e as correções de atenuação e de espalhamento em imagens SPECT do Hospital de Clínicas da Faculdade de Medicina da Universidade de São Paulo, por meio de análises qualitativas e quantitativas das imagens reconstruída a partir das aquisições tomográficas.

Sob um protocolo de SPECT-CT cerebral modificado para duas janelas de aquisição, foram adquiridas imagens SPECT e SPECT-CT (BrightView XCT, Philips) utilizando fantomaJaszczak e reconstruídas pelos métodos FBP, MLEM e OSEM.

Os resultados mostram que o método FBP apresenta imagens de baixa precisão devido à baixa SNR. A avaliação sugere o uso dos métodos iterativos MLEM e OSEM com correção de atenuação como método padrão de reconstrução de imagens de perfusão cerebral. De acordo com a avaliação de imagens do fantomaJaszczak e análise do contraste entre esfera fria ebackground,propõe-se análise observacional e avaliação das imagens clínicas reconstruídas pelo método OSEM com os parâmetros 3 iterações, 16 subsets, filtro Butterworth com frequência de corte 0,34 e potencia 1 , como novos parâmetros padrão de reconstrução de imagens. 
Palavras-chave: SPECT, mapa de atenuação, correção não uniforme de atenuação, correção de espalhamento, tripla janela de energia. 


\section{ABSTRACT}

KÄSEMODEL, T. B. Evaluation of Attenuation and Scattering Correction in SPECT images of a Cerebral Protocol. Dissertação (Mestrado). Faculdade de Filosofia, Ciências e Letras, USP - RP.

Single Photon Emission Computed Tomography (SPECT) is one of the diagnostic modalities in nuclear medicine, it detects the radiation emitted by a radioisotope previously administered to the patient. Since the photons undergo interactions with the patient's body,attenuationand scatteringcorrections are necessary in order to best represent the distribution of the radiopharmaceutical, and thus result in more accurate images.

The aim of this study is to evaluate the standard parameters for tomographic imagesreconstruction, and attenuation and scatter corrections ofSPECT images, from Hospital das Clínicas da Faculdade de Medicina de RibeirãoPreto, Universidade de São Paulo, through qualitativeand quantitative analysis of the reconstructed image obtained from SPECT aquisitions.

Though a modified to two windows of acquisition protocol for cerebral SPECTCT, we acquired SPECT and SPECT-CT images (BrightView XCT, Philips) using phantom Jaszczak and the ones were reconstructed by FBP, MLEM and OSEM methods.

The results show that the FBP method has poor image precision due to low SNR. The review suggests the use of iterative methods MLEM and OSEM with attenuation correction as a standard method of image reconstruction of cerebral perfusion. According to the images the phantom Jaszczak and contrast analysis between cold sphere and background, we propose observational analysis and evaluations of clinical images reconstructed by OSEM method with parameters 3 iterations, 16 subsets, Butterworth filter with cutoff frequency 0.34 and order 1 , as newstandard parameters for image reconstruction parameters.

Keywords: SPECT, attenuation map, non-uniform attenuation correction, scatter correction, triple energy window. 


\section{LISTA DE FIGURAS}

Figura 1 efeito fotoelétrico e a emissão de raios $X$ característicos. Retirada e adaptada de [1] 5

Figura 2 Efeito Compton. Retirada e adaptada [1] 6

Figura 3 Produção e aniquilação de pares. Retirada e adaptada de [2] $\quad 7$

Figura 4 Espalhamento coerente. Retirada e adaptada de [1] 8

Figura 5 Relação entre a energia do fóton incidente na matéria a interação mais provável. Retirada e adaptada [2] 11

Figura 6 Mapa de atenuação e número de TC.Retirada de [3] 17

Figura 7 Espectro de energia e localização e largura das janelas de energia. Retirada e adaptada de [4] 19

Figura 8 Esquema ilustrativo dos princípios básicos e componentes de deteç̧ão do raio gama. Retirada e adaptada de [2] 21

Figura 9 Esquema simplificado da amplificação do sinal no interior da fotomultiplicadora. Retirada e adaptada [2]

Figura 10 Exemplificação da construção de um sinograma. Retirada e adaptada de [1]

Figura 11 Reconstrução da imagem tomográfica a partir do método Retroprojeção Simples.Retirada de [5] 26

Figura 12 Fantoma Jaszczak Deluxe[6] 37

Figura 13 Espectro do Tc99m e Janelas de energia 43

Figura 14 Corte tomográfico do fantoma Jaszczak; padrões cilíndricos da região inferior do fantoma $\quad 46$

Figura 15 Corte tomográfico do FantomaJaszczak; as lesões esféricas frias da região superior do fantoma 46

Figura 16 Perfil do numero de TC do mapa de atenuação 47

Figura 17 Mapa de atenuação; A diferenciação dos tecidos 48

Figura 18 Valores de HU num corte na fatia central do cérebro do mapa de atenuação gerado a partir da Tomografia Computadorizada 49

Figura 19 Reconstrução OSEM sem correção de atenuação 50

Figura 20 Reconstrução OSEM +CUA 50 
Figura 21 Reconstrução OSEM + CNUA 51

Figura 22 Reconstrução OSEM sem correção de atenuação 51

Figura 23 Reconstrução OSEM + CUA. Esferas de acrílico 52

Figura 24 Reconstrução OSEM + CNUA. Esferas de acrílico 52

Figura 25 Melhora no contraste entre a estrutura e o background da imagem 53

Figura 26 Posicionamento das ROls da análise 56

Figura 27 Alteração no número de subsets da reconstrução 57

Figura 28 Imagem reconstruída com 30 iterações e 16 subsets 60

Figura 29 Comparação entre as imagens com diferente parâmetro de frequência de corte do filtro Butterworth reconstrução pelo método MLEM 62

Figura 30 Comparação entre as imagens com diferente parâmetro de frequênciade corte do filtro Butterworth reconstrução pelo método OSEM

Figura 31 Comparação das imagens cuja frequência de corte foi alterada. Reconstrução pelo método OSEM 65 


\section{LISTA DE TABELAS}

Tabela 1 Números de TC para os diferentes tecidos do corpo humano. Extraído de [7]

Tabela 2 Aquisições realizadas e suas respectivas atividades e concentração de radionuclídeo no interior do fantoma

Tabela 3 Condições de Aquisição de SPECT e TC e Parâmetros de Reconstrução

Tabela 4 Número de TC lido nas estruturas do fantoma

Tabela 5 Contraste entre a maior esfera de acrílico e o background do fantomapara as diferentes reconstruções tomográficas com e sem correção não uniforme de atenuação

Tabela 6 Parâmetros utilizados para a reconstrução das imagens

Tabela 7 Contraste entre a esfera de acrílico e o background do fantoma para os diferentes métodos de reconstrução de imagemcom e em correção uniforme de atenuação

Tabela 8 Razão Sinal Ruído do background para as reconstruções pelos diferentes métodos com e sem correção uniforme de atenuação

Tabela 9 Contraste entre a maior esfera de acrílico e o background do fantoma nas reconstruções com e sem correção de atenuação e sem correção de espalhamento pelo método OSEM.

Tabela 10 Nível de correlação de Pearson entre a atividade no interior do fantoma e o contraste entre a maior esfera e o background

Tabela 11 SNR das imagens com CUA e CUA + CE

Tabela 12 Contraste percentual entre a maior esfera de acrílico e o background quando o parâmetro frequência de corte do filtro Butterworth é alterado 


\section{Sumário}

Lista de Figuras $\quad$ ix

Lista de Tabelas xi

1. Introdução 1

2. Fundamentação Teórica 2

2.1. Interação da Radiação com a Matéria 2

2.1.1. Efeito Fotoelétrico 3

2.1.2. Efeito Compton 5

2.1.3. Produção e Aniquilação de Pares 6

2.1.4. Espalhamento Coerente $\quad 7$

2.2. Atenuação 8

2.2.1. Coeficiente de Atenuação 8

2.2.2. Coeficiente de Atenuação por Massa 9

2.3. Correção de Atenuação 11

2.3.1. Correção Uniforme de Atenuação 11

2.3.2. SPECT/CT e Mapa de Atenuação 15

$\begin{array}{ll}\text { 2.4. Correção de Espalhamento } & 17\end{array}$

2.5. Princípios Básicos da Câmara Gama 20

2.6. Reconstrução de Imagens em Medicina Nuclear 22

2.6.1. Retroprojeção Simples e Retroprojeção Filtrada 25

2.6.2. Reconstrução Iterativa 29

2.7. Qualidade de Imagem em Medicina Nuclear 31

2.7.1. Resolução Espacial 32

2.7.2. Contraste 34

2.7.3. Ruído 35

3. Materiais e Métodos 37

3.1. Materiais 37

3.1.1. FantomaJaszczak 37

3.1.2. Philips BrightView XCT 38

3.1.3. JETStreamWorkspace 38

3.2. Métodos $\quad 39$

3.2.1. Aquisição das Imagens e Protocolo de Aquisição 39

3.2.2. Correção de Espalhamento 41 
3.2.3. Avaliação da Qualidade da Imagem

3.2.4. Avaliação da Correlação do Contraste com a Atividade no Fantoma

4. Resultados e Discussão 45

5. Conclusão 66

Referências Bibliográficas $\quad 68$ 


\section{INTRODUÇÃO}

O desenvolvimento computacional e o crescimento do mercado internacional de equipamentos de imagens médicas tem levado a diferentes sistemas de aquisição de imagens médicas e aprimoramento dos procedimentos de reconstrução de imagens. Nos últimos anos têm-se assistido o crescimento de sistemas de imagens híbridos que dispõe de mais de uma modalidade de diagnóstico num mesmo equipamento. Dentre os que mais se destacaram foram os sistemas contendo tomógrafos de raios $\mathrm{X}$ (TC) e tomógrafos por emissão: Tomografia Computadorizada por Emissão de Fóton Único (do inglês, Single PhotomEmissionComputedTomography - SPECT) e Tomografia por Emissão de Pósitron (do inglês, PositronEmissionTomography - PET). Estes sistemas híbridos apresentam o diferencial de oferecer imagens anatômicas fornecidas através da tomografia computadorizada, em conjunto com imagens funcionais resultado da aquisição por tomografia de emissão: SPECT ou PET. Em sistemas híbridos os dois conjuntos de imagens serão adquiridos durante o mesmo exame, sem que seja necessário o deslocamento do paciente nem que exista uma lacuna temporal significativa entre a tomografia de medicina nuclear e a tomografia computadorizada convencional. Assim sendo, diminui-se os problemas para a fusão das imagens das diferentes técnicas tomográficas resultando em melhores imagens para 0 diagnóstico e laudo clínico. Recentemente surgiram sistemas que unem imagens por ressonância magnética (MRI) e PET.

A tomografia computadorizada por emissão de fóton único (SPECT) é uma das modalidades de diagnóstico na Medicina Nuclear em que detecta-se a radiação emitida por um radiofármaco previamente administrado ao paciente, seja por injeção ou ingestão do mesmo a depender do exame a ser realizado. Visto que os fótons emitidos sofre algum tipo de interação com a matéria no interior do corpo do paciente fazem-se necessárias as correções de atenuação e de espalhamento a fim de melhor representar a distribuição do radiofármaco e assim, resultar em imagens mais precisas. As imagens em sistemas SPECT convencionais são reconstruídas com a utilização de um perfil de atenuação uniforme, de acordo com o método de

Chang de correção atenuação e em sistemas híbridos podem ser reconstruídas 
baseando-se em um perfil de atenuação não uniforme, também chamado de mapa de atenuação, que é gerado pela aquisição tomográfica da TC.

O software de reconstrução tomográfica existente no tomógrafo instalado no setor de Medicina Nuclear do Hospital das Clínicas da Faculdade de Medicina da Universidade de São Paulo em Ribeirão Preto não dispõe de meio para que a correção de espalhamento seja feita durante o processo de reconstrução utilizandose somente do software da Philips. Deste modo, atribui-se a tarefa de correção das imagens por meios computacionais ao físico médico do setor para que a correção seja feita utilizando-se de outros softwares de edição de imagem. Tal medida exige um entrosamento ainda maior entre os membros da equipe médica e dos demais servidores do setor de Medicina Nuclear para um mais preciso laudo médico.

O propósito deste trabalho é avaliar as técnicas de correção de atenuação de Chang e o método de correção de atenuação baseado na TC bem como avaliar a aplicação da correção de espalhamento pelo método da tripla janela de energia em imagens de SPECT. Apesar de fazer parte do propósito do trabalho avaliar os efeitos da correção de atenuação baseada na TC, devido à problemas de funcionamento do tomógrafo utilizado para as aquisições das imagens, este item teve de ser avaliado com base em apenas uma aquisição, sem a possibilidade de variação de parâmetros como o kVp e mAs.

\section{FUNDAMENTAÇÃO TEÓRICA}

\subsection{INTERAÇÃO DA RADIAÇÃO COM A MATÉRIA}

Os dois tipos de decaimento radioativo, numa classificação mais geral, são decaimento por emissão de partículas carregas e decaimento radioativo por emissão de radiação eletromagnética. Ondas eletromagnéticas resultantes do interior do núcleo atômico são os chamados raios gama e ondas eletromagnéticas emitidas após a transição eletrônica são chamados raios $X$. Tanto as partículas carregadas quanto a radiação eletromagnética são capazes de transferir sua energia à medida que atravessam a matéria. O mecanismo de transferência de energia, basicamente, se dá por ionização e por excitação de átomos e moléculas. Emissões radioativas são classificadas por radiação ionizante exatamente por ser capaz de proporcionar a ionização de átomos e moléculas. 
A atração e repulsão Coulombiana entre partículas carregadas negativa e positivamente, respectivamente e é responsável pela alteração da trajetória dos elétrons, bem como da radiação alfa e beta que é emitida em alguns decaimentos radioativos.

Raios gama, raios $x$, radiação de aniquilação e são exemplos de radiação de alta energia. Este tipo de radiação atravessa a matéria interagindo através de complexos processos e, por razões práticas, estas interações são tratadas como colisões entre a radiação eletromagnética e um alvo. Sendo que o alvo pode ser 0 núcleo, o elétron ou o átomo como um todo. É importante salientar que a interação da radiação eletromagnética com a matéria não causa a ionização no mesmo instante em que a interação ocorre, por consequência disto, é chamada ionização indireta. Assim, fótons de alta energia são classificados como radiação ionizante secundária ou simplesmente radiação secundária.

Tratando-se de medicina nuclear os quatro tipos de interação da radiação eletromagnética com a matéria que são de grande importância no processo de imageamento são o efeito fotoelétrico, o espalhamento Comptom e a aniquilação de pares. O espalhamento Rayleigh (também conhecido por espalhamento coerente) é outra forma de interação da radiação com a matéria, contudo, a faixa de energia com que o mesmo ocorre o torna irrelevante em Medicina Nuclear.

\subsubsection{Efeito Fotoelétrico}

O efeito fotoelétrico é o processo de absorção atômica no qual a radiação incidente é completamente absorvida pelo átomo sobre o qual incide. Este fenômeno foi enunciado por Albert Einstein em 1905. Einstein focou seu estudo no comportamento particular com que onda eletromagnética é absorvida e emitida e não em seu comportamento ondulatório. Em seu estudo, utilizou-se da condição de energia quantizada proposta por Max Plank em 1900, na qual a energia da radiação eletromagnética emitida e cuja frequência de oscilação é $v$, assume valores inteiros de hv, em que h é a constante de Planck. Ou seja, ao contrário de considerar a luz como uma onda eletromagnética, Eisntein propôs que ela é composta por corpúsculos e denominou-os fótons e cada fóton transporta uma energia dada por hv, em que h é a constante de Planck e $v$ a frequência da radiação. 
De acordo com esta proposta, um fóton transfere toda sua energia para um elétron e, o efeito fotoelétrico ocorre quando esta energia é utilizada para ejetar um elétron do orbital atômico. Normalmente o elétron ejetado neste processo é oriundo de uma camada mais próxima do núcleo e cuja energia de ligação é $E_{\text {ligação. }}$ O elétron ejetado passa a ser chamado de fotoelétron e sua energia cinética é dada pela diferença entre a energia do fóton incidente e a energia de ligação que o mantinha ligado ao átomo.

$$
E_{\text {fotoeletron }}=E_{\text {foton }}-E_{\text {ligação }} \quad \text { Equação } 1
$$

Onde $E_{\text {fotoeletron }}$ é a energia cinética do elétron ejetado do átomo, $E_{\text {foton }}$ é a energia do

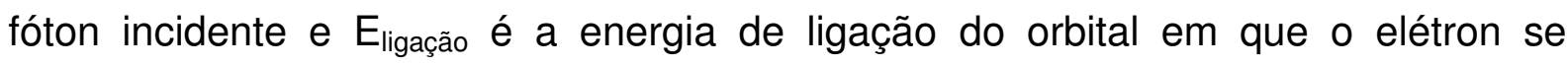
localizava na estrutura atômica. Devido a este tratamento que é dado ao efeito fotoelétrico é possível considerar que este mecanismo de interação com a matéria é uma colisão entre o fóton e o elétron na qual o elétron é ejetado e a energia do fóton incidente é completamente absorvida e, portanto, o fóton desaparece.

Um fotoelétron não será ejetado caso a energia absorvida seja inferior à energia de ligação. O efeito fotoelétrico causa uma vacância no orbital eletrônico e, para que se mantenha a estabilidade eletrônica, esta vacância - comumente chamada de "buraco" - é preenchida com um elétron de uma camada mais externa, ou seja, ocorre a transição eletrônica de um estado menos ligado para um estado mais ligado. Para que esta transição seja possível, é necessário que o elétron libere energia, e a energia liberada é igual à diferença de energia entre as camadas eletrônicas. Deste modo, a radiação emitida quando um elétron transita entre as mesmas camadas eletrônicas terá sempre a mesma energia. Este tipo de radiação é chamado de raios $X$ característico, uma vez que cada átomo possui energias de ligação característica $e$, assim, o raio $X$ emitido é característico da transição que ocorre entre as determinadas camadas orbitais do determinado átomo. Uma vez que a energia de um fóton é dada por $E=h c / \lambda$, conforme a figura 1 , podemos visualizar a emissão dos raios $X$ característicos. 


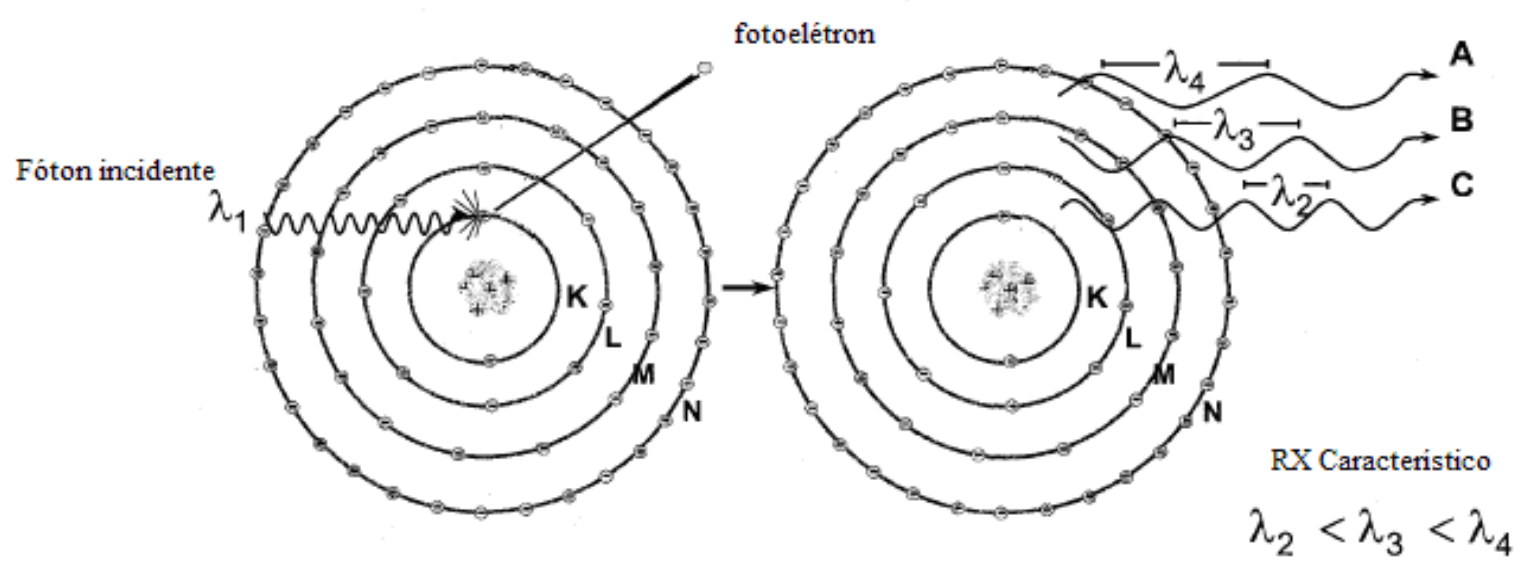

Figura 80 efeito fotoelétrico e a emissão de raios $X$ característicos. Retirada e adaptada de Bushberg, cap3pág 41.

\subsubsection{Efeito Compton}

Assim como o efeito fotoelétrico, o efeito Compton trata-se da interação de uma onda eletromagnética com um elétron orbital. $O$ efeito Compton pode ser visto como uma colisão entre o fóton incidente com um elétron de uma camada mais externa da estrutura atômica. Enquanto o efeito fotoelétrico ejeta um elétron de uma camada mais interna e resulta na absorção total do fóton, o efeito Compton é caracterizado pela absorção parcial da energia, ejeção do elétron e alteração da direção de propagação da radiação incidente. A energia desta radiação incidente é muito maior do que a energia de ligação do elétron ao átomo e assim, a interação pode ser vista como uma colisão entre a radiação e um elétron livre.

A energia mecânica e o momento linear do sistema se conservam neste processo. O elétron, que inicialmente pode ser considerado em repouso, absorve parte da energia do fóton incidente e adquire momento linear e energia cinética. Como ocorre a conservação do momento linear total do sistema, o fóton incidente sofre alteração em sua direção de propagação.

Ao desvio sofrido pela radiação incidente, $\Delta \theta$, dá-se o nome de desvio Compton e este é dependente apenas do ângulo $\theta$ para o qual ocorre o desvio da direção de propagação da radiação.

$$
\Delta \theta=\left(\mathrm{h} / \mathrm{m}_{0} \cdot \mathrm{c}\right) \cdot(1-\cos (\theta)) \quad \text { Equação } 2
$$


em que $m_{0}$ é a massa de repouso do elétron, c é a velocidade da luz no vácuo e h é a constante de Planck.

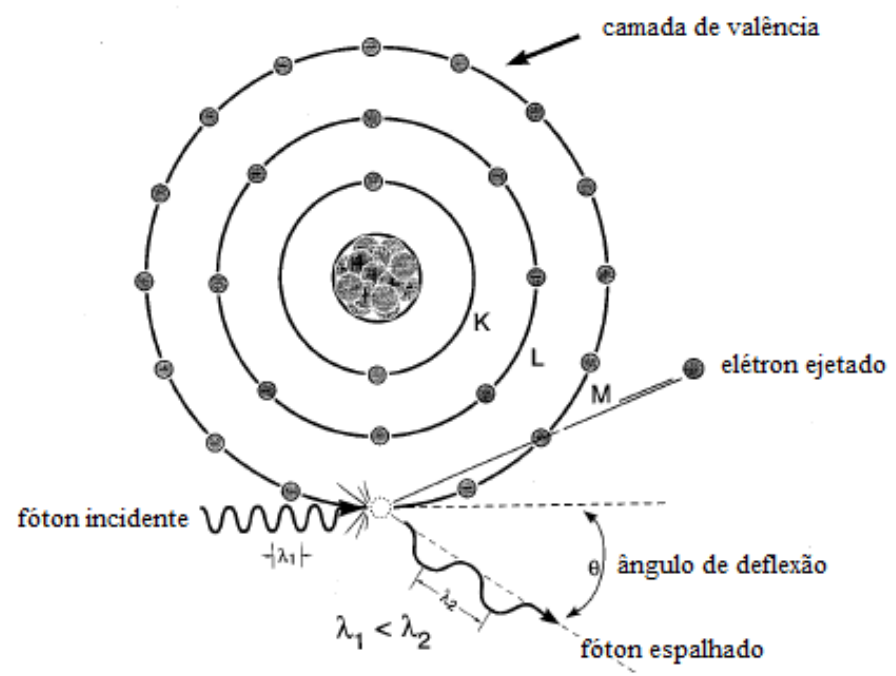

Figura 9 Efeito Compton.

$O$ fóton incidente transfere energia para o elétron e sofre deflexão em sua trajetória. Retirada e adaptada de Bushberg, cap3, pag 38.

\subsubsection{Produção e Aniquilação de Par}

A produção de par ocorre quando um fóton interage com o campo elétrico de uma partícula carregada; esta interação costuma ser com o núcleo atômico, mas também pode ser com um elétron. A radiação desaparece e como consequência, dá origem a um par elétron-pósitron, $\mathrm{e}^{-}+\mathrm{e}^{+}$.

Para que ocorra a criação de um par $\mathrm{e}^{-}+\mathrm{e}^{+}$é necessário que o fóton possua energia mínima igual à energia de repouso das duas partículas.A energia de repouso do elétron e do pósitron é idêntica, visto que ambos são matéria e antimatéria e, consequentemente, possuem mesma massa de repouso, assim, pela relação de Einstein:

$$
\mathrm{E}_{0 \mathrm{e}^{-}}=\mathrm{E}_{0 \mathrm{e}+}=\mathrm{m}_{\mathrm{e}} \cdot \mathrm{c}^{2}=0,511 \mathrm{MeV} \text { Equação } 3
$$

em que $E_{0 e-}$ é a energia de repouso do elétron, $E_{0 e+}$ é a energia de repouso do pósitron, $m_{e}$ é a massa do elétron e c é a velocidade da luz no vácuo. Deste modo, a energia mínima para formar um par elétron-pósitron é de 1,022 MeV. Caso o fóton 
tenha energia excedente a este valor, esta energia é transferida ao par $\mathrm{e}^{-}+\mathrm{e}^{+}$em forma de energia cinética a qual será dissipada através de interações com a matéria, principalmente através de ionização e excitação eletrônica. Quando o pósitron perde toda sua energia cinética e pára, ele interage com um elétron existente no meio e sofre a aniquilação de par e, dá-se origem a um par de fótons de aniquilação, cada um com energia de 0,511 MeV. Por conservação do momento linear, cada um dos fótons de aniquilação são emitidos em sentidos praticamente opostos, conforme representado na Figura 3.

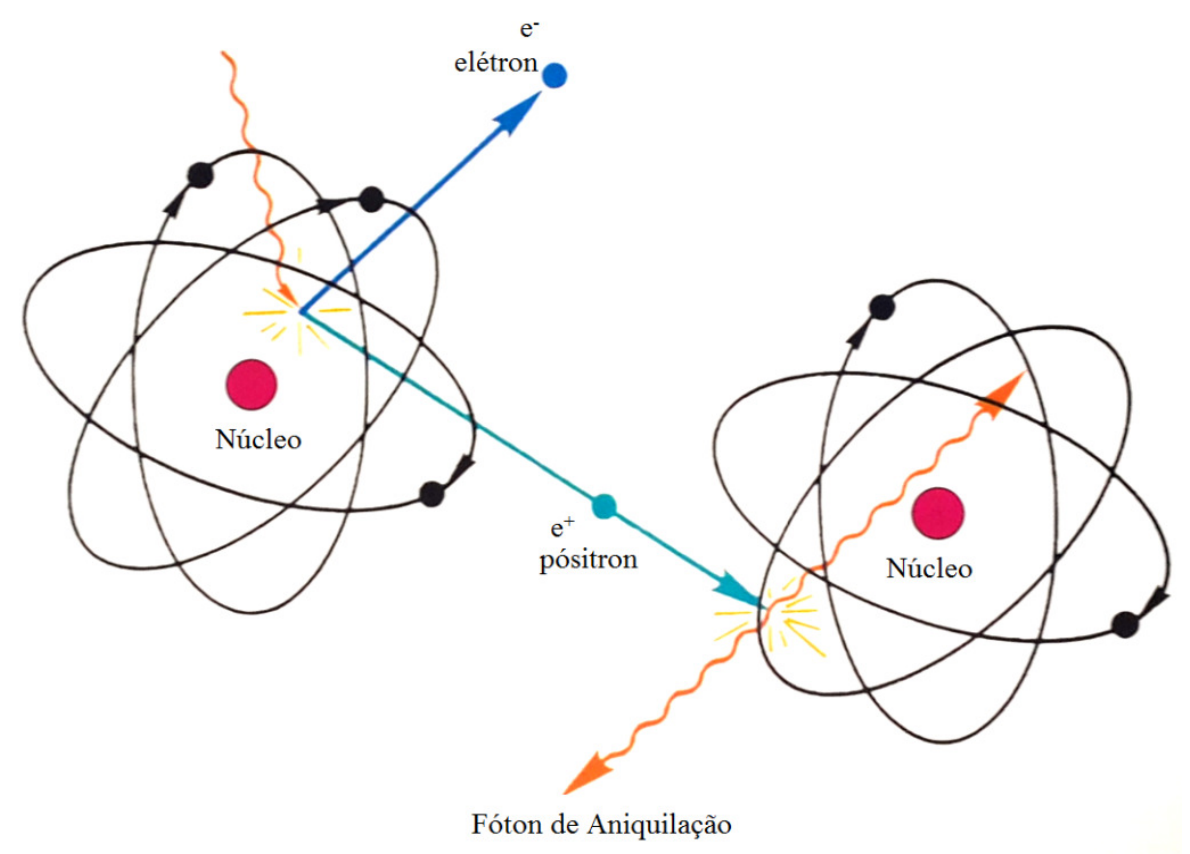

Figura 10 A produção e aniquilação de pares. Retirada e adaptada de . Cherry, Sorenson, cap6pag 77.

\subsubsection{Espalhamento Coerente}

O espalhamento coerente também é conhecido por espalhamento Rayleigh e é uma interação que ocorre entre um fóton e o átomo como um todo. É um fenômeno com maior probabilidade de ocorrência para fótons incidentes cuja energia seja menor do que $10 \mathrm{keV}$. A energia do fóton é totalmente absorvida pelo átomo deixando-o em um estado excitado, porém sem que ocorra ionização. A energia de recuo absorvida pelo átomo após a colisão é então liberada pelo átomo, contudo, com alteração na direção de propagação deste fóton. Esta é a única interação da radiação eletromagnética com a matéria em que o fóton é tratado como 
uma onda; nos demais, a radiação eletromagnética é tratada como fótons. Assim sendo, em termos ondulatórios, a radiação incidente e a emitida após a absorção possuem mesma fase e mesma energia.

Devido ao fato de não se tratar de um mecanismo eficaz de transferência de energia e se tratar de um mecanismo que tem ocorrência significativa para energias fora do espectro de energia utilizada em medicina nuclear, o espalhamento coerente tem pouca importância prática na medicina nuclear.

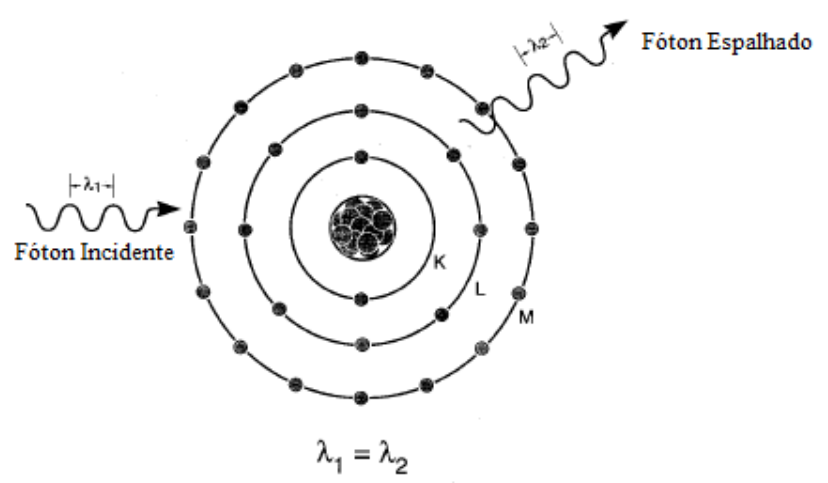

Figura 11 Espalhamento coerente. 0 fóton incidente sofre deflexão em sua trajetória, contudo, sem perder energia. Retirada e adaptada Bushbergcap3, pág. 37.

\subsection{ATENUAÇÃO}

\subsubsection{Coeficiente de Atenuação}

Quando um feixe de fótons desloca-se através da matéria, não é possível prever com precisão o momento em que ocorrerá uma interação entre o fóton e a matéria do meio em que se propaga nem mesmo o tipo de interação em que o mesmo pode se envolver, contudo, a probabilidade de interação depende da energia do fóton incidente e da composição e espessura do material absorvedor. A fração de fótons removidos de um feixe monoenergético de raios gama ou raios $X$ por unidade de espessura do material é chamada coeficiente linear de atenuação, $\mu$.

O processo de atenuação é contínuo por toda a extensão do material, desde a superfície de entrada até a superfície de saída. Sob condições de uma geometria de um feixe estreito, a transmissão de um feixe monoenergético de fótons através de um material absorvedor é descrita pela equação exponencial: 


$$
\mathrm{I}(\mathrm{x})=\mathrm{I}_{0} \cdot \mathrm{e}^{-\mu \mathrm{x}} \quad \text { Equação } 4
$$

onde $\mathrm{I}(\mathrm{x})$ é a intensidade transmitida através de uma espessura $\mathrm{x}$ de material absorvedor, $\mathrm{l}_{0}$ é a intensidade do feixe antes de penetrar no material de coeficiente linear de atenuação $\mu$.

O coeficiente linear de atenuação é uma grandeza dependente da energia do fóton, do número atômico do material do qual o objeto é composto, de sua espessura e densidade e é resultante da soma do coeficiente linear de atenuação individual para cada tipo de interação da radiação com a matéria. Para uma dada espessura, a probabilidade de interação do raio gama (ou raio $X$ ) com a matéria depende do número de átomos que este material possui por unidade de distância. Para um feixe não monoenergético, deve-se fazer ainda a consideração da energia média do feixe de fótons e sua absorção dependente da energia visto que o coeficiente de atenuação linear varia de acordo com a energia do feixe de fótons incidente.

Pode-se definir um coeficiente de atenuação para cada tipo específico de interação de fótons com a matéria (fotoelétrico, Compton, Rayleigh, Aniquilação de pares, etc). A composição de cada um dos coeficientes de atenuação forma o coeficiente total.

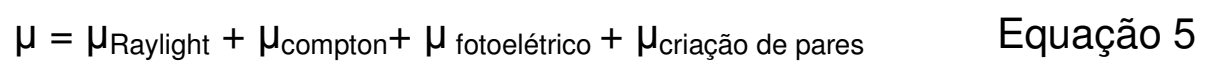

\subsubsection{Coeficiente de Atenuação por Massa}

Uma vez que os objetos são estruturas tridimensionais, é importante considerar sua espessura e densidade. Para uma dada espessura, a probabilidade de interação do fóton com a matéria é dependente do número de átomos por volume da mesma. Desta forma, normaliza-se o valor do coeficiente linear de atenuação para a unidade de densidade do material. Esta grandeza é conhecida por coeficiente de atenuação por massa.

Coeficiente de atenuação por massa $=($ coeficiente linear de atenuação $) /$ densidade $=\underline{\mu} / \rho=$ $\mathrm{cm}^{-1} /\left(\mathrm{g} / \mathrm{cm}^{2}\right)$ 
Utilizar o coeficiente linear de atenuação é intuitivo quando se trata de um material de mesma densidade, mas com diferentes espessuras. Por sua vez, o coeficiente de atenuação por massa assume maior importância em Medicina Nuclear uma vez que depende do número atômico do material e da energia do fóton incidente e é independente do estado físico do material, ou seja, é independente da densidade do corpo.

$$
\mu_{\text {água }} / \rho_{\text {água }}=\mu_{\text {gelo }} / \rho_{\text {gelo }}=\mu_{\text {vapor }} / \rho_{\text {vapor }} \quad \text { Equação } 6
$$

A relação entre o coeficiente de atenuação por massa e energia não é linear. Tendo em vista que a energia de emissão radioativa do radioisótopo mais utilizado em Medicina Nuclear para exames SPECT, o tecnécio 99 metaestável (cujo símbolo é ${ }^{99 \mathrm{~m}} \mathrm{Tc}$ ) é de $140.5 \mathrm{keV}$ e que a tabela de coeficientes de atenuação por massa disponibilizada no site do norte-americano Instituto Nacional de Padrões e Tecnologia (Nationallnstituteof Standards and Technology - NIST) apresenta apenas a energia de $150.0 \mathrm{keV}$, o coeficiente de atenuação por massa para a energia de $140.5 \mathrm{keV}$, por aproximação linear, do osso, tecido adiposo, tecidos moles e cérebro são, respectivamente, $1.60,1.16,1,66$ e $1,65 \mathrm{~cm}^{2} / \mathrm{kg}$.

É possível medir tanto o coeficiente linear de atenuação quanto o coeficiente de atenuação por massa de um material absorvedor através da transmissão de um feixe monoenergético de fótons. A maioria das tabelas são baseadas em cálculos teóricos da Física Atômica e Nuclear.

\subsection{Correção de Atenuação}

\subsubsection{Correção Uniforme de Atenuação}

A radiação emitida devido ao decaimento radioativo do radionuclídeo deve ser captada pelo sistema de detecção para que a imagem possa ser reconstruída. Contudo, a emissão radioativa ocorre no interior do corpo e devido à atenuação dos fótons, tem-se como resultado a diminuição da intensidade energética dos mesmos. O propósito da correção de atenuação em uma imagem é compensar a perda de 
fótons ao longo de uma linha devido à absorção fotoelétrica ou ao espalhamento Compton.

A Figura 5 exibe a relação entre a energia do fóton incidente na matéria de número atômico $\mathrm{Z}$ e a principal forma de interação da radiação com a matéria. Os principais radionuclídeos utilizados para aquisições SPECT são o Tc99m, o Ga67, o Tl101 e o In111 com fotopicos de 140, 103, 157 e dupla emissão em 172 e $245 \mathrm{KeV}$, respectivamente. No espectro de energia em que a medicina nuclear opera, as principais formas de absorção total do fóton é devido à ocorrência do efeito fotoelétrico nos tecidos e, a alteração e sua trajetória e perda de energia, devido ao efeito Compton.

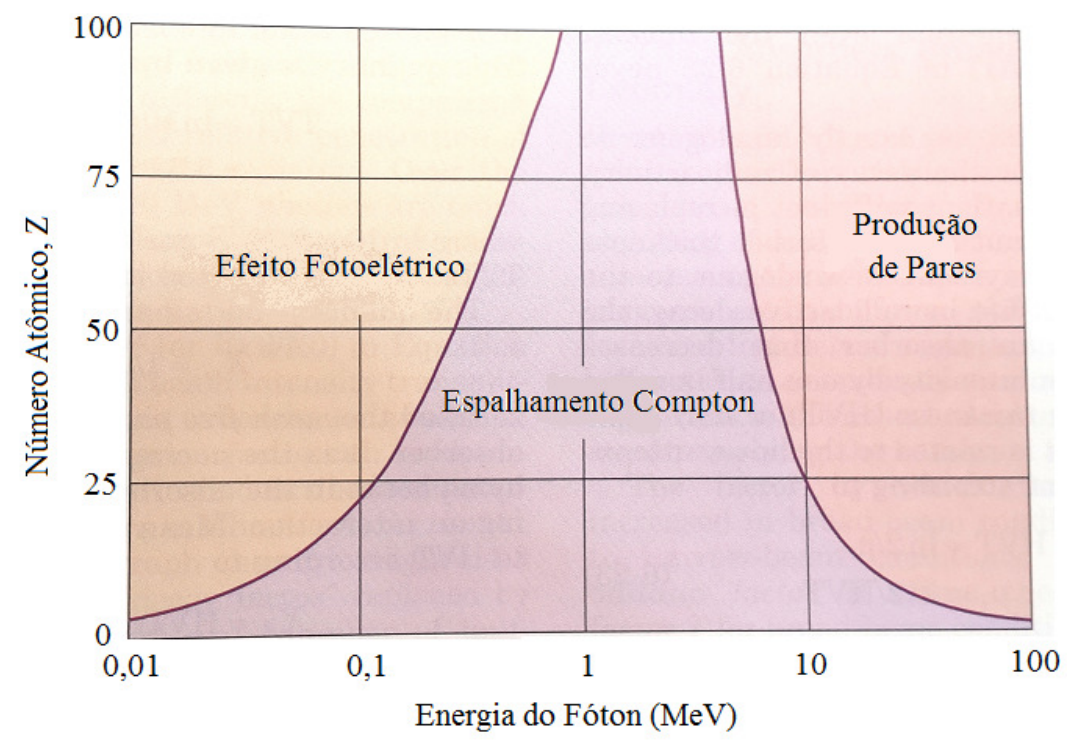

Figura 12 Relação entre a energia do fóton incidente na matéria e a interação mais provável. Retirada e adaptada Cherry, S. R. Cap6, pág.81

A atenuação é uma função da energia do fóton, da composição do meio pelo qual a trajetória do fóton é dada e pela espessura do mesmo. Seu efeito em imagens SPECT é uma degradação na qualidade e quantificação das imagens e comprometimento do diagnóstico clínico [Projeto FRIDA, 2005].

Quando um fóton - ou feixe de fótons - atravessa um material a probabilidade com que haverá interação depende da espessura e composição deste material bem como da energia do fóton.Os fótons de radiação gama que são emitidos do interior do objeto em estudo são atenuados pelo próprio objeto e a redução da intensidade 
dos fótons interfere na qualidade da imagem. Como visto, a intensidade dos fótons que atravessam um meio atenuador é dada pela equação 4.

Dentre as consequências clínicas da não correção dos efeitos da atenuação está a reconstrução de imagens que passam a apresentar artefatos devidos a não correção da atenuação. De maior importância clínica encontra-se a supressão e possível omissão de regiões supercaptantes no interior do corpo do paciente, gerando um falso negativo na imagem e comprometendo o diagnóstico (Cherry, S.R.et al., 2012)

A correção de atenuação pode ser feita, basicamente, considerando duas situações diferentes. A primeira supõe que todas as estruturas internas do corpo possuem a mesma composição e densidade e, portanto, considera que todo o corpo possui um único coeficiente de atenuação. Este método de correção de atenuação foi primeiramente proposto por Chang e ficou conhecido como correção uniforme de atenuação. A segunda situação propõe considerar os diferentes coeficientes de atenuação de cada uma das diferentes estruturas internas e por isso é chamado de método de correção de atenuação não uniforme.

O método de correção de atenuação uniforme é realizado de forma relativamente simples. Os perfis de projeção são corrigidos utilizando-se de média geométrica ou aritmética antes da reconstrução baseando-se em uma estimativa para a espessura, D, do material. Pela média geométrica, a correção é feita multiplicando cada perfil de projeção por um Fator de Correção de Atenuação (FCA) de

$$
F C A=e^{\mu D} \quad \text { Equação } 7
$$

em que a constante $\mu$ é o coeficiente linear de atenuação do material e $D$ é a espessura estimada para o mesmo que pode ser determinada a partir de uma imagem não corrigida ou assumindo um padrão para as medidas e formas do corpo.

Um dos problemas de se corrigir a atenuação desta maneira é que para diferentes posições do campo de visão do detector, o objeto imageado pode apresentar diferentes comprimentos. A solução para esta questão é calcular o FCA para cada pixel após a reconstrução da imagem através do método da retroprojeção 
filtrada sem que nenhuma correção de atenuação seja aplicada. Esta imagem chamaremos de $f^{\prime}(x, y)$. O contorno de $f^{\prime}(x, y)$ é usado para determinar o comprimento estimado do objeto atenuador em cada uma das projeções. Para o cálculo do fator de correção de atenuação consideramos novamente $O$ coeficiente linear de atenuação do objeto imageado para a dada energia do fóton. Agora, o FCA é dependente da posição do pixel e é escrito como função da posição $(x, y)$ na imagem.

$$
F C A(x, y)=N \cdot \sum_{i}^{N} e^{\mu d_{i}}
$$

Equação 8

onde $\mathrm{N}$ é o número de pixels, $d_{i}$ é o comprimento do pixel na projeção i e $\mu$ é o coeficiente linear de atenuação.

A imagem corrigida $f(x, y)$ é dada multiplicando pixel a pixel a imagem não corrigida $f^{\prime}(x, y)$ pelo fator de correção de atenuação:

$$
f(x, y)=f^{\prime}(x, y) \cdot F C A \quad \text { Equação } 9
$$

Os métodos de correção de atenuação baseados na aproximação de Chang são utilizados na maioria dos sistemas comerciais de SPECT e geram resultados aceitáveis em imagens cerebrais onde a presença de osso e de estruturas que apresentem ar é quase inexistente e torna-se passível assumir um coeficiente linear de atenuação constante.

Por sua vez, empregar o método de correção não uniforme significa adquirir uma imagem de transmissão do corpo imageado e baseando-se nesta imagem tomar os coeficientes de atenuação de cada estrutura para aplicar a devida correção. A aquisição da imagem de transmissão pode ser realizada de três maneiras diferentes. Utilizando-se uma fonte colimada do tipo flood, utilizando-se de uma fonte linear (neste caso em três diferentes configurações) e utilizando-se de um escaneamento de tomografia computadorizada (TC). Para a aquisição da imagem de transmissão com uma fonte externa de radiação, utiliza-se um radionuclídeo cuja energia de emissão seja diferente da energia de emissão do radionuclídeo injetado, proporcionando desta maneira, possibilidade de aquisição simultânea. Os últimos modelos de tomógrafos de tomografia de emissão apresentam um sistema híbrido o 
que significa dizer que o mesmo aparelho contém os sistemas de medicina nuclear e de tomografia computadorizada. Clinicamente ganha-se tempo de aquisição e qualidade de imagem. Computacionalmente simplifica-se o processo de corregistro da imagem de medicina nuclear e da tomografia de transmissão uma vez que o paciente se mantém na mesma posição (Cherry, S.R.et al., 2012).

A tomografia computadorizada fornece imagens da anatomia e secção transversal do objeto imageado com alta resolução espacial e alta qualidade e sensibilidade apesar de apresentar especificidade limitada. As imagens de TC são adquiridas com alto fluxo de fótons e são uma representação de alta qualidade muito próxima de como realmente é a atenuação do tecido e, portanto, podem ser utilizadas como base para a correção de atenuação. Cada raio $X$ emitido pelo tubo é captado no detector com intensidade $I_{0}$ alterada pelo fator de atenuação do tecido

$$
I=I_{0} \cdot e^{\Sigma(-\mu x)} \quad \text { Equação } 10
$$

onde 0 índice i indica cada região diferente ao longo da trajetória e $\mu_{i}$ é o coeficiente de atenuação daquele tecido e $x_{i}$ é a espessura correspondente à região do tecido cujocoeficiente de atenuação é $\mu_{\mathrm{i}}$.

As medidas da atenuação obtidas através de todos os raios do feixe e de todos os ângulos de varredura são utilizadas para gerar um arranjo seccional dos coeficientes de atenuação do tecido. Este arranjo dos coeficientes de atenuação forma uma imagem de alta qualidade da atenuação sofrida pelo feixe ao atravessar o tecido e o corpo como um todo e, portanto, é um representante de boa qualidade da anatomia do corpo.

Para padronizar e fornecer uma escala para visualização estes números são convertidos para números de TC também conhecidos por HU (Hounsfield Unit) através da normalização em função do coeficiente de atenuação da água $\left(\mu_{\mathrm{H} 2 \mathrm{O}}\right)$.

$$
H U=1000 x\left(\mu_{\text {tecido }}-\mu_{H 2 O}\right) / \mu_{H 2 O} \quad \text { Equação } 11
$$

deste modo, para diferentes tecidos, temos diferentes números de TC 


\begin{tabular}{||l|c|c|}
\hline Tipo de tecido & Valor médio (HU) & Dispersão \\
\hline Ósseo (compacto) & $>250$ & \\
\hline Ósseo (esponjoso) & $130 \pm 100$ & \\
\hline Tiróide & $70 \pm 10$ & \\
\hline Fígado & $65 \pm 5$ & 45 a 75 \\
\hline Músculo & $45 \pm 5$ & 35 a 50 \\
\hline Baço & $45 \pm 5$ & 35 a 55 \\
\hline Linfoma & $45 \pm 10$ & 40 a 60 \\
\hline Pâncreas & $40 \pm 10$ & 25 a 55 \\
\hline Rim & $30 \pm 10$ & 20 a 40 \\
\hline Gordura & $-65 \pm 10$ & -80 a -100 \\
\hline \hline \multicolumn{2}{|c|}{ Fluidos } & Valor médio (HU) \\
\hline Sangue (coagulado) & $80 \pm 10$ \\
\hline Sangue (venoso) & $55 \pm 5$ \\
\hline Plasma & $27 \pm 2$ \\
\hline Suor ( $>30$ g proteína/l) & $>18 \pm 2$ \\
\hline Transpiração (<30 g proteína/l) & $<18 \pm 2$ \\
\hline Solução & $12 \pm 2$ \\
\hline
\end{tabular}

Tabela 2 Números de TC para os diferentes tecidos do corpo humano. Extraído de <http://www.ebah.com.br/content/ABAAAAtZoAL/apostila-tomografiacomputadorizada?part=7>. Acesso em 12/11/2013.

\subsubsection{SPECT/CT e Mapa de Atenuação}

O surgimento de sistemas híbridos de aquisição de imagens médicas e o aprimoramento dos procedimentos de reconstruções de imagens são exemplos de eventos que somente se tornaram possíveis devido ao desenvolvimento computacional e do crescimento do mercado internacional. $O$ diferencial dos sistemas híbridos existentes no mercado de equipamentos de Medicina Nuclear é fornecer imagens anatômicas resultado da aquisição da tomografia computadorizada e imagens funcionais, respectivas à tomografia de emissão. Dentre as vantagens de dos sistemas híbridos, encontra-se a maior probabilidade de sucesso na fusão das duas imagens uma vez que o paciente permanece na mesma posição durante os dois exames, facilitando o corregistro.

A partir dos coeficientes de atenuação adquiridos na aquisição de TC é possível determinar os fatores de correção de cada tecido e utilizá-los para corrigir a imagem de SPECT. Para garantir a precisão da correção de atenuação é necessário considerar a energia do fóton. $O$ feixe de raios $x$ gerado na TC possui um espectro de energia que vai de zero até a energia máxima do fóton que é gerado para 
determinada tensão aplicada ao tubo de raios X. Os fótons de baixa energia são, em sua maioria, absorvidos pelo tecido. Isto causa um deslocamento do espectro do feixe para as altas energias à medida que o feixe atravessa mais tecidos e, portanto, ocorre uma modificação no valor efetivo do coeficiente de atenuação e produz uma série de artefatos na imagem. Desta maneira, passa a ser de grande importância que 0 feixe de raios $X$ seja filtrado antes de penetrar no paciente e, assim, garantindo que fótons de raios $X$ com energia baixa não atinjam o paciente, diminuindo a dose absorvida pelo mesmo.

Os efeitos da atenuação variam em função da energia (Patton, J. A. e Turkimgton, T. G., 2008). É fundamental converter os dados de coeficiente de atenuação para a energia do raio gama emitido pelo radionuclídeo utilizado no estudo. Tratando-se de feixe heterogêneo, surge o conceito de energia efetiva. Energia efetiva é a energia de um feixe heterogêneo que possui camada semiredutora igual à de um feixe monoenergético. Se a energia efetiva do feixe de raios $X$ utilizado é de $90 \mathrm{keV}$ e o radionuclídeo utilizado para a aquisição da imagem de SPECT foi o ${ }^{99 \mathrm{~m}} \mathrm{Tc}$, cuja energia do gama emitido é de $140 \mathrm{keV}$, o coeficiente de atenuação gerado pela TC deve ser convertido para um feixe de $140 \mathrm{keV}$. Isto é possível porque, fisicamente raio $X$ e raio gama são ambos ondas eletromagnéticas; a diferença entre os dois é a maneira com que foram gerados. Enquanto este é emitido do interior do núcleo atômico, aquele é emitido com a desaceleração de um elétron ao passar próximo de um núcleo atômico ou pela transição eletrônica de um nível orbital mais energético para um nível orbital menos energético, liberando energia. Estes procedimentos matemáticos normalmente são realizados através de um modelo bilinear relacionando os coeficientes de atenuação a uma desejada energia com os números de TC medidos à energia efetiva do feixe de raios $\mathrm{X}$. Este procedimento é efetuado automaticamente pelos softwares de reconstrução que oferecem a correção de atenuação baseada em tomografia computadorizada, como pode ser observado na Figura 6, em que é gerado o mapa de atenuação em número de TC em B, e em A, é possível visualizar os diferentes coeficientes de atenuação linear da estrutura imageada em cada pixel da imagem. 


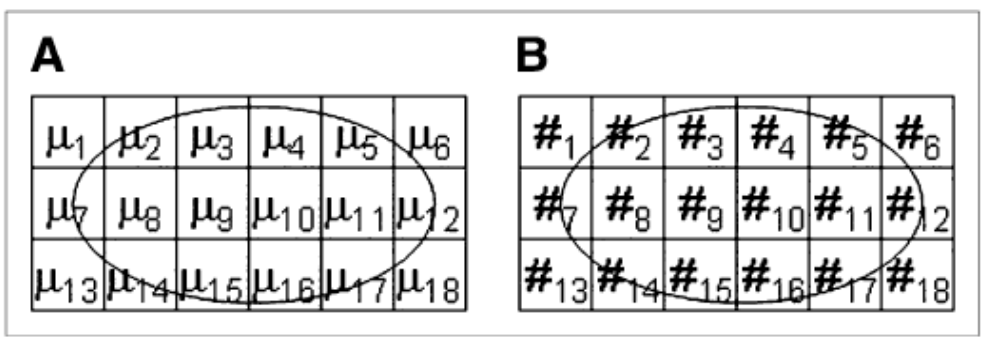

Figura 13 A imagem de TC pode ser utilizada para determinar o coeficiente de atenuação das estruturas internas e de diferentes regiões de um mesmo tecido, permitindo uma correção que considera os valores reais para cada estrutura. Patton, J. A. e Turkimgton, T. G..SPECT/CT Physical Principles and Attenuation Correction.Journalof Nuclear Medicine Technology. Vol 36. № 1, March, 2008.

\subsection{CORREÇÃO DE ESPALHAMENTO}

A degradação da imagem como consequência da interação da radiação com a matéria é inevitável. Conhecer o modo com que essa interação ocorre é de extrema importância para compensar tal degradação na imagem, corrigindo-a e, por fim, resultar em imagens diagnósticas mais precisas. Diferentemente do efeito fotoelétrico em que os fótons são totalmente absorvidos, os que sofrem interação por espalhamento Compton interagem com a matéria ionizando o átomo e passam a se deslocar em uma nova direção de trajetória até serem detectados pelo sistema de detecção ou serem totalmente absorvidos devido a outras interações.

Fótons espalhados podem - e de fato são - detectados. Em medicina nuclear, espalhamento é um grande problema, principalmente quando utiliza-se um radionuclídeo cujo espectro de emissão é multienergético. Neste caso, a aquisição pode ser feita com mais de uma janela de energia. Devido ao espalhamento e consequente perda de energia, fótons mais energéticos podem ser detectados com energia correspondente à uma janela de aquisição de menor energia. Desta maneira, este evento espalhado e detectado, é utilizado na reconstrução da imagem, como se fosse um fóton primário de energia igual ao do fotopico da janela em que foi detectado, contudo, é um fóton espalhado. Em termos de reconstrução da imagem, a contribuição à imagem destes fótons espalhados e detectados é que são erroneamente posicionados e causam diminuição de contraste e, como análise quantitativa, causam a superestimação da atividade real em uma determinada 
posição do objeto imageado. (Cherry, S. R. et al, 2012) Ou seja, são detectados eventos que na verdade são resultado do processo de espalhamento e que serão posicionados na imagem como se fossem eventos primários, diminuindo o contraste da imagem.

No geral, a correção de espalhamento envolve um processo de aquisição direta ou de modelamento matemático para estimar a porção de fótons espalhados presente na janela do fotopico utilizada para reconstruir a imagem. A correção de espalhamento baseada em medidas é representada principalmente pelo método da Dupla Janela de Energia (DJE) e método da Tripla Janela de Energia (TJE). (Dewajara, Y. K. et al., 2012) Segundo estes métodos, a aquisição é feita utilizandose de janelas de energia, as quais são configuradas com uma amplitude energética, ou seja, fótons com energia entre dois valores serão contabilizados e utilizados para a reconstrução da imagem. A largura da janela de energia é expressa em porcentagem e a energia do fotopico é o centro da janela. Por exemplo, o ${ }^{99 \mathrm{~m}} \mathrm{Tc}$ emite fótons de $140.5 \mathrm{keV}$ e utiliza-se janela de energia de $20 \%$, o que significa dizer que eventos detectados com energia entre 126.45 e $154.55 \mathrm{keV}$. A janela de energia sobre o fotopico é chamada de janela principal e sua largura é definida de modo que o fotopico como um todo esteja em seu interior. As janelas de energia adicionais são ditas como janelas de energia de espalhamento, podendo ser superiores ou inferiores à janela do fotopico. Estas, por sua vez, captarão fótons cuja energia é diferente da energia do fotopico que serão utilizados para estimar a quantidade de fótons espalhados foram captados na janela principal. Com ampla utilização em exames de Medicina Nuclear tanto para inalação pulmonar ou cintilografia óssea quanto para imageamento da atividade cerebral, o ${ }^{99 \mathrm{~m}} \mathrm{Tc}$ é um radionuclídeo de fotopico único. Na maioria dos protocolos clínicos a janela de energia para a aquisição de imagens possui largura de 20\%, centrada em $140 \mathrm{keV}$, energia correspondente à energia dos fótons emitidos quando 0 radionuclídeo sofre decaimento.

No método TJE, o espalhamento é estimado como a área sob o trapézio que une as duas janelas de espalhamento adjacentes. Para cada projeção i, o número de contagens espalhadas no janela do fotopico, $\mathrm{C}_{\mathrm{i}, \text { esp }}$, é calculado como proposto na equação 12: 


$$
C_{i, \text { esp }}=\left(C_{i, \text { inf }} / W_{\text {inf }}+C_{i, \text { sup }} / W_{\text {sup }}\right) \cdot W_{\text {ttp }} / 2 \quad \text { Equação } 12
$$

onde $\mathrm{C}_{\mathrm{i} \text {, infe }} \mathrm{C}_{\mathrm{i}}$, sup são as contagens nas janelas de espalhamento inferior e superior, respectivamente, no i-ésimo pixel da projeção e, $W_{\text {inf }}, W_{\text {sup }}$ e $W_{\text {ftpsão as larguras da }}$ janela de espalhamento inferior ao fotopico, da janela de espalhamento superior ao fotopico e da janela do fotopico, respectivamente.No caso dos métodos iterativos de reconstrução, o espalhamento é calculado tomando esta equação como base em cada uma das diferentes iterações (Ogawa, K. et al, 1991)

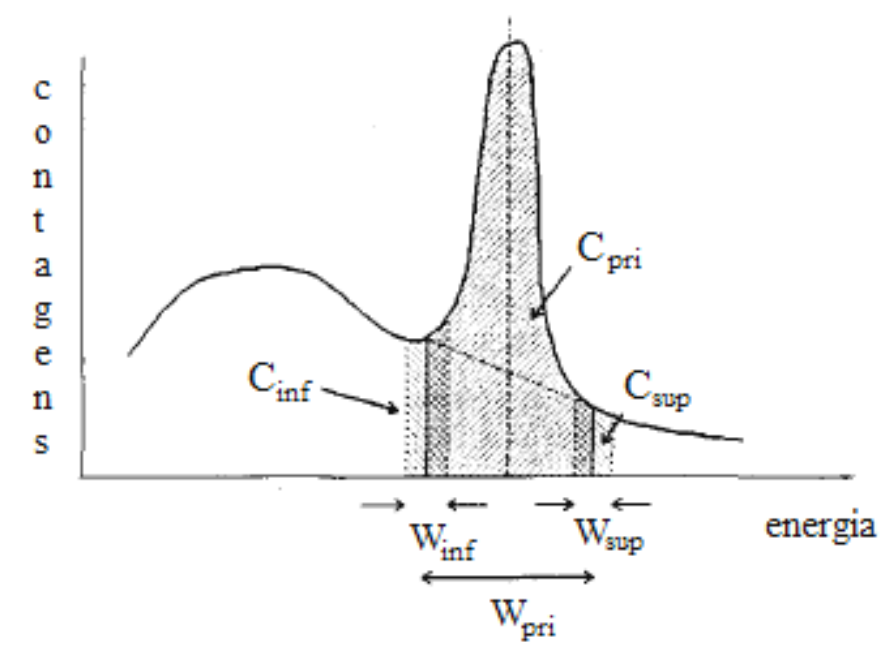

Figura 14 Espectro de energia e localização e largura dasjanelas de energia de uma aquisição em que será realizada a correção de espalhamento pelo método Tripla Janela de energia. Retirada e adaptada de Ogawa, K. Harata, Y., Kubo, A., Hashimoto, S.A practical method for position dependent compton-scatter correction in single photon emission CT.IEEE Transactionsof Medical Imaging, vol. 10 no. 3, setembro de 1991.

Uma vez que as janelas de espalhamento utilizadas para estimar a quantidade de eventos espalhados na janela do fotopico são estreitas, as imagens com correção de espalhamento segundo o método da TJE tendem a apresentar maior ruído e, portanto, passa a ser importante a aplicação de um filtro passa baixa após a correção.

Os métodos de múltiplas janelas de energia para correção de espalhamento foram desenvolvidos para sistemas SPECT [Jaszczaket al., 1984] e, com o 
desenvolvimento do sistema 3D para aquisições de PET e melhora na resolução energética destes tomógrafos, tornou-se possível aplicar os métodos de janelas de energia em PET [Zaidi, 2000], mas nem todos os métodos de correção de espalhamento foram implementados nos ambientes clínicos

\subsection{PRINCÍPIOS BÁSICOS DA CÂMARA GAMA}

Para que a imagem seja formada, em tomografia de emissão, é necessário que o fóton seja detectado pelo sistema de detecção que recebe o nome de câmara gama. Seus principais componentes são o colimador, o cristal de cintilação, o guia de luz e o arranjo de fotomultiplicadoras.

Cada um destes componentes tem uma função de extrema importância para que a imagem seja formada. A Figura 8 é uma representação de uma câmara gama convencional de um sistema SPECT. O colimador é uma estrutura de material atenuante com um grande número de orifícios e que tem como principal função definir a direção dos fótons que atingirão o cristal cintilador, diminuindo consideravelmente o número de eventos espalhados detectados. O segundo componente é o cristal cintilador que fica posicionado logo em sequência do colimador. As câmaras gamas de SPECT costumam ser produzidas com cristais de iodeto de sódio dopado com tálio [Nal(TI)], cristal de baixo custo. A eficiência de detecção dos raios gama que 0 atingem aumenta com o aumento da espessura, contudo, o aumento da espessura diminui a resolução espacial intrínseca do sistema, portanto, os sistemas são construídos de maneira a otimizar a detecção e a resolução espacial. Afim de maximizar a saída de luz, o cristal é envolto por um material altamente reflexivo, como, por exemplo, o $\mathrm{TiO}_{2}$. A estrutura do cristal é extremamente sensível a choques e a variações na umidade e para efeitos de proteção, o cristal é hermeticamente selado em uma fina capa de alumínio. Algumas câmara gama possuem um guia de luz constituído de plástico que possui a função de aumentar a eficiência da captação da luz produzida pelos cristais e a aumentar a uniformidade da captação de luz como função da posição. 


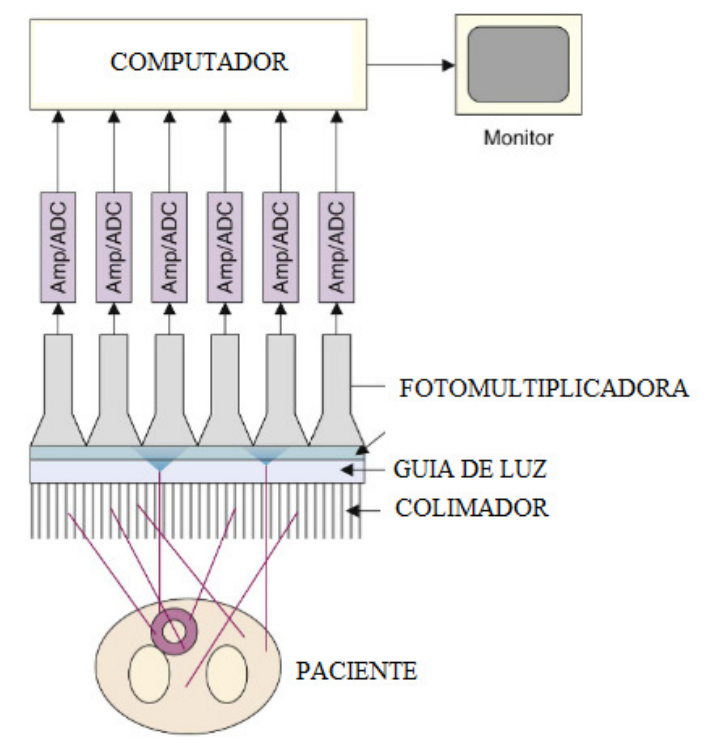

Figura 8 Esquema ilustrativo dos princípios básicos e componentes de detecção do raio gama. Retirada e adaptada de Cherry, S. R. Cap. 13, pág 196.

Acoplado ao cristal, posiciona-se o arranjo das fotomultiplicadoras. Para maximizar a área de cobertura do cristal, o padrão de fotomultiplicadoras é construído em uma forma hexagonal.Uma vez que são extremamente susceptíveis a campos magnéticos, os tubos de fotomultiplicadoras possuem um envolto de mimetal, um material com alta permeabilidade magnética que blinda o tubo da fotomultiplicadora contra campos magnéticos externos para prevenir mudanças de ganho devido a alterações na orientação da câmara gama. Um fóton de luz produzido no cristal atinge a fotomultiplicadora e esta, libera um elétron por efeito fotoelétrico. Dentro das fotomultiplicadoras (Figura 9) existem estruturas chamadas dinodos que são responsáveis por aumentar o número de elétrons e assim o sinal é amplificado e enviado para um computador que avalia a posição $x, y$ e a energia do fóton detectado bem como aplica correções de uniformidade e de linearidade ao sinal. 


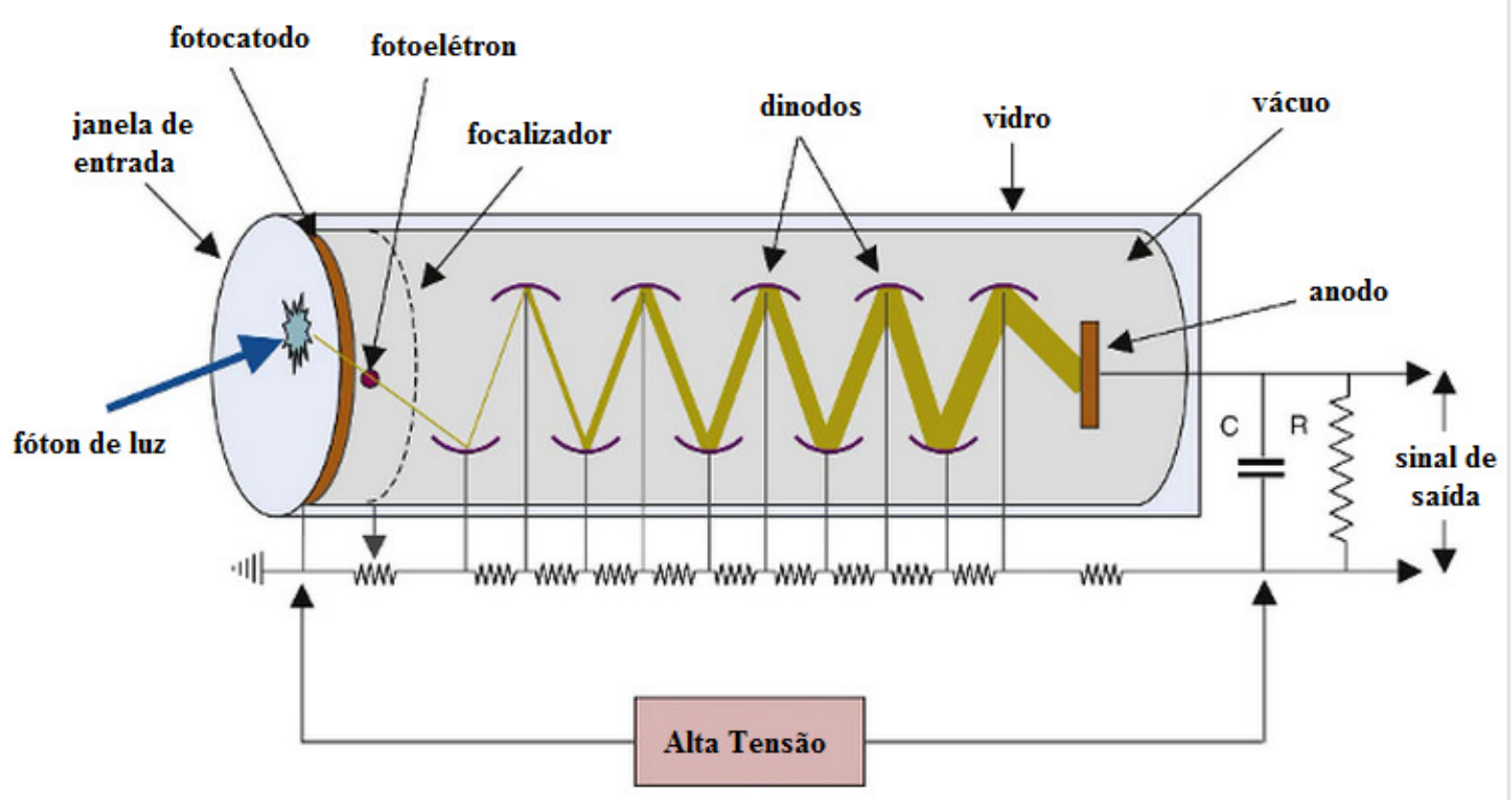

Figura 9 Esquema simplificado da amplificação do sinal no interior da fotomultiplicadora. Retirada e adaptada Cherry, S. R., cap. 7, pág. 98.

\subsection{RECONSTRUÇÃO DE IMAGENS EM MEDICINA NUCLEAR}

A palavra tomografia vem da união de dois radicais gregos: tomo que significa fatia secçãoe grafia cujo significado é escrita, ou seja, o termo tomografia pode ser traduzido como o registro das fatias, na forma de imagem. A formação da imagem, na radiologia, depende da atenuação do raio $X$ gerado por uma fonte externa ao passar por um tecido, na medicina nuclear, por sua vez, explora-se a distribuição de radionuclídeos no interior do corpo.Deste modo, a tomografia computadorizada utilizada na radiologia é chamada de tomografia computadorizada de transmissão, uma vez que o feixe de raios $X$ é transmitido através do objeto imageado e a tomografia computadorizada utilizada em medicina nuclear é chamada de tomografia computadorizada de emissão por utilizar-se de raios gama emitidos pelo próprio objeto imageado para formar a imagem. Portanto, objetivo geral da reconstrução tomográfica em geral é gerar uma imagem bidimensional transversal do interior do objeto imageado. Assim, imagens em medicina nuclear representam a distribuição espacial, em termos de contagens em uma dada posição no plano transversal do corpo.

O problema básico de reproduzir a distribuição do radionuclídeo em um corpo real na forma de uma imagem é que este corpo possui três dimensões e uma imagem é representada num plano, ou seja, em duas dimensões. Para tanto, uma 
dimensão será suprimida e estruturas internas sofrerão sobreposição. A maneira encontrada para resolver este problema foi de realizar aquisições com os detectores posicionados nas diferentes posições angulares do paciente, tomando imagens anteriores, posteriores, laterais e oblíquas. Desta forma, torna-se possível distinguir as estruturas internas e passa a ser possível a quem visualiza as imagens, reconstruir mentalmente a imagem tridimensional aproximada, uma vez que o interior do corpo contem inúmeras estruturas e a biodistribuição do radionuclídeo depende de cada organismo. De modo a concluir que pode-se inferir uma imagem aproximada, mas não exata, da natureza da distribuição do radionuclídeo no interior do corpo uma vez que trata-se de um problema de alta complexibilidade.

Os princípios matemáticos do método de reconstrução de imagem foram desenvolvidos e propostos por Johann Radon em 1917. O matemático austríaco provou que a imagem de um objeto desconhecido pode ser reproduzida caso se tenha um numero infinito de projeções através deste objeto, mas somente após o desenvolvimento de tomografias computadorizadas no início dos anos 70 é que estes conhecimentos de reconstrução de imagens puderam ser aplicados para fins médicos. Os algoritmos de reconstrução utilizando retroprojeção filtrada foram criados por Bracewell e Riddle, em 1967.

Assumimos inicialmente que os dados são coletados utilizando uma gama câmera padrão com colimador de septos paralelos. Para simplificar a análise, assumimos também que o colimador permite a passagem de raios gama cujo ângulo de incidência é perpendicular ao plano do cristal cintilador e blinda os raios gama cujo ângulo de incidência seja diferente de $90^{\circ}$.Conhece-se por linha de resposta o cilindro definido pela extensão geométrica de um dos buracos do colimador e a integral de linha sobre cada linha de resposta retorna o valor da quantidade medida pelo detector naquela linha de resposta, ou seja, retorna as contagens registradas para aquela posição. O conjunto completo de todas as integrais de linha de todas as linhas de resposta do detector é chamado de projeção e cada projeção corresponde a uma fatia perpendicular do objeto.

Para cada projeção a gama câmera posicionada em um ângulo e, deste modo, ao fim da aquisição tomográfica tem-se um conjunto de projeções coletadas em diferentes ângulos de um objeto desconhecido. Para análise, introduziu-se um sistema de coordenadas que é estacionário em relação ao sistema de detecção e 
não ao objeto. Com uso de uma rotação de coordenadas, passamos a considerar o sistema de coordenadas ( $r, s)$, o qual considera a gama câmera em repouso. Temos que a relação entre os dois sistemas de coordenadas é dada pelas equações 13a.e $13 b$.

$r=x \cdot \cos (\varphi)+y \cdot \operatorname{sen}(\varphi)$

Equação 13a.

$s=y \cdot \cos (\varphi)-x \cdot \operatorname{sen}(\varphi)$

Equação 13b.

em que $\varphi$ é o ângulo de rotação da gama câmera, $(\mathrm{x}, \mathrm{y})$ é o sistema de coordenadas do objeto imageado e $(r, s)$ é o sistema de coordenadas que considera a gama câmera em repouso.

As equações acima são utilizadas para determinar a maneira com que a radioatividade detectada em uma localização $(x, y)$ contribui para o sinal registrado na posição $r$ de uma projeção adquirida na rotação de um ângulo $\varphi$, como mostra a figura 10. É comum encontrar o conjunto completo das projeções mostrado de uma forma matricial em duas dimensões. Cada linha está associada à projeção 1D obtida para cada ângulo. Cada coluna indica a distância medida em relação ao centro da imagem. A este conjunto de projeções dá-se o nome de sinograma uma vez o conjunto de projeções de uma fonte pontual tem a forma de uma senóide.O sinograma é uma maneira útil de representar os dados coletados durante o escaneamento tomográfico e pode ser utilizado para determinar as causas de artefatos nas imagens de SPECT e PET.O conjunto das projeções formam a transformada de Radon e é utilizado para reconstruir a imagem tanto no método analítico quanto nos métodos iterativos. 

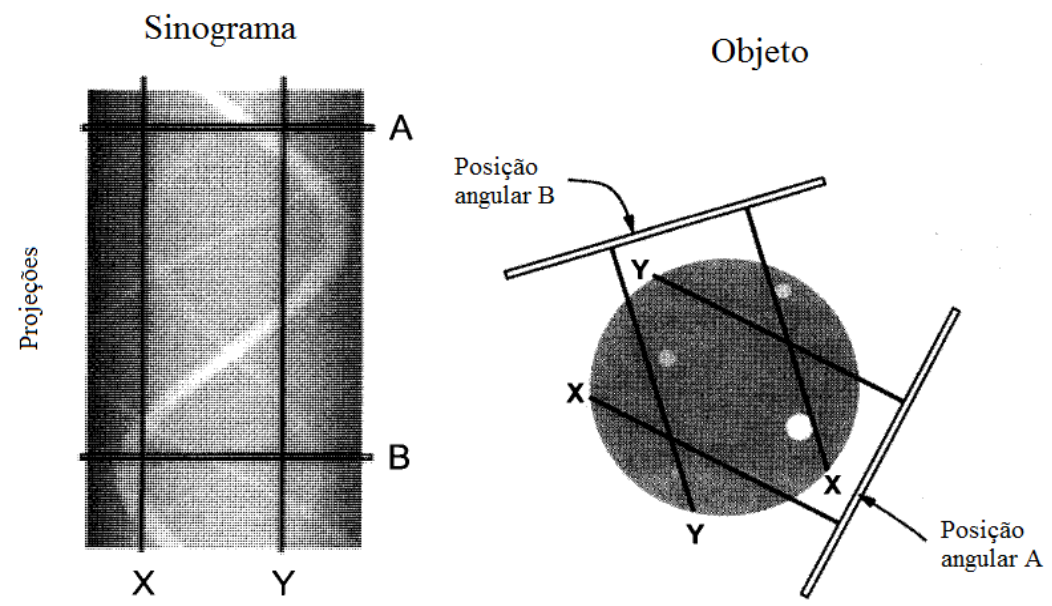

Figura 10 Exemplificação da construção de um sinograma. Cada linha corresponde a uma posição angular, as quais são representadas de modo que o ângulo 0 localiza-se no topo do sinograma e a última posição angular, na última linha. Retirada e adaptada de Bushberg, J. T. et al., cap 13, pág 347.

O modo analítico de reconstrução de imagens é baseado no Teorema de Corte de Fourier (TCF). (Projeto FRIDA, 2006). Soluções analíticas normalmente são realizadas uma única vez para reconstruir a imagem transaxial. A outra classe de soluções é chamada de iterativa uma vez que a reconstrução da imagem transaxial é feita por uma série de repetições do método até que um pré-especificado critério seja atingido, mas é importante esclarecer que todos os métodos de reconstrução são aproximações da realidade, e portanto, não resultam em imagens fiéis à real distribuição de atividade.

Ao tratar de processamento de imagens, trabalha-se com dois domínios: 0 domínio real (também chamado de domínio da imagem) e o domínio das frequências. O primeiro é quando a representação da distribuição das emissões radioativas é feita em termos da posição. Por sua vez, o segundo é referente à aplicação da transformada direta de Fourier sobre a imagem modificando-a para expressar os dados de acordo com funções trigonométricas cujas características são dadas em função da variação das frequências e amplitudes.

No domínio das frequências, uma imagem apresenta dados com ampla abrangência. Sabe-se que frequências altas estão relacionadas com transições rápidas como, por exemplo, bordas e pequenos objetos. Os ruídos incluem-se como sinais de alta frequência (Dewajara et al, 2012). De mesmo modo, sabe-se que baixas frequências relacionam-se a objetos maiores. Deste modo, a transformada de 
Fourier divide a imagem em diversas componentes. Cada uma destas componentes é relativa a cada uma das frequências existentes na imagem.

\subsubsection{Retroprojeção Simples e Retroprojeção Filtrada.}

Como já dito, o objetivo geral da reconstrução tomográfica em medicina nuclear é gerar uma imagem 2D transversal da distribuição de atividade interna de um objeto, $f(x, y)$, a partir de um sinograma ou de um conjunto de projeções. $A$ realidade é que os perfis, $\mathrm{p}(\varphi, r)$, são adquiridos em ângulos discretos, $\varphi$, e cada perfil é uma amostra em discretos intervalos ao longo de $r$.

A aproximação mais simples de reconstruir uma imagem a partir de suas projeções é pelo método analítico chamado retroprojeção simples.

Para reconstruir a imagem transversal baseando-se neste método, tomamos os perfis de sensibilidade adquiridos a partir das diferentes posições angulares do detector ao redor do objeto e os enviamos para a matriz da imagem.Para cada pixel da imagem de coordenadas [linha, coluna] $=(x, y)$, a contribuição da projeção adquirida segundo um ângulo $\varphi$, medido em relação à vertical, é calculada determinando o valor da distância ao centro da projeção dada pela equação 14

$$
r=y \cdot \cos \varphi+x \cdot \operatorname{sen} \varphi \quad \text { Equação14 }
$$

e, posteriormente, as contagens gravadas em uma projeção específica são distribuídas para cada um dos pixeis da imagem que fazem parte da linha de resposta do elemento da projeção localizadado em r. Quando as retroprojeções de todos os perfis são adicionadas à imagem, obtem-se uma aproximação da distribuição da radioatividade interna à fatia escaneada (Figura 11). Matematicamente, a retroprojeção de $\mathrm{N}$ perfis é descrita por

$$
f^{\prime}(x, y)=(1 / N) \cdot \Sigma p(x \cdot \cos \varphi+y \operatorname{sen} \varphi) \quad \text { Equação } 15
$$

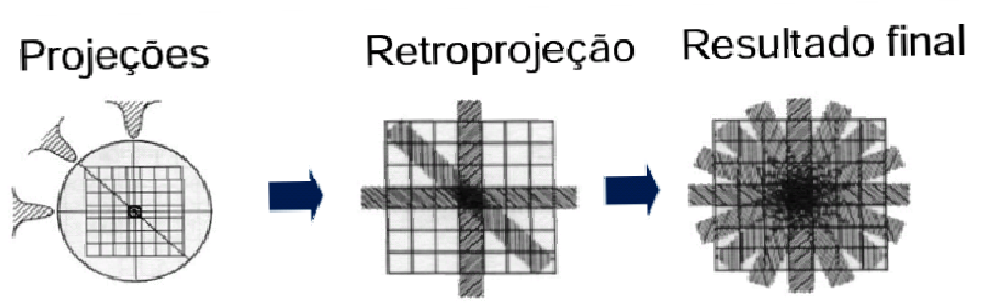

Figura 11 Reconstrução da imagem tomográfica a partir do métodoRetroprojeção Simples. Cada um dos perfis são retroprojetados para a matrizda imagem. Retirada de <http://www.walmorgodoi.com/arquivos/Palestra Reconstrucao Imagens.pdf> 
A imagem final contém artefatos oriundos de contagens em áreas externas à verdadeira localização da fonte.Quando tomam-se poucas posições angulares, após a reconstrução da imagem é possível visualizar o que é conhecido como "artefato estrela". A qualidade da imagem pode ser melhorada aumentando o número de projeções, contudo, mesmo com um número infinito de projeções, a imagem final ainda seria borrada nas bordas. A relação matemática que descreve a dependência entre a imagem real e a imagem reconstruída por retroprojeção é dada por (15):

$$
F^{\prime}(x, y)=f(x, y) \otimes(1 / r) \quad \text { Equação } 15
$$

Onde $\gtrsim$ é um símbolo matemático que representa o processo de convolução e $r$ é a distância ao centro da fonte pontual.

Com a finalidade de corrigir o efeito de borramento $1 / r$ que as imagens reconstruídas através do método retroprojeção simples apresentam, criou-se o método conhecido por retroprojeção filtrada, muito conhecida também pelo seu acrônimo do inglês Filtered Back Projection, FBP. Pequenos objetos e bordas são exemplos de sinais de alta frequência; o borramento das imagens reconstruídas por retroprojeção se apresenta, principalmente, nas fronteiras dos objetos. Como já dito, em processamento de imagens, é conveniente trabalhar no domínio das frequências, a reconstrução por retroprojeção filtrada é um exemplos em que esta mudança espaço torna o processo mais simples. Para minimizar o efeito de borramento a imagem passa pelo processo de filtragem. Cada um dos filtros existentes é uma operação matemática que é aplicada na imagem e que é capaz de atenuar ou destacar diferentes frequências e, portanto, destacar diferentes características da imagem. Tratando-se do borramento $1 / r$ especificamente, sobre a imagem aplica-se um filtro rampa combinado com um filtro passa-baixa. Isto pode ser feito de duas maneiras: no domínio espacial ou no domínio das frequências. Neste, é necessário aplicar a transformada de Fourier na imagem onde é passível trabalhar com as frequências dos sinais através da multiplicação das transformadas de Fourier do filtro pela imagem e, posteriormente, realizar a transformada inversa do resultado deste produto e, naquele, é necessária a convolução da função matemática que descreve o filtro com a imagem a ser filtrada. Em termos de tempo, a operação realizada no domínio das frequências é muito mais rápida e passa a ser clinicamente mais viável e em termos de precisão diagnóstica a filtragem no espaço 
das frequências é mais eficaz e, portanto, passa a ter importância clínica e diagnóstica.

O filtro rampa aplicado na imagem é caracterizado por dar importância com diferentes pesos às frequências que compõe a imagem. Frequências baixas recebem um peso menor enquanto altas frequências recebem peso maior. $\mathrm{Na}$ prática, cada projeção é filtrada com o filtro rampa e, no processo, é possível que receba valores negativos que cancelar-se-ão com os valores positivos existentes na vizinhança da borda da imagem, e tem por resultado final melhorar a diferenciação das bordas do objeto.

Um dos problemas de se aplicar um filtro rampa na imagem é que não somente as altas frequências das bordas das imagens serão destacadas, mas as altas frequências relativas a ruídos estatísticos também receberão mesmo tratamento. Como alternativa de priorizar diferentes características da imagem, 0 filtro modificado e adquire uma forma arredondada para que suprima o aumento de altas frequências espaciais. Para cada modificação do filtro rampa, o filtro recebe outro nome. Os mais comuns são os filtros Shepp-Logan, Hamming e Butterworth. As equações matemáticas para cada um dos filtros estão descritas abaixo:
Rampa:
$R(\omega)=\omega$
Equação 16
Shepp-Logan:
$\operatorname{SL}(\omega)=\left[\operatorname{sen}\left(\pi \omega / 2 \omega_{\text {corte }}\right)\right] /\left(\pi \omega / 2 \omega_{\text {corte }}\right)$
Equação 17
Hamming:
$H(\omega)=0,54+0,46 \cdot \cos \left(\pi \omega / \omega_{\text {corte }}\right)$
Equação 18
Butterworth:
$B(\omega)=1 /\left(1+\left|\left(\omega / \omega_{\text {corte }}\right)\right|^{2 \mathrm{~N}}\right.$
Equação 19

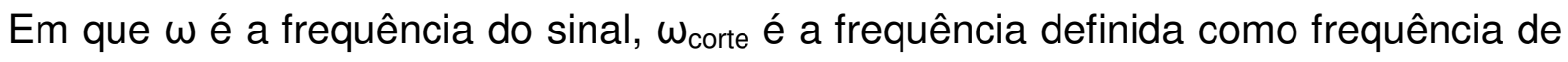
corte e $\mathrm{N}$ é a ordem.A ordem relaciona-se com a inclinação da curva do filtro e, consequentemente, com as frequências que são atenuadas quando o filtro é aplicado. Maiores valores para a ordem, produzem filtros com uma queda abrupda da curva do filtro e a banda de frequências atenuadas é maior.

Como tudo em imageamento diagnóstico, a seleção do filtro depende da aplicação clínica. A frequência de corte, por sua vez, deve ser escolhida como o ponto em que existe o máximo de ruído e o mínimo de dados oriundos do paciente e normalmente varia de 0,2 a 1,0 vezes a frequência de Nyquist (Cherry, S. R. et al, 2012).

Resumidamente, o processo da reconstrução da imagem tomográfica pelo método da retroprojeção filtrada segue seis etapas. A primeira é a aquisição das 
projeções para a obtenção do sinograma. Em seguida calcula-se a transformada de Fourier unidimensional sobre as projeções. O terceiro passo é a aplicação do filtro (rampa, Shepp-Logan, Hamming, Butterworth, etc.).Posteriormente à aplicação do filtro, calcula-se a transformada inversa de fourier retornando ao espaço da imagem. Em seguida, retroprojeta-se os valores calculados e, finalmente, obtém-se a imagem tomográfica.

\subsubsection{Reconstrução Iterativa}

$\mathrm{Na}$ essência, um algoritmo de reconstrução iterativa reconstrói a imagem aproximando-a da imagem real, $f(x, y)$, através da média de sucessivas aproximações - ou estimativas. O processo de reconstrução iterativa, basicamente, baseia-se em estimação e comparação e os métodos de reconstrução iterativa se diferem na maneira com que as projeções são comparadas e qual o tipo de correção que é aplicada sobre as estimativas.

Geralmente a estimativa inicial é muito simples; como uma estimativa em branco ou homogênea. Utilizando-se esta estimativa inicial, inicia-se o cálculo das projeções que teriam sido medidas, por meios de detecção, para a imagem estimada, utilizando um processo conhecido por projeção direta, gerando um sinograma estimado para a imagem em processo de reconstrução. O conjunto de projeções (sinograma) gerado a partir desta imagem é comparado com o conjunto de projeções da imagem real.

A estimativa inicial dificilmente será semelhante à imagem real, entretanto, a diferença entre as projeções estimadas e as atuais é utilizada para atualizar a estimativa atual e criar uma nova estimativa mais próxima da projeção real. 0 processo de atualização e comparação é repetido até que a diferença entre o perfil direto-projetado para a imagem estimada e o perfil da imagem real caia para menos que um nível específico. Para minimizar o tempo computacional para que se atinja o nível de aceitação, costuma-se utilizar uma imagem reconstruída através da retroprojeção filtrada.

Através de reconstruções iterativas é possível incorporar os diferentes tipos de correções de efeitos físicos após ou simultaneamente à reconstrução, isto ocorre porque os métodos iterativos de reconstrução de imagens consideram que as projeções podem ser modeladas a partir do pré-suposto de que as contagens nos 
detectores segue a distribuição de Poisson, ou seja, levando em conta a natureza estocástica da geração da radiação como processo físico. Os algoritmos de reconstrução iterativa permitem ainda incorporar as correções de atenuação não uniforme, redução ou remoção de espalhamento, variação da resolução espacial com a distância bem como os efeitos de decaimento radioativo.

Assim, na prática, os métodos de reconstrução iterativa buscam resolver $g=A . f$, em que $g$ é o vetor de valores do sinograma, $A$ é a matriz na qual será reconstruída a imagem e $f$ é o vetor desconhecido dos valores de pixel da imagem. Uma vez que as medidas estão sujeitas à variações devido ao fenômeno probabilístico de desintegrações radioativas, por simplificação de cálculos, $g$ é tomado desconsiderando o fenômeno probabilístico e $f$ é uma solução particular correspondente para a medida particular de $g$.

O método conhecido por MLEM, acrônimo do inglês MaximumLikelihoodExpectationMaximization, a fim de determinar a melhor estimativa de uma solução geral para $f$, utiliza-se a lei de Poisson que permite predizer a probabilidade de contar um dado número de eventos se a média de desintegrações é conhecida. E, para cada iteração, o algoritmo cumpre os passos:

1. Expectation: calcula-se a fórmula que expressa a semelhança de qualquer imagem reconstruída com os dados medidos;

2. Maximization: encontra-se a imagem que possui a maior semelhança com os dados medidos.

A equação da imagem resultado, após $k$ iterações é dada por:

$$
\bar{f}_{j}^{(k+1)}=\frac{\bar{f}_{j}^{(k)}}{\sum_{i=1}^{n} a_{i j}} \sum_{i=1}^{n} \frac{g_{i}}{\sum_{j^{\prime}=1}^{m} a_{i j^{\prime}} \bar{f}_{j^{\prime}}^{(k)}} a_{i j} .
$$

Equação 20

Em que: $\quad g=$ vetor dos dados da projeção

$\mathrm{f}=$ vetor dos dados da imagem

$A=$ matriz da imagem

$\mathrm{k}=$ iteração 
i = índice da projeção

j = índice do pixel

$\mathrm{g}_{\mathrm{i}}=$ número de contagens no i-ésimo bin de um conjunto de projeções

$a_{i j}=$ valor do elemento da i-ésima linha e j-ésima coluna da matriz $\mathrm{A}$

$\mathrm{f}_{\mathrm{j}}=$ número de desintegrações no j-ésimo pixel da fatia

$\bar{g}_{i}=$ valor médio de $g_{i}$, assumindo $g_{i}$ como uma variável aleatória que obedece a distribuição de Poisson

$\dot{\mathrm{f}}_{\mathrm{j}}=$ valor médio de $\mathrm{g}_{\mathrm{i}}$, assumindo $\dot{\mathrm{f}}_{\mathrm{j}}$ como uma variável aleatória que obedece a distribuição de Poisson

$\mathrm{m}=$ número de pixeis

$\mathrm{n}=$ número de bins

Simplificando a explicação da equação 1 , o fator $g_{i} / \Sigma a_{i j} \cdot \dot{f}_{j}^{(k)}$ é a razão do número de contagens medidas para a média do número de contagens no bin i da estimativa atual. $O$ termo $\left(g_{i} / \Sigma a_{i j} \cdot \dot{f}_{j}^{(k)}\right)$. $a_{i j}$ é a retroprojeção dessa razão para o pixel j. A equação 20 é aplicada pixel a pixel, sendo estendida por toda a imagem e podendo ser interpretada como: a imagem da k-ésima iteração é multiplicada pela retroprojeção normalizada tomando-se as contagens em cada projeção pela contagens da projeção da k-ésima iteração. A cada iteração $k$, temos uma nova estimativa disponível. As projeções medidas finalmente são comparadas com as projeções da estimativa atual. O algoritmo MLEM converge lentamente, exigindo muito tempo e desempenho computacional (Hudson, H. M. et al. 1994).

Como maneira de acelerar o processo de convergência, Hudson e Larkin aprimoraram o algoritmo MLEM, criando o algoritmo Ordered Subsets Expectation Maximization - OSEM. Neste método de reconstrução de imagens tomográficas, 0 conjunto de projeções é dividido em subconjuntos. É interessante para que o algoritmo trabalhe bem que os subconjuntos contenham o mesmo número de projeções.

O método MLEM é aplicado sobre cada subconjunto, independentemente. Como passa trabalhar com um numero reduzido de projeções para calcular as estimativas, o método OSEM converge mais rápido do que o seu antecessor. Por exemplo, se utilizar de 16 subconjuntos, em média, a convergência com o método OSEM será 16 vezes mais rápida do que com o método MLEM. 


\subsection{QUALIDADE DE IMAGEM EM MEDICINA NUCLEAR}

Qualidade de imagem é um termo genérico que é válido para todos os tipos de imagens, sejam elas diagnósticas ou não.Neste quesito, "qualidade“ passa a ser algo subjetivo e dependente da finalidade para a qual a imagem foi produzida e do julgamento de quem a avalia. Tratando-se de medicina diagnóstica por imagem, uma imagem de qualidade é aquela com a qual é possível fazer um diagnóstico preciso.Em Medicina Nuclear, uma imagem de qualidade está relacionada com a capacidade do dispositivo de aquisição de imagem de diferenciar estruturas com diferença de captação do radiofármaco.

O termo qualidade de imagem é utilizado como fundamento de referência do quão fidedignamente o objeto imageado é exibido na imagem reconstruída.A qualidade da imagem em Medicina Nuclear sofre limitações de diversos fatores que podem variar desde a performance do sistema de detecção dos fótons até questões de performance do método de reconstrução de imagens e de filtros utilizados.A qualidade da imagem é caracterizada e dividida em duas vertentes: a primeira considera os efeitos físicos e os analisa qualitativamente por meio de medidas ou cálculos sobre a imagem ou sobre o sistema de detecção como um todo. Trata-se do cálculo e tomada de dados para análise de resolução espacial, contraste e ruído da imagem. A segunda é considerada uma vertente qualitativa e considera a performance do observador tomando como base imagens obtidas a partir de diferentes métodos e utilizando-se de diferentes parâmetros para isso, neste quesito, trata-se de uma avaliação subjetiva que certamente sofre influência dos parâmetros avaliados na vertente quantitativa. Contudo, a relação entre as duas vertentes não é de fácil concordância uma vez que o sistema de detecção visual humano é complexo e a capacidade de distinção de detalhes diagnósticos sofre influência da experiência individual de cada observador.

De um modo geral, contraste, resolução espacial e ruído estão intimamente relacionados entre si. Uma melhora em um dos fatores pode significar uma deterioração de um - ou mais - dos outros fatores. É a aplicação clínica e a finalidade diagnóstica da imagem que regem qual - ou quais - dos fatores deve ser minimizado para que a imagem seja otimizada para sua finalidade. 


\subsubsection{Resolução Espacial}

Uma imagem bidimensional, em termos de análise de imagem, possui altura, largura e intensidade da escala de cores utilizada para representar o objeto imageado. A altura e largura da imagem são dimensões espaciais e possuem unidades de comprimento. A resolução espacial diz respeito à capacidade do sistema de imageamento utilizado para a aquisição de perceber e reproduzir a forma e os detalhes da imagem e ou de diferenciar dois objetos cuja distância entre eles seja muito pequena. Imagens de Medicina Nuclear apresentam uma limitação intrínseca da resolução espacial e não possuem o detalhamento de borda que o sistema de tomografia, por exemplo. Como fatores que influenciam na limitação da resolução espacial da imagem de medicina nuclear lista-se a resolução do colimador e a resolução intrínseca.

A resolução do colimador é tomada como a principal causa da limitação da resolução espacial uma vez que o material absorvedor do qual o colimador é composto restringe a captação dos fótons para uma linha de resposta específica da largura do diâmetro dos furos do colimador. Sob condição de apresentar eficiência razoável, os furos do colimador devem apresentar diâmetro relativamente largo, causando um borramento na imagem mais intenso à medida que o diâmetro dos furos do colimador aumenta isso causa um comprometimento da diferenciação entre estruturas, principalmente, na região de sua borda, região de fronteira entre duas regiões. A resolução do colimador é um fator distância-dependente o que significa dizer que quanto mais longe a fonte estiver do detector pior é a resolução espacial. Este efeito indesejado é de impossível remoção e é conhecido como efeito do volume parcial.

Outro fator é a resolução espacial intrínseca do sistema de detecção e é dependente da energia dos raios gama. Quanto menor a energia do fóton, pior é a resolução espacial intrínseca. Esta sofre influência das variações estatísticas nas fotomultiplicadoras e em caso de dispositivos com elementos de detecção discretos, como ocorre o PET, o tamanho de cada um dos elementos de detecção influi de maneira determinante na resolução espacial intrínseca do sistema.

A resolução espacial afeta o contraste da imagem e, portanto, a capacidade do sistema de detectar pequenas estruturas com baixa ou moderada razão entre a 
atividade da lesão e a atividade do BG. A princípio, em termos de contraste, estruturas muito pequenas podem ser detectadas sim, mas somente se a razão entre sua atividade e a atividade do BG for muito alta, contudo, mesmo que sejam detectadas, seu volume parcial poderá não ser precisamente definido, uma vez que depende da resolução espacial do sistema de detecção.

\subsubsection{Contraste}

Contraste significa diferença. Em radiodiagnóstico, o contraste é definido principalmente pela diferença de densidade entre os diferentes tecidos pelos quais o raio $X$ atravessa antes de atingir o filme radiográfico. Em Medicina Nuclear, 0 contraste da imagem indica a diferença de intensidade em distintas áreas com relação ao diferente nível de captação do radiofármaco pelo paciente. No geral, busca-se um agente que resulte na maior relação de captação entre a lesão e o background. Para tanto, utilizam-se diferentes radiofármacos para os diferentes propósitos diagnósticos uma vez que cada fármaco tem afinidade com um determinado tipo de tecido.

Os mecanismos de interação da radiação com a matéria são fatores que afetam o contraste da imagem e, de modo geral, também estão envolvidos no ruído estatístico. Estes fatores mais especificamente afetam a razão contraste ruído, conhecida pelo acrônimo CNR do inglês contrast-to-noiseratio.

A definição mais geral de contraste considera a variação do sinal de uma região de interesse para o sinal da região que o rodeia.Seja $R_{0}$ a taxa de contagem sobre um tecido normal e $R_{\downarrow}$ a contagem sobre a lesão, o contraste da região é definido como

$\mathrm{C}_{\mathrm{l}}=\left(\mathrm{R}_{\mathrm{l}}-\mathrm{R}_{0}\right) / \mathrm{R}_{0}=\Delta \mathrm{R} / \mathrm{R}_{0}$

em que $\Delta R$ é a mudança da taxa de contagem da lesão para o tecido normal. É comum expressar o contraste em porcentagem, ou seja, $C_{\mid}=0,1=10 \%$ de contraste entre as estruturas analisadas.

É provável que o fator que mais influencia no contraste da imagem seja a taxa de contagens adicional relativa ao background cujo efeito é adicionar contagens, uniformemente ou não, à distribuição de atividade de interesse. Em questão de imagem diagnóstica de Medicina Nuclear, a radiação espalhada detectada e a 
radiação de background diminuem o contraste entre a estrutura de interesse e 0 meio em que a mesma está inserida. Com o uso de computadores, é possível aplicar a "subtração de BG" ou "melhora de contraste" e assim, restaurar o contraste original, ao menos em termos de brilho relativo entre a lesão e o tecido normal que a rodeia. Entretanto, estes algoritmos de correção aumentam o ruído estatístico (Dewajaraet al 2012) e não distinguem um artefato de uma lesão verdadeira. Deste modo, é possível aumentar o contraste de qualquer artefato de reconstrução.

\subsubsection{Ruído}

O ruído em imagens pode ser caracterizado como ruído randômico e ruído estruturado. O primeiro é de fácil detecção uma vez que se manifesta na forma de granulações, largamente encontradas em imagens de Medicina Nuclear e é causada devido às variações na taxa de contagens durante a aquisição da imagem e, por isso, também é conhecido como ruído estatístico. O segundo, por sua vez, relaciona-se com as variações não randômicas na taxa de contagem que são impostas e que interferem na percepção do objeto de interesse. Um exemplo de ruído estruturado é a própria distribuição de emissão do radionuclídeo por si só ou artefatos do sistema de detecção.

É comum associar ruído com imagens de estruturas muito pequenas, contudo o ruído randômico está presente em todas as imagens de Medicina Nuclear, incluindo imagens de estruturas relativamente maiores do que a limitação espacial do sistema de aquisição. Em imagens cujo contraste das estruturas é baixo, a presença do ruído afeta substancialmente a detectabilidade e compromete 0 diagnóstico, uma vez que o parâmetro crítico para avaliar a detectabilidade de um objeto é a razão contraste-ruído (CNR).

O critério utilizado para detectar uma lesão é conhecido como critério de Rose (Cherry, S.R., et al., 2012) que toma como padrão para detectabilidade de uma lesão o valor calculado do CNR ser compreendido entre 3 e 5 . O observador deve ser capaz de distinguir o ruído relativo ao BG do ruído presente na lesão em áreas numericamente iguais em cada uma das regiões da imagem. O valor real do CNR depende da forma e tamanho do objeto, do contorno do perímetro da lesão e distância até o sistema de detecção bem como de fatores subjetivos como a experiência do observador que avalia a imagem. 
O fato é que computar o ruído em tomografia de emissão é uma tarefa complicada uma vez que o nível de intensidade de cada pixel é derivado de cálculos que envolvem diversas projeções e de outros diversos pixeis da imagem. Nesta questão avaliam-se a propagação de ruído, a razão sinal-ruído - do acrônimo americano SNR, signal to noise ratio - e a já mencionada razão contraste-ruído (CNR). Estes fatores se diferenciam pelo comportamento em imagens planas convencionais de Medicina Nuclear. Neste tipo de imagem, a SNR para cada pixel individual é tomado como a raiz quadrada do número de contagens naquele pixel específico. Embora o SNR dependa da raiz quadrada do número de contagens registradas durante a aquisição a relação entre este número e SNR de cada pixel é mais complicada ao considerar o tamanho e forma do objeto imageado, bem como $o$ tamanho da matriz e dos pixels que a formam. Conforme Cherry Simon et al, 2012, supondo um cilindro de diâmetro $\mathrm{D}$ e preenchido com radioisótopo distribuído uniformemente em seu interior, que o intervalo entre as projeções é de $\Delta r$ e que o número de eventos detectados é $\mathrm{N}_{\text {imagem, }}$, para uma imagem reconstruída com FBP e filtro rampa numa matriz $D x D$ com o tamanho de pixel igual a $\Delta r \times \Delta r$ é possível mostrar que o SNR de cada pixel individual da imagem é dada pela equação 21:

$$
\mathrm{SNR}_{\text {pixel }}=\left[12 \mathrm{~N}_{\text {imagem }} /\left(\pi^{2}(\mathrm{D} / \Delta r)^{3}\right)\right]^{1 / 2} \quad \text { Equação } 21
$$

Em termos de detectabilidade de lesão e a fim de considerar as contagens no interior de uma região de interesse (RI) o SNR da estrutura é definido como o número médio de eventos detectados no interior da RI dividido pelo desvio padrão das intensidades dos pixels no interior desta mesma RI, deste modo, considera-se

$$
\mathrm{SNR}=\mathrm{N}_{\mathrm{R}} / \sigma_{\mathrm{Rl}} \quad \text { Equação } 22
$$

em síntese, a relação sinal-ruído compara o nível de sinal detectado com o nível de ruído no próprio sinal. Assim, quanto mais alto for o valor do SNR, menor é o desvio entre os sinais detectados e portanto, menor o ruído na imagem, ou seja, mais uniforme. 


\section{MATERIAIS E MÉTODOS}

\subsubsection{MATERIAIS}

\subsubsection{SIMULADOR JASZCZAK}

O simulador Jaszczak fornece informações de desempenho de qualquer sistema de PET ou de SPECT. No caso de uma aquisição de SPECT, com uma única imagem tomográfica do simulador é possível avaliar diferentes características da gama câmera do sistema.

O simulador , Figura 12, é utilizado para avaliação do sistema de aquisição de imagem, tanto para avaliação do colimador, artefatos, calibração do sistema como um todo e seus parâmetros de reconstrução. Além disso, também é utilizado para testes de aceitação, testes de qualidade da rotina, controle e garantia de qualidade,avaliação de erro do centro de rotação, artefatos de não uniformidade, mudanças do raio de rotação na resolução espacial bem como a avaliação da compensação da atenuação e do espalhamento também são outros itens nos quais o simulador é empregado.

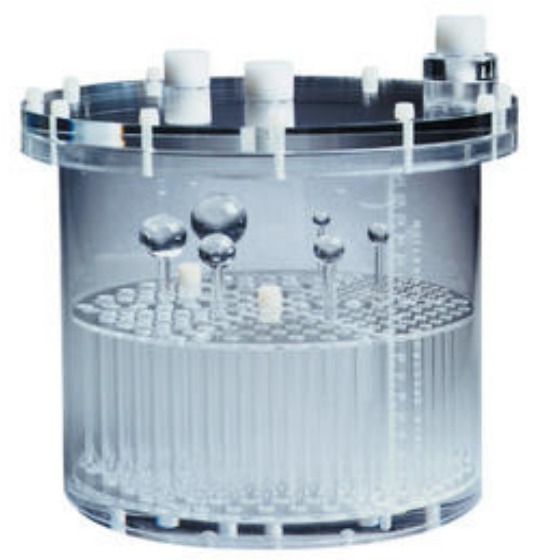

Figura 12 Simulador Jaszczak Deluxe utilizado para a aquisição das imagens

A parte inferior do simulador é composta por padrões de cilindros cujos diâmetros variam de $4.8 \mathrm{~mm}$ a $19.1 \mathrm{~mm}$. É possível encaixar esferas sólidas de diferentes diâmetros que variam de $12.7 \mathrm{~mm}$ a $38 \mathrm{~mm}$. Com esse sistema, é 
possível fazer uma análise da resolução espacial do sistema. Na parte superior, é possível fazer análise da uniformidade da imagem e formação de artefatos. No simulador, podem ser inseridas esferas ocas preenchidas com radionuclídeo com atividade maior do que a do background, de maneira a gerar uma imagem que simula regiões quentes.

\subsubsection{PHILIPS BRIGHTVIEW XCT}

O Brightview da Philips é um sistema médico híbrido de diagnóstico por imagem que integra uma câmara gama de medicina nuclear com ângulo variável de diversas funcionalidades e um dispositivo de raios $X$ com painel plano para tomografia computadorizada por transmissão.

A correção de atenuação baseada em tomografia computadorizada está disponível para todos os radionuclídeos de uso clínico e rotineiro em Medicina Nuclear. Os protocolos de uso da TC devem ser definidos pelo usuário e podem ser configurados para uso de correção de atenuação ou de localização das lesões.

\subsubsection{JETSTREAM WORKSPACE}

O JETStreamWorkspace é um sistema de visualização e processamento de imagens de Medicina Nuclear acoplado ao sistema da Philips BrightView XCT e oferece a possibilidade de correção de atenuação uniforme ou não uniforme, contudo a subtração das projeções de aquisições simultâneas para correção de espalhamento não é permitida. A correção de espalhamento somente é permitida baseando-se na estimativa de fótons espalhados que é feita baseando-se na aquisição da TC, contudo, a dose se à qual o paciente seria submetido fosse alta poderia não ser justificável e, portanto, a aplicação das correções de atenuação não uniforme e de espalhamento pode passar a ser não indicada, mas quanto a TC é feita com a finalidade de correção de atenuação e os parâmetros de aquisição são adequados para tal, a dose no paciente é baixa. 


\subsection{MÉTODOS}

\subsubsection{AQUISIÇÃO DAS IMAGENS E PROTOCOLO DE AQUISIÇÃO}

As aquisições das imagens foram feitas com o simulador Jaszczak no setor de Medicina Nuclear do Hospital de Clínicas da Faculdade de Medicina da Universidade de São Paulo, campus Ribeirão Preto - USPRP.

Ao todo foram realizadas onze (11) aquisições com diferentes valores de atividade de radioisótopo no interior do simulador. A imagem é uma representação da real distribuição do radionuclídeo no interior do simulador, portanto, esperava-se que, com a variação na concentração de radionuclídeo houvesse uma variação no contraste das estruturas. A Tabela 2 exibe a configuração de preparo dosimulador para cada uma das aquisições. Devido à instabilidade no abastecimento de energia $\mathrm{e}$ consequente desligamento do tomógrafo, as aquisições 8 e 9 foram descartadas.

\begin{tabular}{|c|c|c|}
\hline Aquisição & Atividade (MBq) & Concentração $(\mathrm{MBq} / \mathrm{L})$ \\
\hline 1 & 391,09 & 48,89 \\
\hline 2 & 840,50 & 105,06 \\
\hline 3 & 783,98 & 97,10 \\
\hline 4 & 726,44 & 90,80 \\
\hline 5 & 553,28 & 69,16 \\
\hline 6 & 488,39 & 61,05 \\
\hline 7 & 462,32 & 57,79 \\
\hline $8\left(^{*}\right)$ & 428,77 & 53,60 \\
\hline $9\left(^{*}\right)$ & 417,41 & 52,18 \\
\hline 10 & 1158,85 & 144,86 \\
\hline 11 & 1060,94 & 132,62 \\
\hline
\end{tabular}

Tabela 2 Aquisições realizadas e suas respectivas atividades e concentração de radionuclídeo no interior do simulador . 
O protocolo utilizado para as aquisições da presente pesquisa é baseado no atual protocolo de imagens cerebrais do setor de Medicina Nuclear supracitado tendo como única alteração o número de janelas de aquisição. $O$ protocolo de aquisição de imagens cerebrais do setor possui uma única janela de energia, centrada no fotopico do radionuclídeo utilizado para as imagens, no caso, o tecnécio e o centro da janela de energia em $140,5 \mathrm{keV}$ e o protocolo de aquisição de imagens para esta pesquisa possui duas janelas de energia. De acordo com a funcionalidade do sistema JETStream, teve de sercriado um novo isótopo de radionuclídeo, salvá-lo para enfim configurar a janela de aquisição desejada centrada em 112,25 keV com largura de 25\% (98,00 a 126,50 kEV). Para janela do fotopico, por questões de instabilidade do sistema tivemos de adquirir as imagens com o fotopico deslocado para $143 \mathrm{keV}$ com uma janela de $20 \%$ (128,30 a 157,30 keV) para a primeira aquisição e, para as demais, com o aumento da instabilidade e necessidade de realizar a aquisição sem que se pudesse esperar a visita do engenheiro responsável, o fotopico foi deslocado para $145 \mathrm{keV}$ e a janela de 20\% (130,50 a $159,5 \mathrm{keV}$ ) foi mantida. A janela de energia superior ao fotopico para implementação do método da tripla janela de energia de correção de espalhamento foi suprimida como já descrito na literatura [ Dewajara et al., 2012; Ogawa et al., 1991; Hutton et al, 2011]. O método de correção de espalhamento tripla janela de energiacom a definição de três janelas de energia é indicado para radionuclídeos com multifotopicos ou para aquisições com mais de um radionuclídeo [Siegelet al, 1999]. A aquisição da tomografia computadorizada foi realizada com $120 \mathrm{kVp}$ e $2 \mathrm{~mA}$ como meio de reduzir a dose depositada [Dewajara, et al, 2012] no paciente e segundo protocolo de aquisição tomográfica para correção de atenuação.

As reconstruções foram feitas segundo os parâmetros de reconstrução da Tabela 3 abaixo, preservando as recomendações de parâmetros de reconstrução de imagens cerebrais e, posteriormente alterando-os afim de avaliar a alteração no contraste resultante. Primeiramente, foram feitas as reconstruções baseando-se no padrão aplicado às reconstruções de imagens dos exames de perfusão cerebral (método OSEM, 3it8s, filtro Butterworth com frequência de corte 0,34 e potência 1). Para comparação e avaliação do padrão de reconstrução de imagens cerebrais, foram reconstruídas imagens utilizando-se dos diferentes métodos de reconstrução de imagem que o sistema JETStream oferece: FBP e MLEM, bem como 
reconstruções utilizando o método OSEM, contudo, com distinto número de iterações (3 e 30) e ou subsets (8 e 16), da frequência de corte do filtro Butterworth $0,34$ e 0,1$)$ e da respectiva potência (1 e 2). Para efeito de comparação e avaliação o método MLEM também foi reconstruído com diferentes números de iterações (8 e 25) e diferentes frequência de corte do filtro $\operatorname{Butterworth}(0,34$ e 0,1$)$.

\begin{tabular}{|c|c|c|c|}
\hline \multicolumn{3}{|c|}{ Condições de Aquisição de SPECT e TC e Parâmetros de Reconstrução } \\
\hline \multicolumn{2}{|c|}{ SPECT } & \multicolumn{2}{c|}{ CT } \\
\hline Tamanho da Matriz & $128 \times 128$ & $\mathrm{kVp}$ & 2 \\
\hline Tempo por Frame & 25 s/frame & $\begin{array}{c}\text { Espessura } \\
\text { da Fatia }\end{array}$ & 2 \\
\hline Colimador & LEHR & mAs & 30 \\
\hline $\begin{array}{c}\text { Método de } \\
\text { Reconstrução }\end{array}$ & FBP, MLEM, OSEM & & \\
\hline Frequência de Corte & 0,34 / 0,1 & & \\
\hline Filtro & Butterworth & & \\
\hline Potência & 1 & & \\
\hline Número de Iterações & 3,30 (OSEM), 8, 25 (MLEM) & & \\
\hline Subsets & 8,16 & & \\
\hline
\end{tabular}

Tabela 3 Condições de Aquisição de SPECT e TC e Parâmetros de Reconstrução

\subsubsection{CORREÇÃO DE ESPALHAMENTO}

O software de reconstrução tomográfica existente no tomógrafo instalado no setor de Medicina Nuclear do Hospital das Clínicas da Faculdade de Medicina da Universidade de São Paulo em Ribeirão Preto não dispõe de meio para que a correção de espalhamento seja feita durante o processo de reconstrução utilizandose somente do software da Philips. Deste modo, a correção de espalhamento (CE) foi feita por meios computacionais utilizando-se do MatLab.

A correção de espalhamento baseada no método da tripla janela de energia foi realizada estimando a quantidade de fótons primários utilizando-se de uma janela de energia principal centrada na energia do fotopico e outra janela de energia, 
chamada de janela de espalhamento, localizada imediatamente antes da janela de energia principal e, como proposto na literatura, a janela de energia superior ao fotopico foi suprimida a fim de diminuir o ruído estatístico na imagem corrigida (Ogawa, K. et al, 1991; Hutton, B.F. et al, 2011; Dewajara, Y. K., et al. 2012). As contagens totais na janela do fotopico de uma aquisição é o conjunto das contagens dos fótons primários e fótons espalhados detectados na referida janela. Para realizar a correção de espalhamento, é necessário calcular os fótons primários existentes nesta janela (equação 23). Para tanto, utilizam-se as contagens na janela de espalhamento.

$$
\mathrm{C}_{\text {prim }}=\mathrm{C}_{\text {total }}-\mathrm{C}_{\text {espalhados }} \quad \text { Equação } 23
$$

emC $\mathrm{C}_{\text {espalhados }} \mathrm{são}$ os eventos espalhados registrados na janela de espalhamento, $\mathrm{C}_{\text {total }}$ é o número de contagens totais registradas na janela do fotopico e $\mathrm{C}_{\text {prim }}$ é o número estimado de fótons primários.

$\mathrm{Na}$ figura 13, é possível verificar a posição das janelas de energia sobre o espectro do tecnécio-99m simulado. O espectro existente na imagem é resultado de uma simulação de aquisição SPECT utilizando-se da plataforma GATE, acrônimo de Geant4 Application for TomographicEmission. Na simulação em questão, o número total de fótons registrados foi de 35938, com energia média de 0,1168 MeV e valor de desvio quadrático médio (root meansquare, RMS) dos valores igual a $0,02816 \mathrm{MeV}$. Uma vez que o espectro da figura é um espectro simulado, o fotopico do tecnécio-99m é de 140,5 keV. No momento de nossas aquisições o fotopico era de 143 e $145 \mathrm{keV}$, o que explica as posições das janelas na figura não estarem centralizadas no fotopico. 


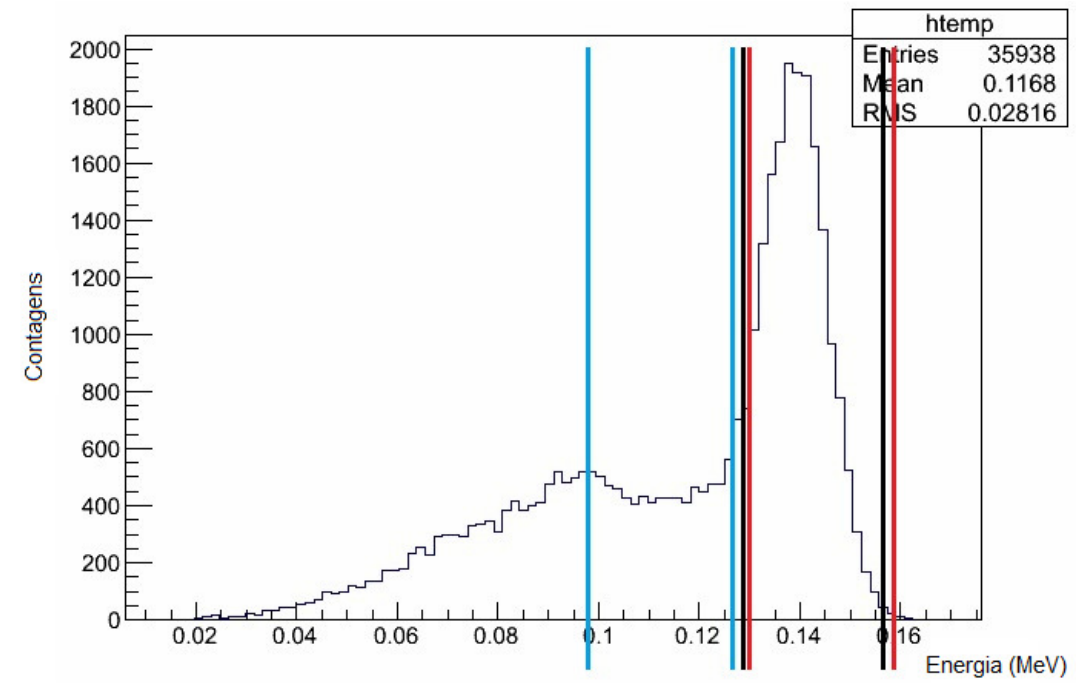

| Janela principal. centro em $143 \mathrm{keV}$

| Janela de espalhamento. centro em $112,5 \mathrm{keV}$

Janela principal. centro em $145 \mathrm{keV}$

Figura 13 Espectro do Tc99m e Janelas de energia das aquisições tomográficas realizadas.

Selecionar janelas mais largas pode reduzir o ruído estatístico por aceitar mais fótons, uma vez que baixas contagens pode gerar uma imagem repleta de artefatos (Hutton, B. F. et al, 2011). O protocolo utilizado para a aquisição das imagens tomográficas apresenta as janelas do fotopico e de espalhamento com mesma largura. A largura das janelas de aquisição são fatores para estimar a quantidade de fótons espalhados na janela do fotopico e calcular os fótons primários.

$$
\mathrm{C}_{\text {esp }}=\left(\frac{\mathrm{C}_{\text {inf }}}{\mathrm{L}_{\mathrm{i}}}+\frac{\mathrm{C}_{\text {sup }}}{\mathrm{L}_{\mathrm{s}}}\right) * \frac{\mathrm{L}_{\text {prin }}}{2}
$$

Equação 24

$\mathrm{C}_{\text {esp }}$ são as contagens de eventos espalhados, $\mathrm{C}_{\text {inf }}$ e $\mathrm{C}_{\text {sup }}$ são as contagens na janela inferior e superior, respectivamente e $L_{i}, L_{s}$ e $L_{\text {prin }}$, as larguras das janelas inferior, superior e principal, respectivamente. As contagens de espalhamento estimadas foram subtraídas das contagens totais, pixel a pixel, conforme a equação 24 , dando origem à imagem com correção de espalhamento. 


\subsubsection{AVALIAÇÃO DA QUALIDADE DA IMAGEM}

A qualidade das imagens foi avaliada de acordo com o valor do SNR e do contraste das simulações de lesões frias com o background. Foi desenvolvido um algoritmo utilizando-se da plataforma MatLab para tais cálculos.

O SNR foi calculado para a simulação de lesão e para o background, tomando-se como base a equação 22

$$
\mathrm{SNR}=\mathrm{N}_{\mathrm{RI}} / \sigma_{\mathrm{ROI}}
$$

Equação 22

em que $N_{R l}$ é o número médio de contagens na região de interesse (ROI)selecionada e $\sigma_{\mathrm{RO}} \mathrm{O}$ desvio padrão dos valores. Cada ROI da lesão foi posicionada sobre a maior lesão fria da imagem, em dez fatias em que a mesma está presente para efeito de média de valores. O mesmo procedimento foi repetido para o cálculo do SNR do background, em que a ROI foi posicionada à mesma distância radial que a lesão simulada se encontra.

O contraste entre a lesão e o background foi calculado tomando a média das

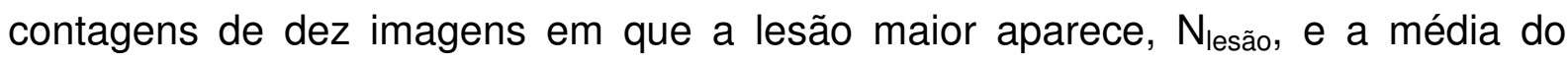
background na região central das dez mesmas imagens, $\mathrm{N}_{\mathrm{BG}}$ e assim:

$$
\text { Contraste }=\frac{\mathrm{N}_{\mathrm{BG}}-\mathrm{N}_{\text {lesão }}}{\mathrm{N}_{\mathrm{BG}}}
$$

\section{Equação 25}

\subsubsection{Avaliação de Correlação do Contraste com a Atividade no Simulador}

Para fins de avaliar a existência de correlação entre os valores de contraste, o que seria esperado, e atividade em cada simulador , foi calculado o coeficiente de correlação de Pearson entre a atividade do simulador e o contraste obtido, da maior esfera, para efeito de existência de correlação foi considerado um coeficiente maior que 0,54 , em módulo, e um $\mathrm{p}$ menor que 0,05 . 


\section{RESULTADOS EDISCUSSÃO}

A Tomografia Computadorizada do simulador foi realizada segundo os parâmetros de aquisição para correção de atenuação propostos pela Sociedade de Medicina Nuclear e Imagem Molecular para imagens SPECT-CT (Delbeke, D. et al, 2006.) os quais visam a redução de dose no paciente. Após a reconstrução tomográfica, a imagem da tomografia do simulador permite a visualização das lesões esféricas frias diferenciando-as do background (Figura 15). O mesmo se aplica à visualização dos padrões cilíndricos frios (Figura 14). O número de TC das estruturas internas do simulador estão apresentados na Tabela 4. O interior do simulador fora preenchido com Tc99m diluído em água, portanto, a média do número de TC ser $-5,78 \mathrm{HU}$ com desvio padrão das medidas $5,22 \mathrm{HU}$, ou seja, compreende o número de TC teórico da água, $\mathrm{OHU}$. O desvio padrão é uma medida da dispersão estatística, indicando o quanto os valores medidos variam em relação à sua média. Um alto valor de indica pouca precisão nos valores que pode estar associado à instabilidade do sistema de detecção.

\begin{tabular}{|l|l|l|}
\hline \multicolumn{3}{|c|}{ Número de TC } \\
\hline & Média $(\mathrm{HU})$ & Desvio Padrão $(\mathrm{HU})$ \\
\hline Esferas & 107,40 & 1,06 \\
\hline Região Externa & $-1000,00$ & 0,00 \\
\hline Background & $-5,78$ & 5,22 \\
\hline
\end{tabular}

Tabela 4 Número de TC lido nas estruturas do simulador . 


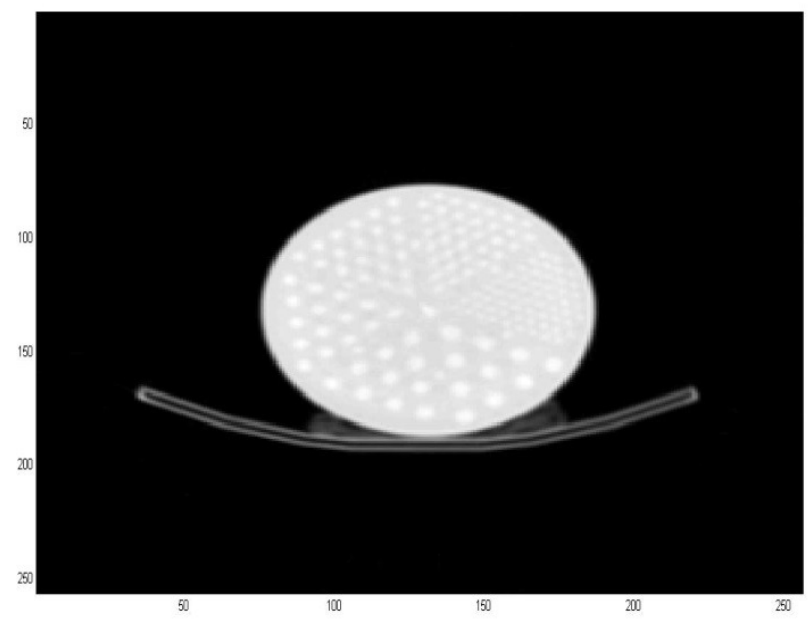

Figura 14 Corte tomográfico do simulador Jaszczak em que é possível visualizar e diferenciar os padrões cilíndricos frios da região inferior do simulador .

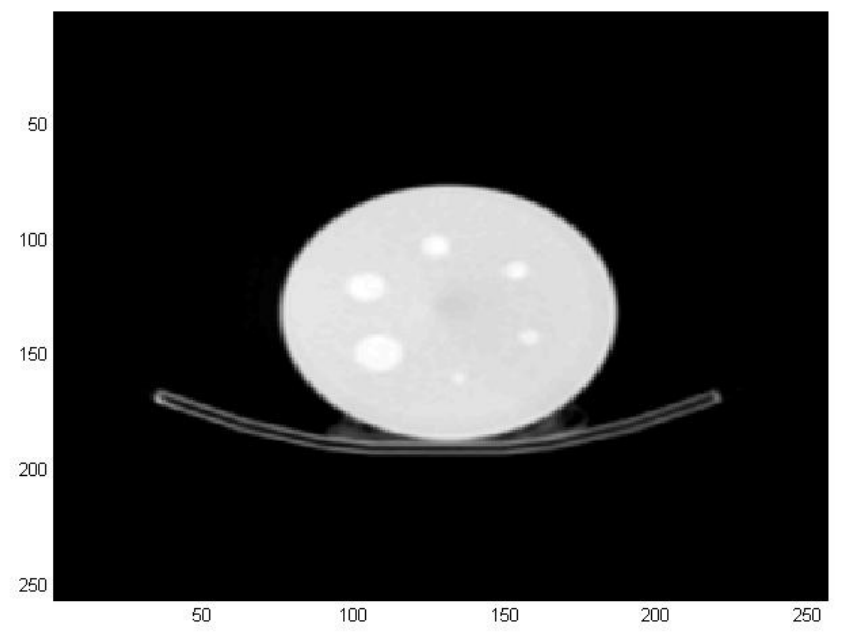

Figura 15 Corte tomográfico do Simulador Jaszczak em que é possível visualizar e diferenciar as esferas frias da região superior do simulador .

Para a reconstrução de imagens utilizando o JETStream, deve-se selecionar simultaneamente o conjunto de dados da aquisição de Medicina Nuclear e o arquivo da TC. Após a reconstrução, foram aplicadas as duas diferentes possibilidades de janelamento para a visualização da imagem tomográfica que serviria como mapa de atenuação: osso e tecidos moles, sem que fossem percebidas diferenças entre os mapas de atenuação gerados. Esta avaliação do mapa de atenuação era necessária uma vez que o ajuste do janelamento poderia mascarar resultados e negligenciar 
estruturas, contudo, o mapa de atenuação gerado é sempre o idêntico independente da opção de janelamento selecionada no processo de reconstrução de imagem. Quaisquer parâmetros e adoção dos janelamentos de reconstrução mencionados não foram capazes de gerar mapas de atenuação diferentes. O mapa de atenuação que é gerado não apresenta variação nos números de TC no interior do simulador . Todas as fatias apresentam o mesmo e constante número de TC, $365 \mathrm{HU}$. Como resultado, a correção de atenuação baseada num mapa de atenuação em que toda a estrutura apresenta mesmo HU é semelhante à correção uniforme de atenuação, com a diferença de que a correção baseada em TC considera a densidade real da estrutura imageada e não a densidade da água ou de um material equivalente ao do simulador . A Figura 16 mostra num gráfico dos valores de pixeis. Os resultados não foram os esperados.

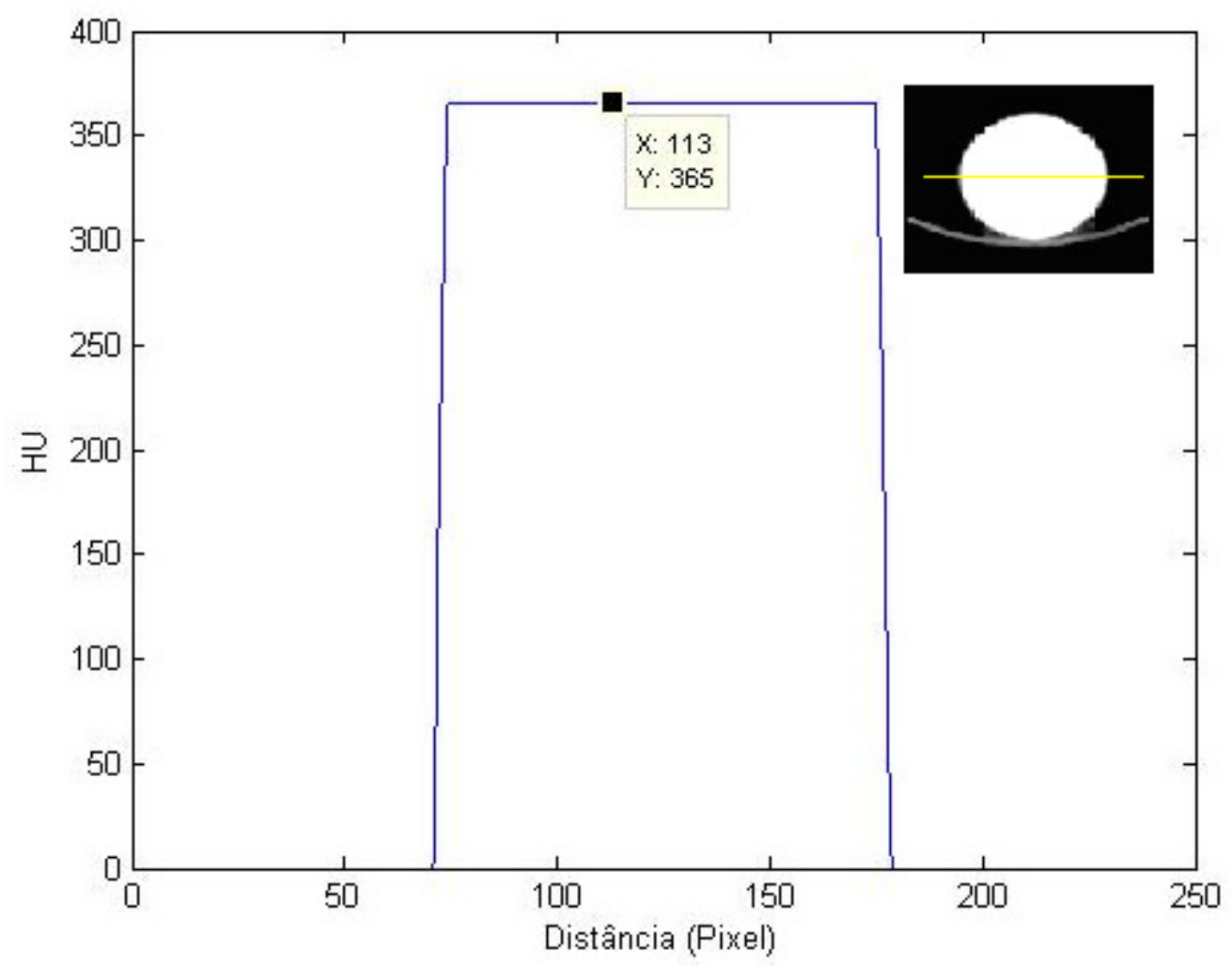

Figura 16 A figura no canto superior indica a linha do corte para a verificação dos valores de HU. O valor permanece inalterado dentro do simulador, sofrendo variações apenas nas bordas.

Tomando um exame SPECT-CT anonimizado para preservar a identidade do paciente previamente realizado na BrightView XCT, avaliou-se o mapa de atenuação 
gerado após a reconstrução tomográfica aplicada sobre a TC para gerar o mapa de atenuação. Após a reconstrução da imagem, o mapa de atenuação gerado diferencia apenas osso, ar e tecido cerebral, sem diferenciar massa cerebral cinzenta e branca. Isto pode ser visualizado na Figura 17. Tratando-se de um corte tomográfico da região central do cérebro é possível perceber a uniformidade da imagem do mapa de atenuação gerado (Figura 18) e o recorrente valor de $365 \mathrm{HU}$ como número de TC do tecido cerebral.

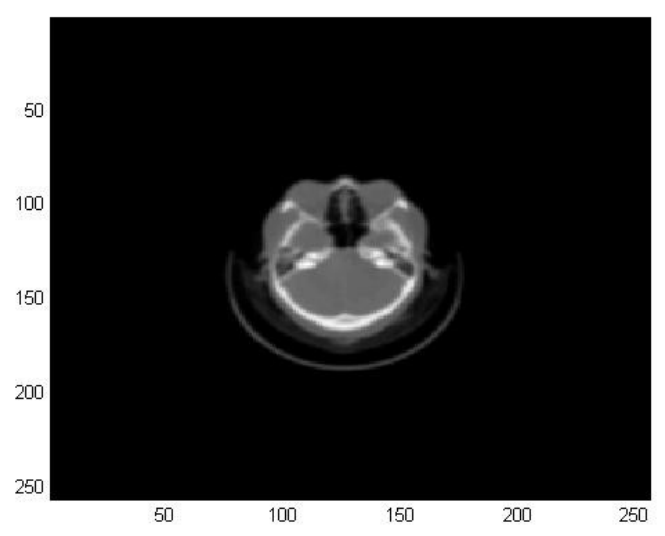

Figura 17 Mapa de atenuação gerado a partir da Tomografia Computadorizada. A diferenciação dos tecidos somente é possível para estruturas cuja densidade é muito distinta. 


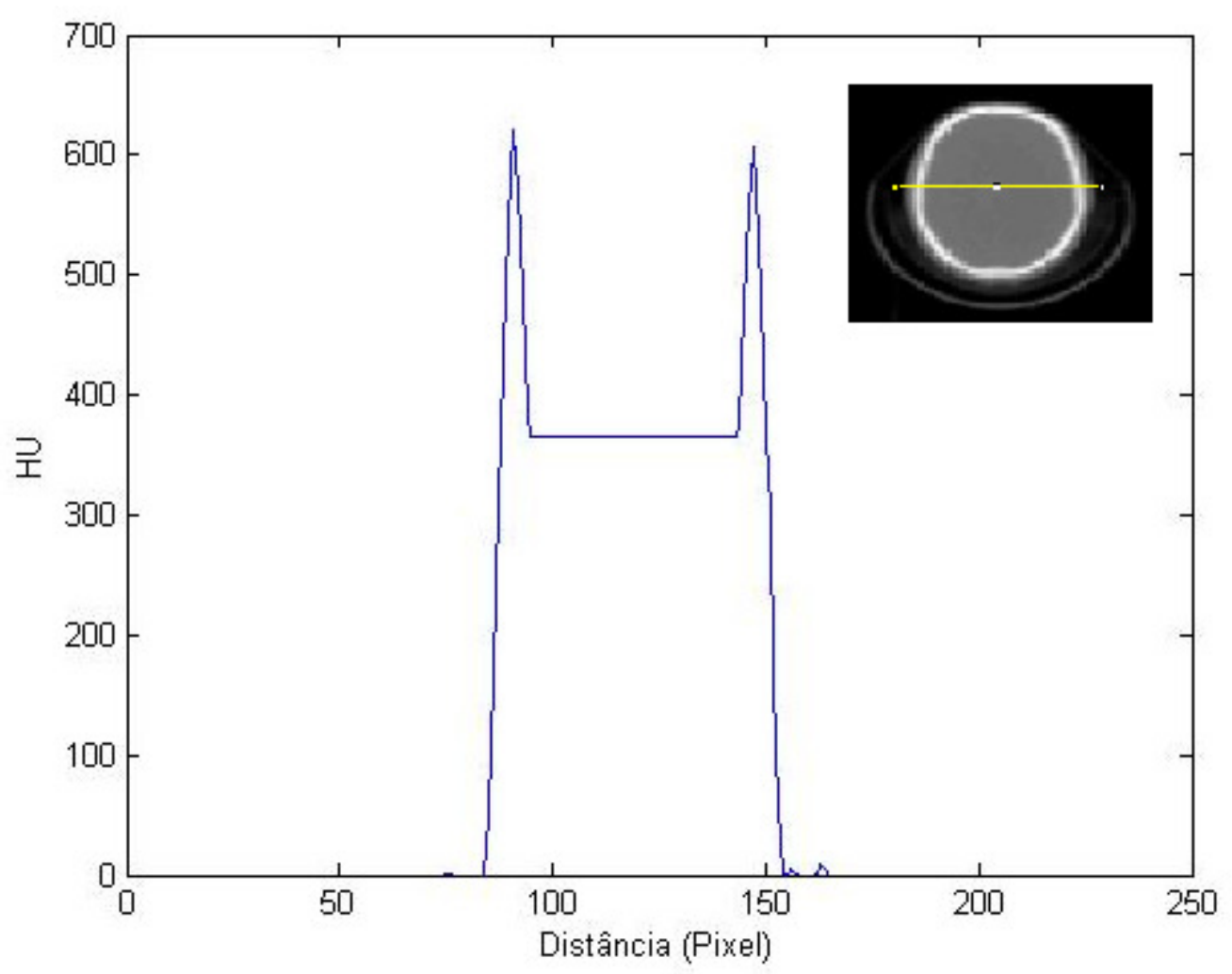

Figura 18 Análise da uniformidade dos valores de HU num corte na fatia central do cérebro do mapa de atenuação gerado a partir da Tomografia Computadorizada. 0 mapa de atenuação não diferencia massa cinzenta de massa branca.

Tanto para a aquisição do simulador Jaszczak quanto para a aquisição do SPECT-CT cerebral citado foi informado no registro do estudo que o mesmo seria um estudo cerebral.

A correção não uniforme de atenuação (CNUA) foi avaliada através da análise do contraste entre a maior esfera de acrílico no interior do simulador e o background e através da análise observacional dos padrões de cilindros existentes no simulador e comparada com os resultados da mesma análise feita sobre imagens reconstruídas sem correção de atenuação e com correção uniforme de atenuação. Os parâmetros do filtro Butterworth aplicado (frequência de corte e potência) foram mantidos constantes para que os resultados pudessem ser comparados entre si. As Figuras 19, 20 e 21 mostram, respectivamente, os padrões cilíndricos nas reconstruções OSEM sem correção de atenuação, OSEM com correção uniforme de atenuação (CUA) e OSEM com correção não uniforme de atenuação (CNUA). A Figura 19, apresenta claramente o efeito de borda comum em imagens SPECT sem correção de atenuação. A borda aparenta ser uma região mais captante do que 0 
interior da estrutura, contudo, isto é resultado da atenuação do feixe de fótons ao atravessar a estrutura, para fins diagnósticos, dependendo de qual é o exame, é necessária a correção de atenuação. Observacionalmente, a reconstrução com correção não uniforme de atenuação (Figura 21) apresentou menos ruído do que a imagem com correção uniforme de atenuação (Figura 20). Contudo, esta análise qualitativa através da observação não é capaz de definir qual imagem apresenta maior contrasteentre as estruturas e, portanto, a capacidade preditiva do diagnóstico não deve ser analisada somente baseada neste método de análise.

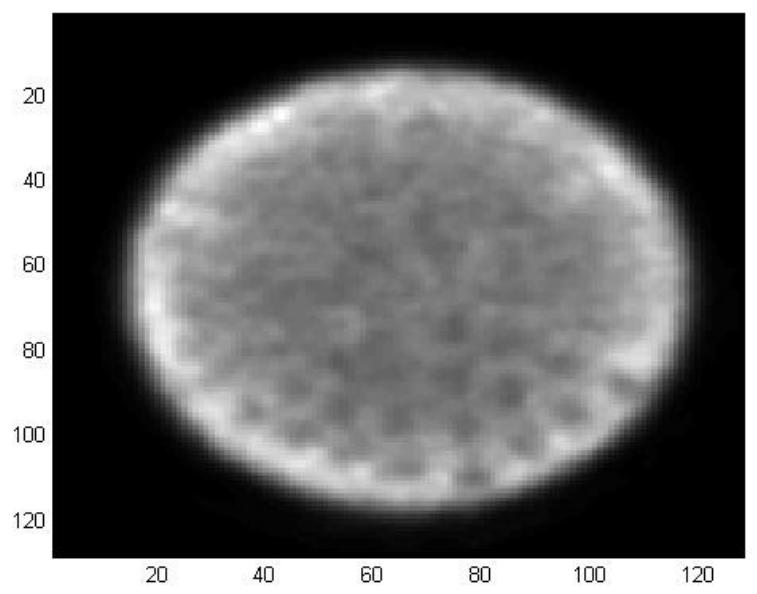

Figura 19 Reconstrução OSEM sem correção de atenuação (OSEM).

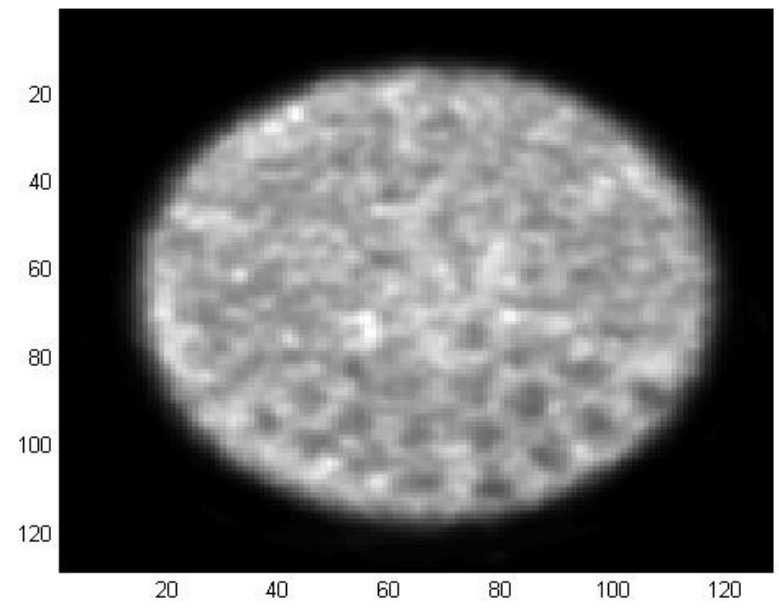

Figura 20 Reconstrução OSEM com correção uniforme de atenuação (OSEM + CUA). 


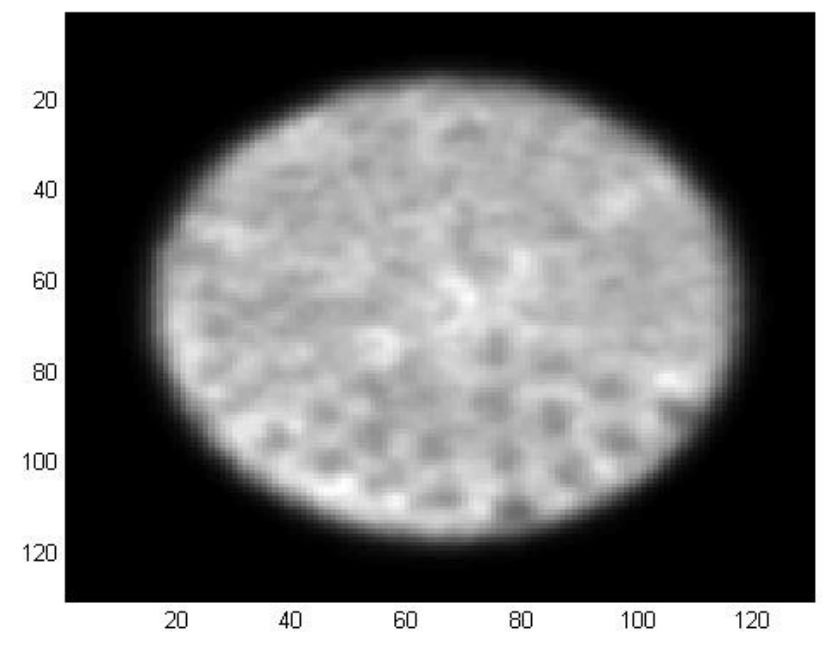

Figura 21 Reconstrução OSEM com correção não uniforme de atenuação (OSEM + CNUA).

A análise quantitativa, por sua vez, foi realizada analisando o contraste entre a esfera de acrílico de $38 \mathrm{~mm}$ de diâmetro e o background.Quantitativamente, a análise através do cálculo do contraste utilizando a Equação 24 revela que a correção não uniforme de atenuação foi superior à CUA, apesar deapresentar diferença percentual baixa (Tabela 5). A maior esfera fria é visualizada em todas as reconstruções e distintos métodos de correção de atenuação: OSEM sem correção de atenuação (Figura 22), OSEM +CUA (Figura 23) e OSEM + CNUA (Figura 24).

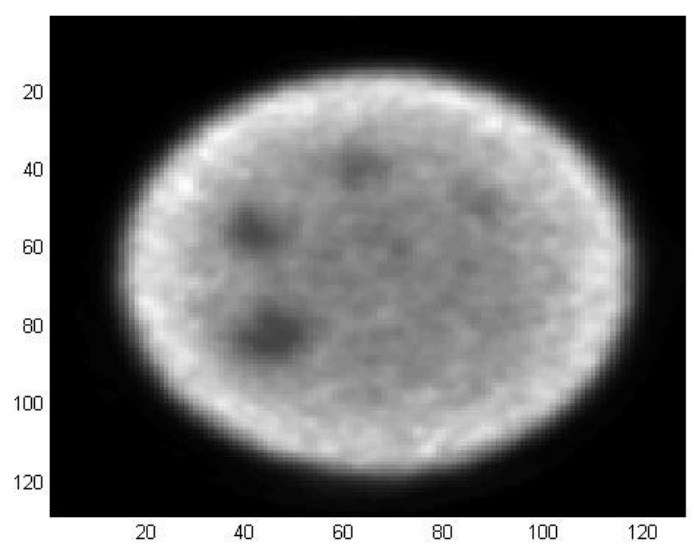

Figura 22 Reconstrução OSEM sem correção de atenuação. Esferas de acrílico. 


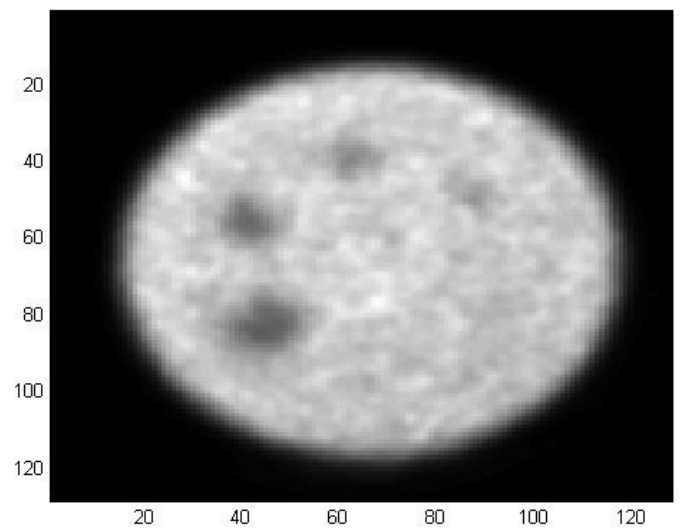

Figura 23 Reconstrução OSEM + CUA. Esferas de acrílico.

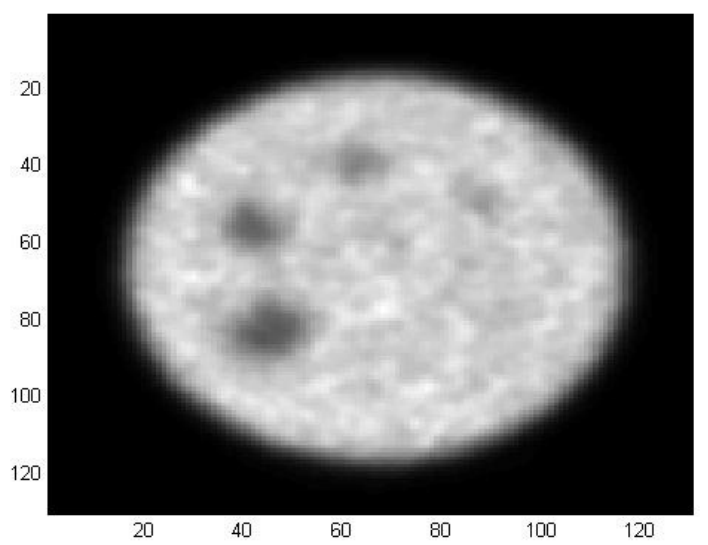

Figura 24 Reconstrução OSEM + CNUA. Esferas de acrílico.

Aumento do contraste entre as esferas e o background

\begin{tabular}{|c|c|}
\hline & Contraste (\%) \\
\hline OSEM & 39,04 \\
\hline OSEM + CUA & 45,30 \\
\hline OSEM + CNUA & 49,00 \\
\hline
\end{tabular}

Tabela 5 Contraste entre a maior esfera de acrílico e o background do simulador para as reconstruções sem correção de atenuação, com correção uniforme de atenuação e com correção não uniforme de atenuação. A correção não uniforme de atenuação discretamente superou a correção uniforme de atenuação.

Quando a correção não uniforme de atenuação foi combinada à correção de espalhamento, o contraste entre a maior esfera e o background atinge $64,88 \%$, ou seja, um ganho de $39,83 \%$ sobre o contraste da mesma estrutura quando a imagem 
foi reconstruída utilizando-se do método OSEM sem realizar correção de atenuação (Figura 25).
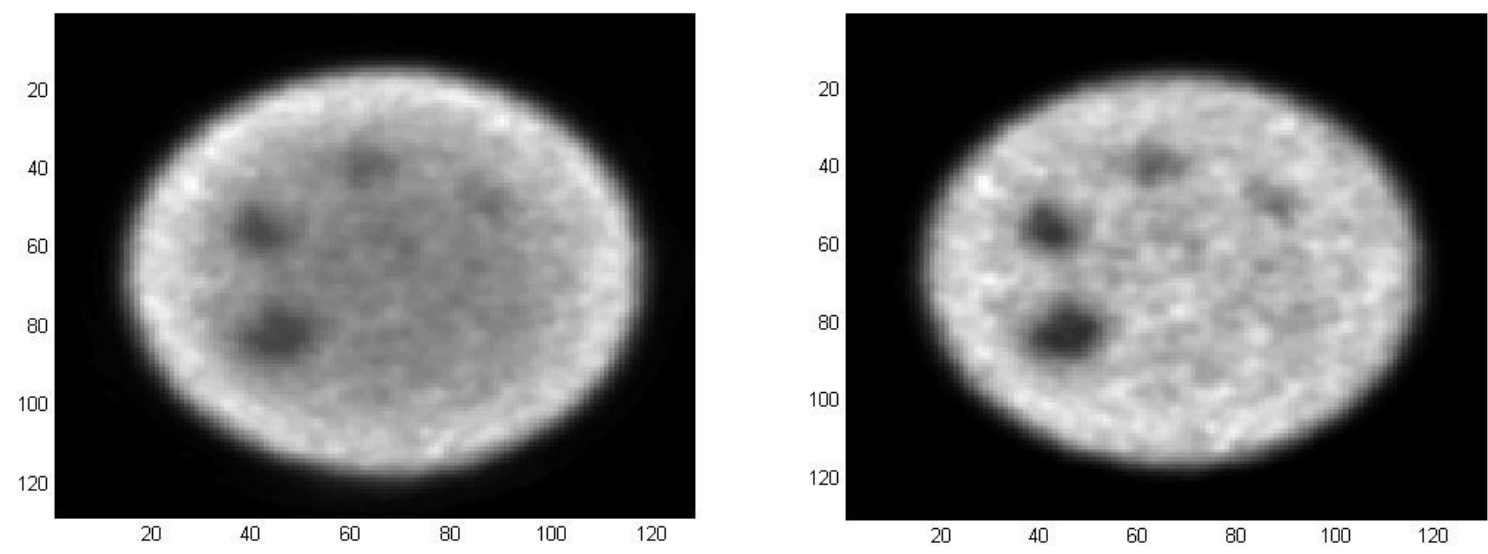

Figura 25 OSEM (E) e OSEM + CNUA + CE (D). Melhora no contraste entre a estrutura e o background da imagem. mais garantia na precisão diagnóstica.

Além do ganho no contraste, o fato de ter-se um topograma da estrutura para melhor localização das áreas hiper ou hipocaptantes é uma justificativa para o uso da TC. O presente estudo não visou analizar a precisão e influência do uso da TC com o propósito de localização e por isso não serão realizadas maiores discussões sobre isto. Contudo, a melhora da precisão oferecida na localização das áreas hiper ou hipocaptantes através da TC é inegável quando comparada à localização sem a TC e não poderia deixar de ser comentada.

A correção de atenuação é necessária uma vez que distribuição do radiofármaco nas diferentes estruturas e tecidos do paciente geram padrões de atenuação que afetam a trajetória dos raios gama ao detector e, assim, causam perda estatística influenciando o diagnóstico clínico por subestimar a captação nas regiões mais centrais do corpo imageado. A correção de atenuação foi avaliadaatravés do cálculo do contraste descrito na sessão 3.2.2. O contraste percentual entre a esfera de acrílico e o background foi calculado utilizando uma rotina para MatLab em que os arquivos de aquisição na janela do espalhamento e na janela do fotopico são selecionados. O método de correção de espalhamento requer uma série de parâmetros, como por exemplo, a largura das janelas de 
aquisição. A rotina criada para realizar a correção de espalhamento coleta estes dados diretamente do arquivo DICOM e realiza os cálculos que o método requer.

A Tabela 6 contém os dados do contraste calculado entre a maior esfera e o background. A primeira linha das tabelas 7 a 10, indicada como aquisição "1 (*)" é relativa à primeira aquisição, utilizando os parâmetros de reconstrução para MLEM de 8it, e como parâmetros do filtro Butterworth, frequência de corte 0,34 e potência 1; para a reconstrução utilizando o método OSEM, os parâmetros utilizados foram os parâmetros padrão para reconstrução de imagens em estudos cerebrais: 3it8sub, filtro Butterworth com frequência de corte 0,34 e potência 1. As demais reconstruções foram realizadas segundo a Tabela 6 .

As regiões de interesse foram criadas e posicionadas computacionalmente utilizando a ferramenta roipoly do MatLab, a uma mesma distância radial, sobre a esfera e na região do background a fim de garantir que a área da região de análise seja a idêntica em todas as imagens. Manualmente não seria possível a mesma precisão.

\begin{tabular}{|c|c|c|}
\hline \multicolumn{2}{|c|}{ Iterações } & Subsets \\
\hline OSEM & MLEM & \\
\hline 3 & 25 & 16 \\
\hline
\end{tabular}

Tabela 6 Parâmetros utilizados para a reconstrução das imagens. 


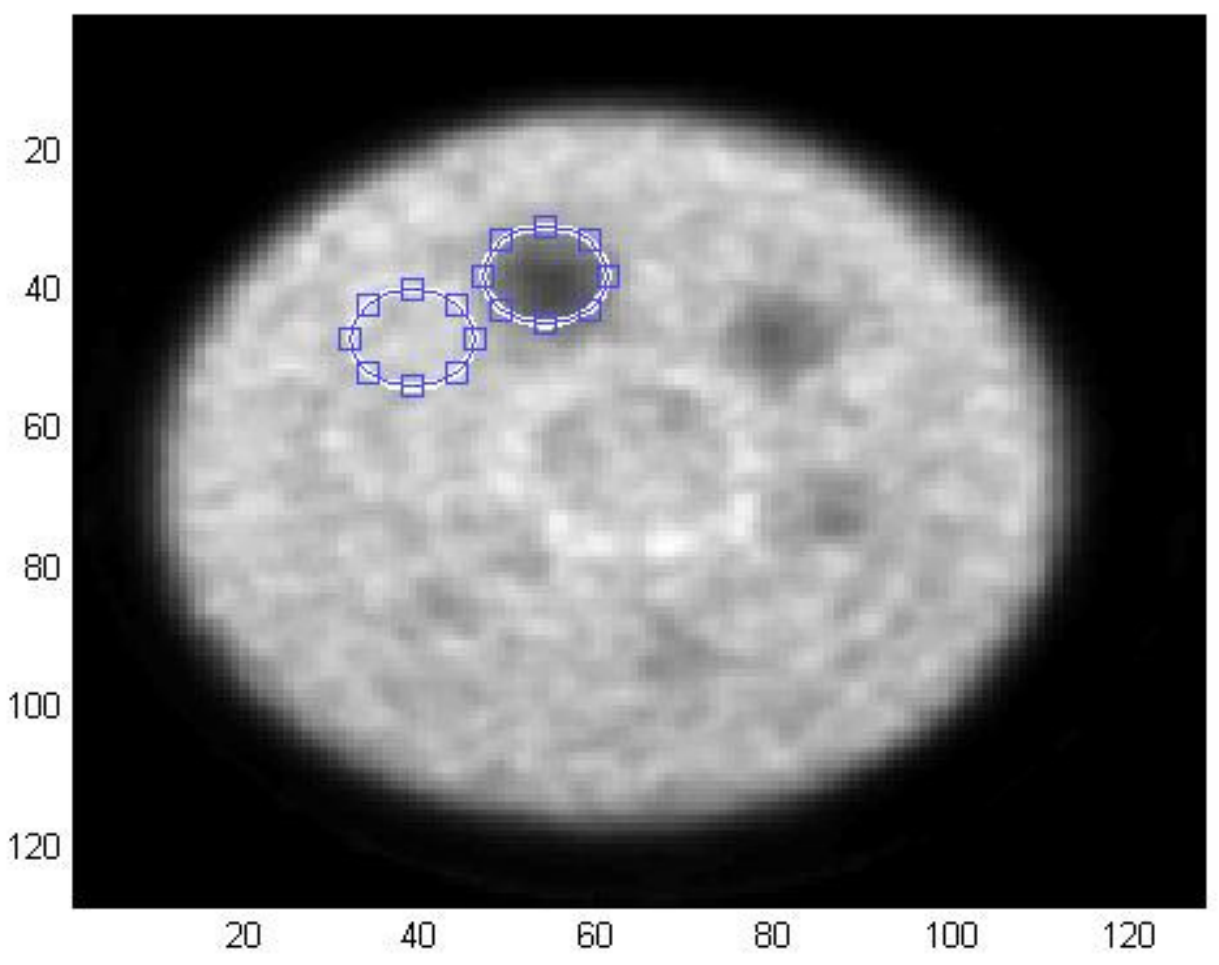

Figura 26 Posicionamento das ROls utilizadas para o cálculo do contraste entre a maior esfera e o background.

\begin{tabular}{|c|c|c|c|c|c|c|}
\hline & \multicolumn{6}{|c|}{ Contraste (\%) } \\
\hline Aquisição & FBP & FBP + CUA & MLEM & MLEM + CUA & OSEM & OSEM + CUA \\
\hline $1\left(^{\star}\right)$ & & & 19,00 & 31,50 & 39,04 & 45,30 \\
\hline 1 & 57,35 & 55,44 & 54,97 & 52,85 & 52,96 & 50,74 \\
\hline 2 & 42,24 & 40,87 & 54,43 & 53,58 & 47,48 & 46,24 \\
\hline 3 & 54,65 & 52,72 & 62,83 & 61,12 & 58,33 & 56,48 \\
\hline 4 & 50,20 & 48,08 & 60,84 & 59,10 & 57,29 & 55,38 \\
\hline 5 & 63,60 & 63,39 & 62,48 & 62,23 & 58,87 & 58,57 \\
\hline 6 & 61,04 & 61,19 & 59,07 & 59,21 & 50,74 & 50,83 \\
\hline 7 & 62,42 & 62,09 & 56,16 & 55,80 & 45,32 & 44,53 \\
\hline 10 & 49,33 & 47,86 & 49,78 & 48,36 & 50,76 & 49,42 \\
\hline 11 & 58,82 & 57,61 & 58,74 & 57,51 & 45,58 & 44,08 \\
\hline
\end{tabular}

Tabela 7 Contraste entre a esfera de acrílico e o background do simulador para os diferentes métodos de reconstrução de imagem FBP, MLEM e OSEM, com e sem correção uniforme de atenuação, CUA. 


\begin{tabular}{|c|c|c|c|c|c|c|}
\hline & \multicolumn{5}{|c|}{ SNR } \\
\hline & FBP & $\begin{array}{c}\text { FBP } \\
+ \text { CUA }\end{array}$ & MLEM & MLEM+CUA & OSEM & OSEM+CUA \\
\hline $1\left(^{*}\right)$ & & & 40,9703 & 37,9593 & 17,9106 & 17,0995 \\
\hline 1 & 5,2984 & 5,2197 & 10,4320 & 10,0749 & 9,3580 & 9,0494 \\
\hline 2 & 8,8990 & 8,6218 & 13,7468 & 14,5673 & 22,1292 & 20,9874 \\
\hline 3 & 8,6370 & 8,4134 & 11,1377 & 11,7889 & 10,1422 & 10,9436 \\
\hline 4 & 6,7325 & 6,5065 & 12,5633 & 11,7170 & 15,4738 & 14,5185 \\
\hline 5 & 6,7107 & 6,5724 & 11,9981 & 11,3608 & 12,6622 & 12,0142 \\
\hline 6 & 7,4094 & 7,3759 & 13,7313 & 13,7612 & 14,0087 & 13,3614 \\
\hline 7 & 5,9564 & 5,9312 & 13,2225 & 13,2416 & 12,9931 & 12,3972 \\
\hline 10 & 8,6994 & 8,6589 & 17,0933 & 16,6465 & 13,7197 & 13,6431 \\
\hline 11 & 9,2433 & 9,333 & 18,4288 & 19,3932 & 11,7201 & 12,3123 \\
\hline
\end{tabular}

Tabela 8 Razão Sinal Ruído do background para as reconstruções pelos métodos FBP, MLEM e OSEM com e sem correção uniforme de atenuação (CUA)

O método e parâmetros padrão de reconstrução de imagem no setor de Medicina Nuclear do Hospital de Clínicas da Faculdade de Medicina da Universidade de São Paulo - campus Ribeirão Preto, OSEM (3it8sub e filtro Butterworth com $\mathrm{f}=0,34$ e potência $=1$ ) e correção uniforme de atenuação apresentou contraste inferior quando comparado com o contraste das imagens reconstruídas pelo mesmo método (Tabela 7), alterando apenas o número de subsets para 16 e mantendo inalterados os demais parâmetros (Figura 26). A SNR das imagens sem correção uniforme de atenuação não sofreu variação significativa em comparação à SNR das imagens com correção uniforme de atenuação. (Tabela 8) O método OSEM com 3it16 e filtro Butterworth com $\mathrm{f}=0,34$ e potência=1 e correção uniforme de atenuação e correção de espalhamento apresentou $9,94 \%$ de ganho no contraste quando comparado ao método padrão com as mesmas correçõe. A imagem sem correção uniforme de atenuação nem correção de espalhamento apresentou um ganho maior no contraste, $27,65 \%$, porém não se indica a aplicação clínica de imagens sem correção de atenuação. 


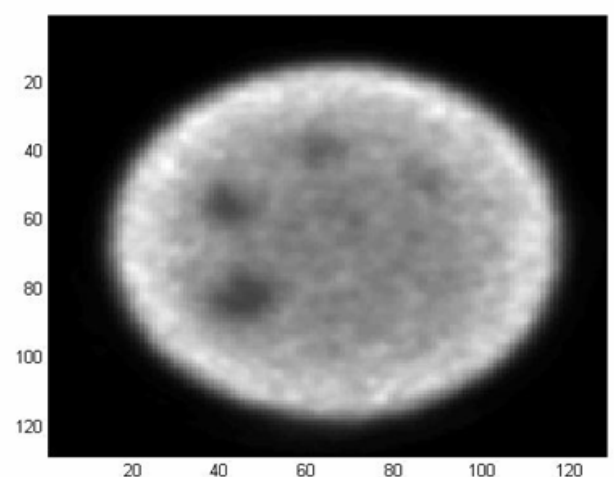

A

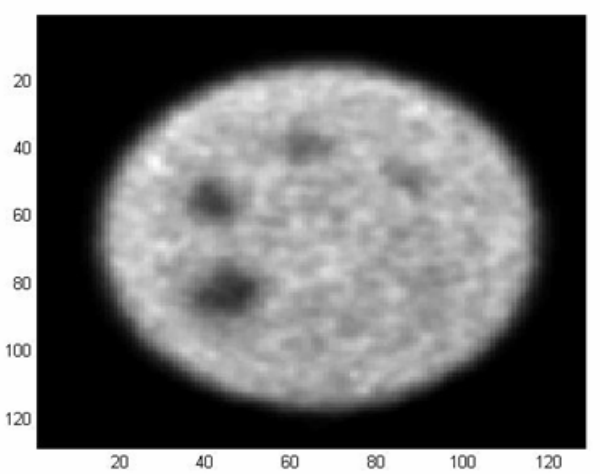

$\mathrm{C}$

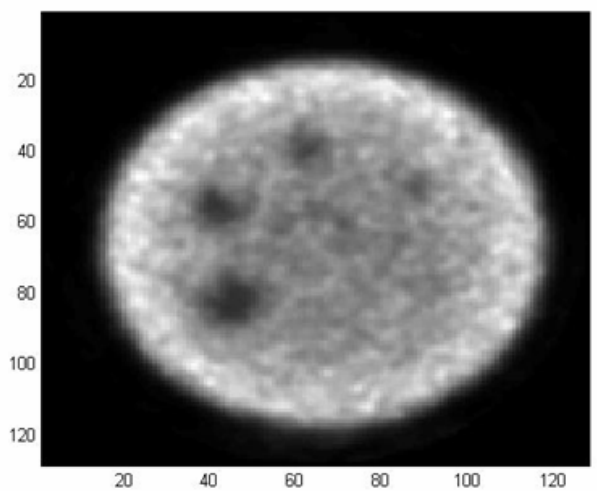

B

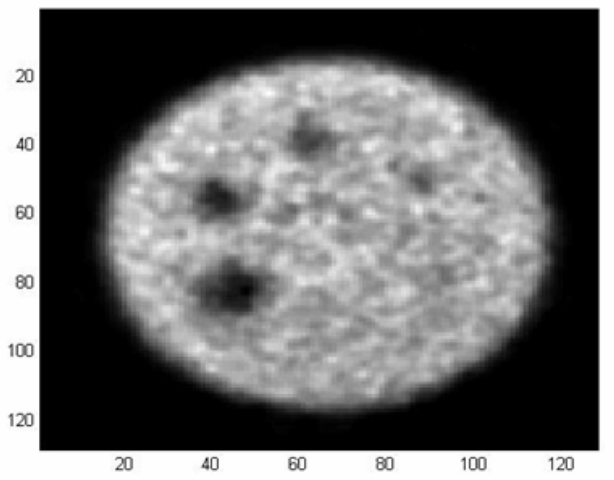

D

Figura 27 OSEM, 3it8s (A), OSEM, 3it16s (B), OSEM+CNUA+CE, 3it8s (C) e OSEM+CNUA+CE, 3it16s (D). Alteração no número de subsets da reconstrução melhora do contraste entre as lesões frias e o background.

A correção uniforme de atenuação aplicada sobre as imagens durante 0 processo de reconstrução melhora a detectabilidade e as fronteiras das estruturas, por excluir o efeito de borda existente nas reconstruções sem correção de atenuação garantindo, por fim, uma melhor precisão diagnóstica numa análise observacional principalmente em relação a estruturas próximas das bordas do objeto apesar de o ganho no contraste calculado é baixo ou inexistente sendo calculada uma leve redução no contraste. Entretanto, quando combinada à correção de espalhamento, o contraste aumenta, bem como a detectabilidade subjetiva através do ganho nos valores do contraste na região das bordas. A correção uniforme de atenuação combinada à correção de espalhamento (CE) resultou em um ganho no contraste em todos os métodos de reconstrução, sendo que o ganho variou de 18,0 a 23,4\% para a reconstrução pelo método FBP, 19,4 a 25,9\% para MLEM e 17,5 a $27,0 \%$ para o OSEM. O contraste percentual entre a maior esfera e o background para os diferentes métodos de reconstrução pode ser analisado na Tabela 9. 


\begin{tabular}{|c|c|c|c|c|c|c|}
\hline & \multicolumn{6}{|c|}{ Contraste (\%) } \\
\hline $\begin{array}{c}\text { Aquisição } \\
\text { FBP }\end{array}$ & $\begin{array}{c}\text { FBP + CUA + } \\
\text { CE }\end{array}$ & MLEM & $\begin{array}{c}\text { MLEM + CUA + } \\
\text { CE }\end{array}$ & OSEM & $\begin{array}{c}\text { OSEM + CUA + } \\
\text { CE }\end{array}$ \\
\hline $1\left(^{*}\right)$ & & & 19,00 & 45,89 & 39,04 & 60,52 \\
\hline 1 & 57,35 & 71,71 & 54,97 & 71,09 & 52,96 & 69,25 \\
\hline 2 & 42,24 & 52,87 & 54,43 & 71,34 & 47,48 & 60,22 \\
\hline 3 & 54,65 & 68,24 & 62,83 & 79,81 & 58,33 & 73,73 \\
\hline 4 & 50,20 & 64,88 & 60,84 & 77,34 & 57,29 & 73,26 \\
\hline 5 & 63,60 & 80,28 & 62,48 & 83,51 & 58,87 & 76,32 \\
\hline 6 & 61,04 & 79,83 & 59,07 & 79,75 & 50,74 & 69,48 \\
\hline 7 & 62,42 & 76,08 & 56,16 & 69,69 & 45,32 & 54,94 \\
\hline 10 & 49,33 & 64,30 & 49,78 & 63,33 & 50,76 & 64,88 \\
\hline 11 & 58,82 & 74,84 & 58,74 & 75,51 & 45,58 & 58,15 \\
\hline
\end{tabular}

Tabela 9 Contraste entre a maior esfera de acrílico e o background do simulador nas reconstruções sem correção de atenuação e sem correção de espalhamento e reconstruções em que ambas correções são realizadas. Observa-se ganho significativo no contraste principalmente para a reconstrução através do método iterativo OSEM.

Esperava-se que a atividade no interior do simulador no momento da aquisição fosse influenciar no resultado do contraste entre as estruturas avaliadas, contudo, nota-se uma semelhança entre os resultados do contraste analisado para um mesmo método de reconstrução de imagens sem parente correlação com a atividade do radionuclídeo no interior do simulador. Para avaliar a existência ou não desta correlação, calculou-se o coeficiente de correlação de Pearson entre os valores do contraste de cada reconstrução com a atividade de radionuclídeo existente no interior do simulador é apresentado na Tabela 10 e indicou que os valores correlacionam-se por um nível de correlação, $\mathrm{n}_{\text {cor }}$, de -0,54, -0,48, -0,33, 0,36, - -0,20 e -0,25 respectivamente para os diferentes métodos de reconstrução, FBP, FBP + CUA + CE, MLEM, MLEM + CUA + CE, OSEM e OSEM+ CUA + CE. O sinal negativo de $\mathrm{n}_{\text {cor }}$ indica que, tratando-se de uma lesão fria simulada, com o aumento da atividade na região que o circunda, o contraste deveria diminuir. Quanto mais próximo de um valor unitário, maior seria esta correlação. Portanto, constatouse a independência entre estes fatores.

\begin{tabular}{|c|c|c|c|c|c|c|}
\hline & FBP & $\begin{array}{c}\text { FBP + CUA + } \\
\text { CE }\end{array}$ & MLEM & $\begin{array}{c}\text { MLEM + CUA + } \\
\text { CE }\end{array}$ & OSEM & $\begin{array}{c}\text { OSEM + } \\
\text { CUA + CE }\end{array}$ \\
\hline$n_{\text {cor }}$ & $-0,54$ & $-0,48$ & $-0,33$ & $-0,36$ & $-0,20$ & $-0,25$ \\
\hline$p$ & 0,13 & 0,19 & 0,40 & 0,34 & 0,61 & 0,52 \\
\hline
\end{tabular}

Tabela 10 Nível de correlação entre a atividade no interior do simulador e o contraste entre a maior esfera e o background para cada um dos métodos de reconstrução de imagem

A correção de espalhamento através do método da Tripla Janela de Energia aumenta o contraste entre as estruturas imageadas sob o preço de aumentar o ruído 
estatístico na imagem como um todo (Dewajara, Y. K., et al. 2012). O ruído foi calculado como descrito em 3.2.2. Um baixo valor de SNR indica que a razão entre as contagens e o desvio padrão dos valores são comparáveis e que o sinal pode ser confundido com o ruído, ou seja, deseja-se uma imagem com SNR o mais alto possível uma vez que um alto SNR indica uma imagem cujo sinal é facilmente diferenciável do ruído. Na Tabela 11, destacam-se os baixos valores de SNR para a reconstrução das imagens através do método $\mathrm{FBP}$, indicando o alto ruído existente nas respectivas imagens, apesar de que o contraste entre a esfera e background seja alto, o baixo valor de SNR não é aceitável, uma vez que o poder preditivo do diagnóstico passa a ser comprometido com o alto índice de ruído na imagem.

\begin{tabular}{|c|c|c|c|c|c|c|}
\hline & \multicolumn{6}{|c|}{ SNR } \\
\hline Aquisição & FBP+CUA & $\begin{array}{c}\text { FBP+CUA } \\
+ \text { CE }\end{array}$ & MLEM+CUA & $\begin{array}{c}\text { MLEM+CUA } \\
+ \text { CE }\end{array}$ & OSEM+CUA & $\begin{array}{c}\text { OSEM+CUA } \\
+ \text { CE }\end{array}$ \\
\hline $1\left(^{*}\right)$ & & & 37,9593 & 23,35 & 17,0995 & 9,86 \\
\hline 1 & 5,2197 & 3,74 & 10,0749 & 8,00 & 9,0494 & 5,29 \\
\hline 2 & 8,6218 & 5,87 & 14,5673 & 9,52 & 20,9874 & 13,90 \\
\hline 3 & 8,4134 & 5,46 & 11,7889 & 8,39 & 10,9436 & 7,67 \\
\hline 4 & 6,5065 & 4,38 & 11,7170 & 8,79 & 14,5185 & 10,20 \\
\hline 5 & 6,5724 & 3,99 & 11,3608 & 6,20 & 12,0142 & 7,43 \\
\hline 6 & 7,3759 & 5,11 & 13,7612 & 9,70 & 13,3614 & 8,28 \\
\hline 7 & 5,9312 & 4,21 & 13,2416 & 9,06 & 12,3972 & 9,01 \\
\hline 10 & 8,6589 & 6,48 & 16,6465 & 13,10 & 13,6431 & 10,19 \\
\hline 11 & 9,333 & 6,03 & 19,3932 & 11,01 & 12,3123 & 9,33 \\
\hline
\end{tabular}

Tabela 11 SNR das imagens com correção de atenuação e sem correção de espalhamento e das imagens com ambas correções indicando a deterioração do sinal ao aplicar a correção de espalhamento

Já era esperado que os valores de SNR para as imagens reconstruídas com os métodos iterativos MLEM e OSEM com correção uniforme de atenuação e de espalhamento diminuíssem em relação ao SNR das imagens sem correção. Contudo, clinicamente, a análise de uma imagem é feita através de observação e, na análise observacional das imagens, percebe-se o aumento do contraste muito mais evidente do que o aumento do ruído. Deste modo, a correção de espalhamento é indicada por apresentar maior ganho no contraste do que redução da SNR. Tratando-se do método FBP, o ruído possui presença significativa nas imagens reconstruídas através do método independente de haver ou não correção de espalhamento. 

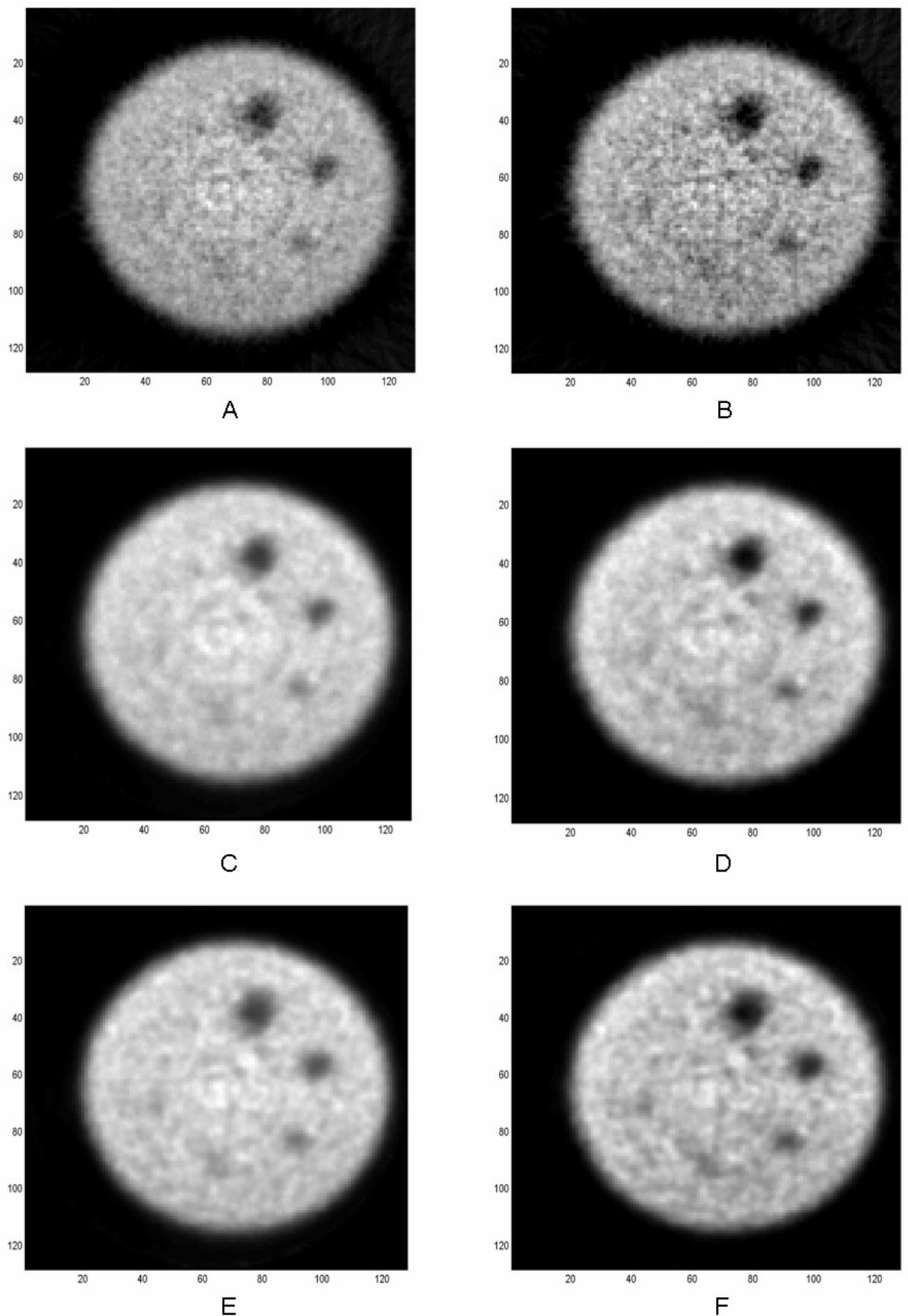

Figura 28 Reconstruções FBP+CUA (A), FBP+ CUA+CE (B), MLEM+CUA (C), MLEM+ CUA+ CE (D), OSEM+CUA (E) e OSEM+ CUA+ CE (F). A evidente presença de ruído na imagem cuja reconstrução foi através do método FBP e o aumento do contraste entre as esferas de acrílico e o background. $\mathrm{Na}$ análise visual, a reconstrução pelo método OSEM apresenta menos ruído do que as demais. $\mathrm{Na}$ análise quantitativa, os métodos iterativos não apresentam diferença percentual significativa. Imagens reconstruídas da aquisição 10. 
As reconstruções iterativas, MLEM e OSEM (Figura $26 \mathrm{C}$ a F) assemelham-se muito entre si em termos do borramento da imagem e do aumento do contraste das porções com distintas densidades inseridas no simulador em relação a quando aplicada a correção uniforme de atenuação e a correção de espalhamento. De um modo geral, o método de reconstrução MLEM, apresentou melhores resultados quantitativos de contraste e SNR. Quando analisadas por observação, os dois métodos apresentaram imagens relativamente parecidas, apesar de que as esferas visíveis na imagem reconstruídas com o método MLEM realmente aparentam ser mais escuras do que as esferas visíveis nas imagens reconstruídas com OSEM, confirmando o maior contraste quando as imagens são reconstruídas com o método MLEM. Em contrapartida, quando a imagem é reconstruída pelo método OSEM, e sob análise observacional, demonstra melhor a presença de 5 das 6 esferas existentes. Nenhum dos métodos permitiu a visualização das 6 esferas de acrílico. A correção de espalhamento, em ambas reconstruções, apesar de aumentar o ruído, não tornou um método menos eficiente a outro.

Como de acordo com a proposta da reconstrução OSEM, o método realizou a reconstrução das imagens com mais rapidez do que as imagens reconstruídas com o MLEM, ainda mais quando o número de iterações utilizadas foi alto. Este não foi o propósito de análise deste trabalho, porém, com o avanço computacional, a diferença de segundos não pode ser considerada determinante para escolher um método a outro ainda mais que esta diferença de tempo para reconstrução tende a diminuir com o avanço e aprimoramento da capacidade computacional. Portanto, a reconstrução com alto número de iterações torna-se clinicamente possível e esperase resultados mais verossimilhantes com a real distribuição do radionuclídeo. Dewajara, Y. K, et al., 2012 propõe o uso de número de iterações aproximado de trinta (30) iterações para maior precisão em objetos grandes e, para objetos pequenos, um número maior ainda. A recomendação do fabricante para reconstrução iterativa baseada na estimativa inicial sendo a reconstrução FBP, é de utilizar entre dez (10) e quinze (15) iterações. Contudo, altos valores para quantidade de iterações geram imagens mais nítidas à custa do aumento do ruído como pode ser visto na Figura 27. Ou seja, os parâmetros para ajuste e aumento do contraste interferem diretamente no ruído da imagem. Neste caso, vale a não utilização de um alto número de iterações, visando não aumentar o ruído e aplicar 
filtros pós reconstrução ou simplesmente, um filtro passa baixa no processo da reconstrução.

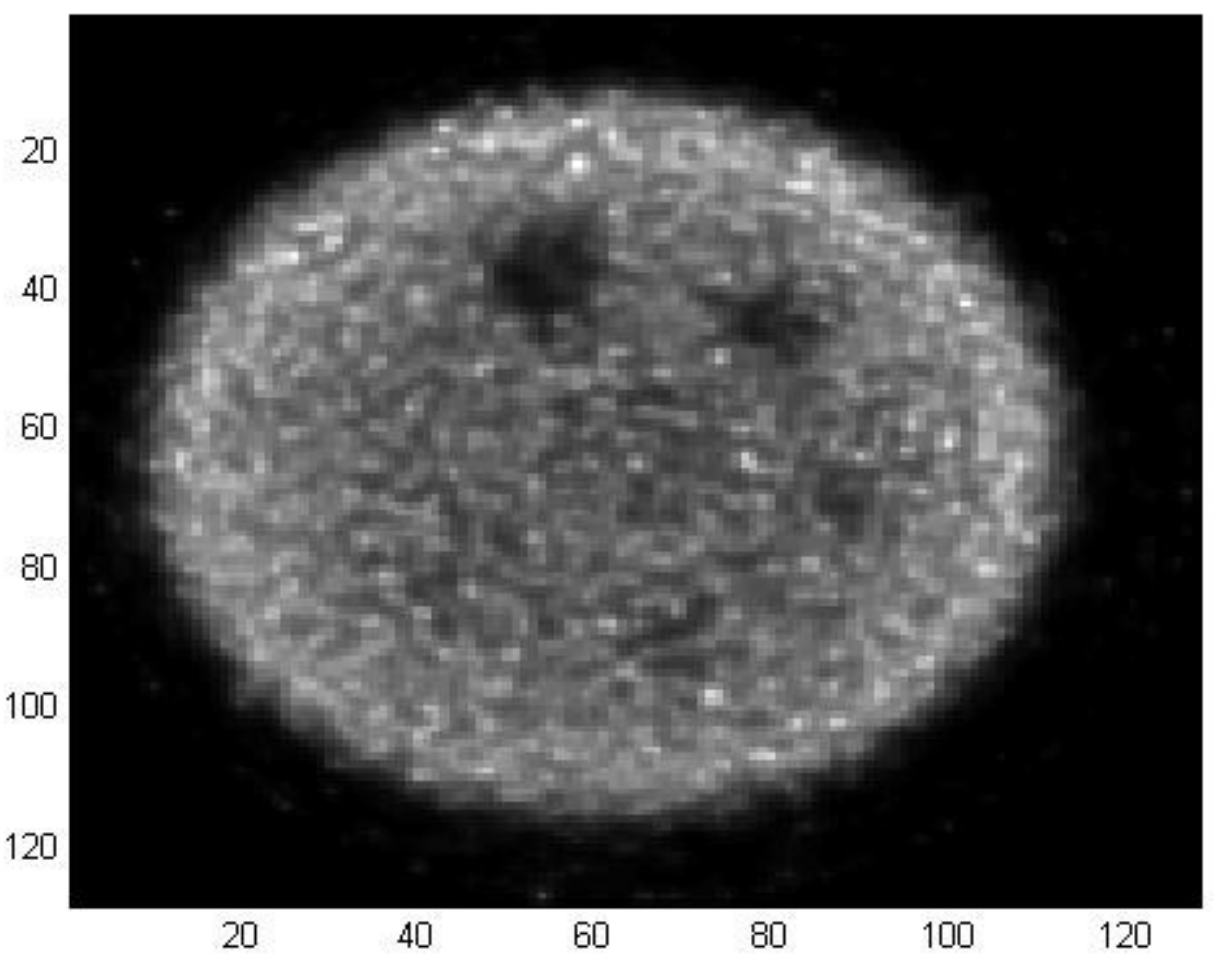

Figura 29 Imagem reconstruída com 30 iterações e 16 subsets resultando em uma imagem com alto ruído estatístico. Devido a grande presença de ruído, a imagem perde poder diagnóstico.

A fim de avaliar os efeitos da frequência de corte do filtro Butterworth sobre o contraste entre a maior esfera fria e o background, as imagens foram reconstruídas utilizando os mesmos parâmetros de reconstrução do método (25it para o método MLEM e 3it16s para o método OSEM) e somente a frequência de corte foi alterada. A Tabela 12 apresenta o contraste percentual entre as estruturas para a aquisição de número 4 reconstruída de acordo com estes parâmetros.

\begin{tabular}{|c|c|c|c|c|}
\hline & \multicolumn{4}{|c|}{ Contraste (\%) } \\
\hline & MLEM + CUA & MLEM + CUA + CE & OSEM + CUA & OSEM + CUA + CE \\
\hline$f=0,34$ & 59,10 & 77,34 & 55,38 & 73,26 \\
\hline$f=0,10$ & 29,99 & 40,40 & 32,18 & 43,25 \\
\hline
\end{tabular}

Tabela 12 Contraste percentual entre a maior esfera de acrílico e o background quando o parâmetro frequência de corte do filtro Butterworth é alterado. O parâmetro padrão para reconstrução é tomado como $\mathbf{f}=\mathbf{0 , 3 4}$. 
Os valores obtidos para o contraste, numa análise quantitativa, indicam que a reconstrução de acordo com o parâmetro padrão ( $f=0,34)$ é mais indicada, e, numa análise qualitativa, a imagem reconstruída com o parâmetro teste apresenta amaciamento exagerado, causando o negligenciamento de estruturas. A imagem é substancialmente homogênea, mas a supressão do ruído elimina também sinal importante para a visualização das estruturas frias no interior do simulador. As Figuras 28 e 29 mostram esta questão. Fica a critério do corpo médico definir qual frequência de corte mais indicada para cada situação clínica.

Devido a instabilidades do sistema de detecção, as imagens apresentam artefato de reconstrução na área central da imagem. 


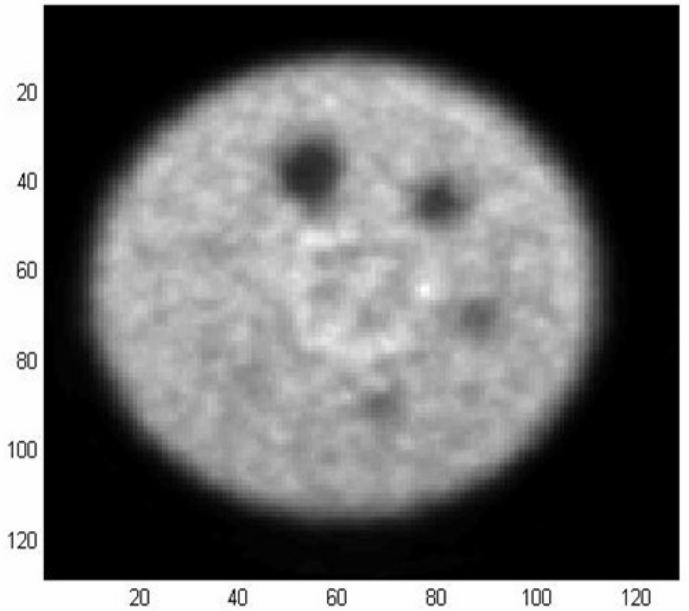

A

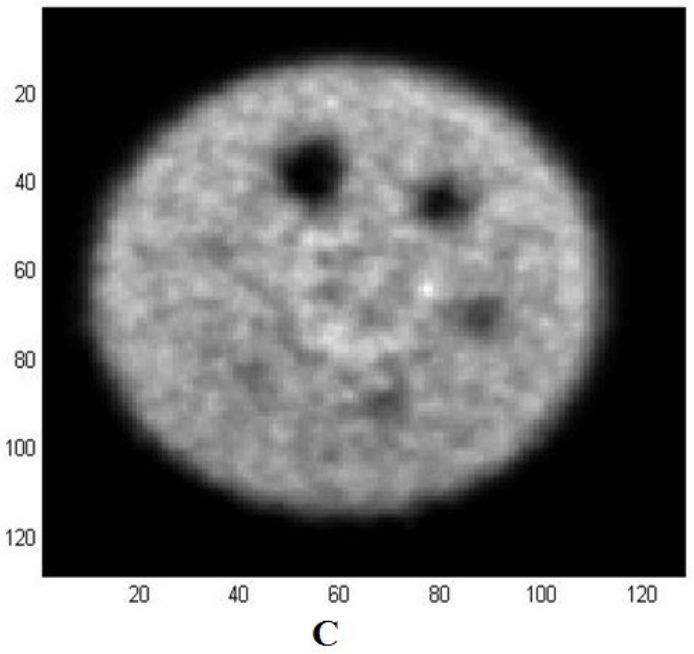

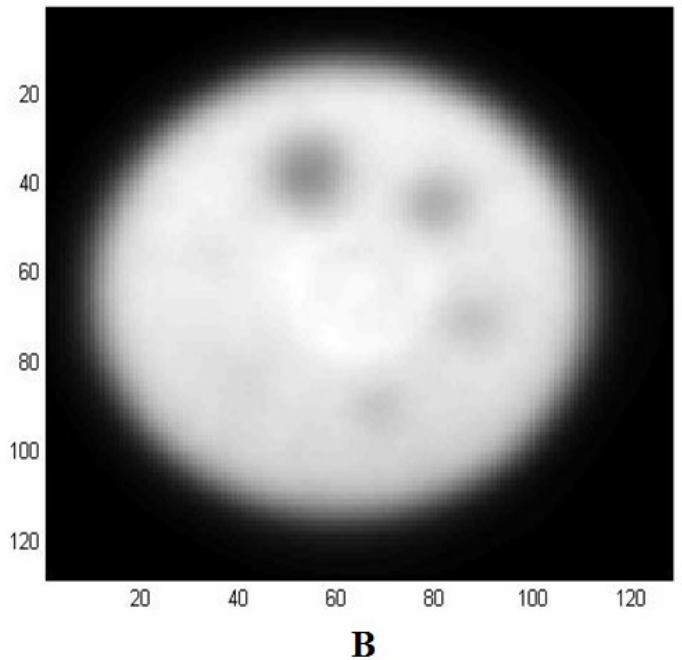

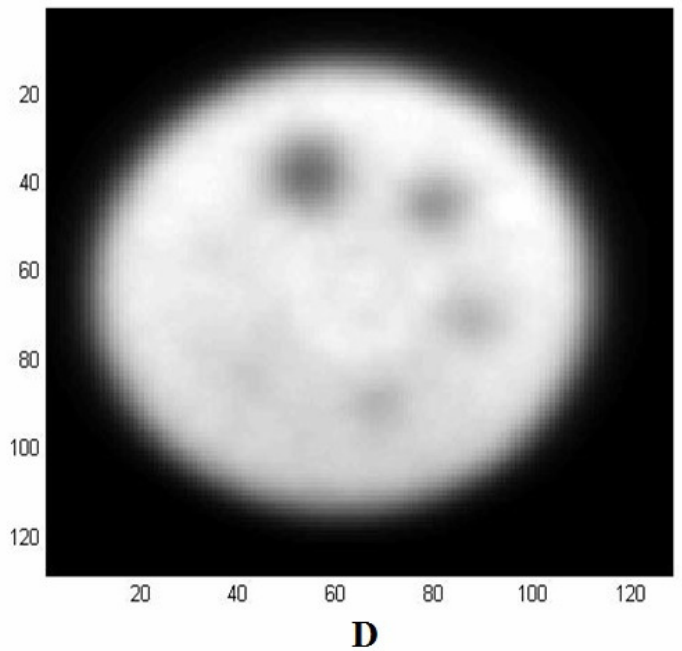

Figura 30 MLEM + CUA, $f=0,34$ (A) MLEM + CUA, $f=0,1(B), M L E M+C U A+C E, f=0,34$ (C) $e$ MLEM + CUA + CE, $f=0,1$ (D). Comparação entre as imagens com diferente parâmetro de frequência de corte do filtro Butterworth. Baixa frequência de corte gera imagens mais homogêneas com o preço de praticamente negligenciar estruturas. 

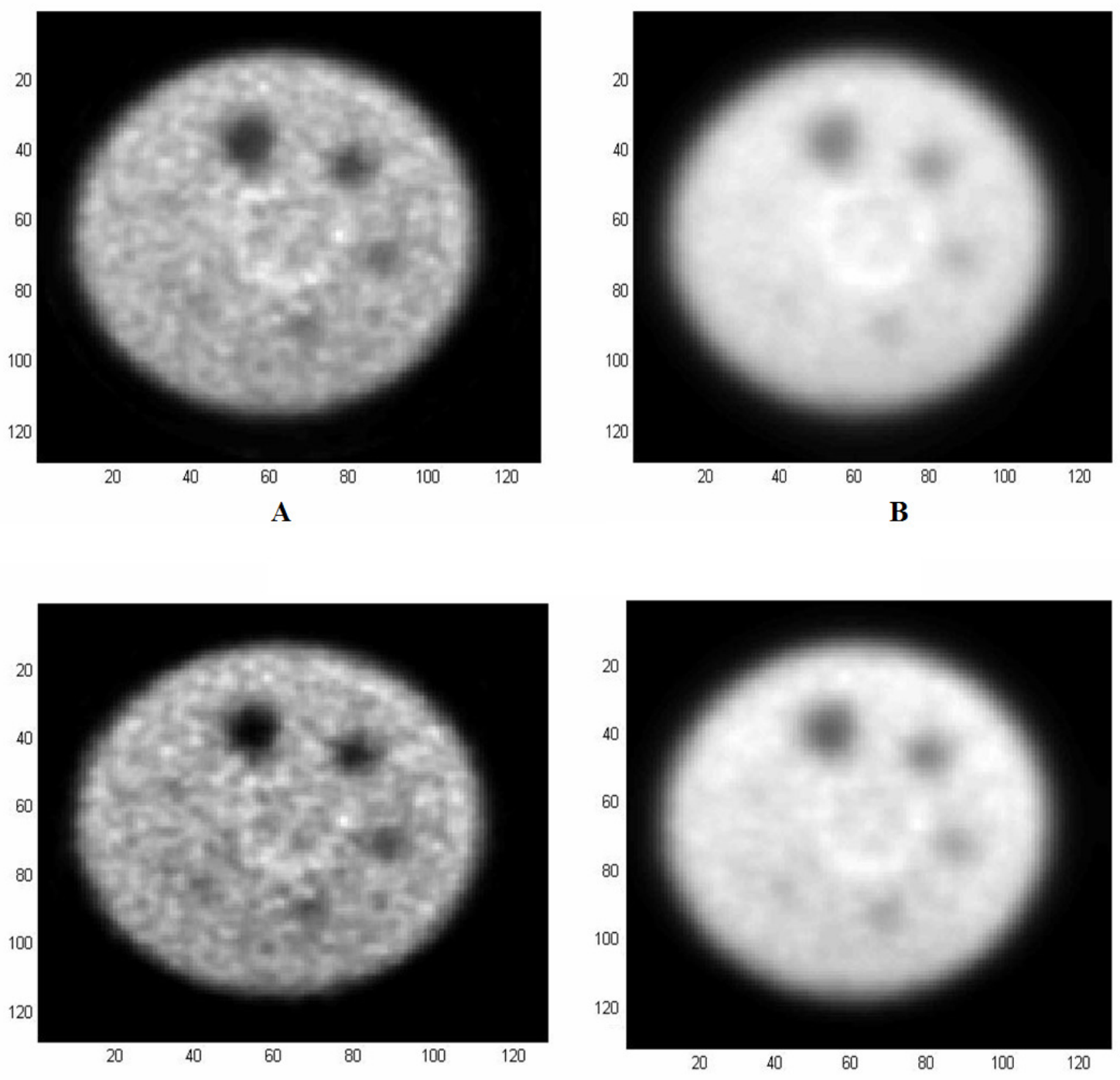

C

D

Figura 31 OSEM + CUA, $f=0,34$ (A) OSEM + CUA, $f=0,1(B)$, OSEM + CUA + CE, $f=0,34$ (C) $e$ OSEM + CUA + CE, $f=0,1$ (D). Comparação entre as imagens com diferente parâmetro de frequência de corte do filtro Butterworth. Assim como no método MLEM, a baixa frequência de corte gera imagens mais homogêneas com o preço de praticamente negligenciar estruturas quando reconstrói-se imagens utilizando o método OSEM. 


\section{CONCLUSÃO}

O presente trabalho apresentou a comparação entre os diferentes métodos de reconstrução de imagens em Medicina Nuclear existentes no software do tomógrafo instalado no setor de Medicina Nuclear do Hospital de Clínicas da Faculdade de Medicina da Universidade de São Paulo, campus Ribeirão Preto, bem como uma avaliação da correção de atenuação aplicada pelo software seguindo os parâmetros utilizados para reconstrução de imagens SPECT cerebral no referido setor.

Imagens diagnósticas em Medicina Nuclear podem ser reconstruídas com e sem correção de atenuação e a correção de espalhamento, por sua vez, não foi possível ser realizada no software do tomógrafo, o que dificulta a implementação clínica do método na rotina. Contudo, é inegável o aumento do contraste entre as estruturas imageadas quando a correção de espalhamento é aplicada, sendo, portanto, interessante, avaliar sua aplicabilidade à rotina, pois pode gerar ganhos de qualidade aos diagnósticos e/ou pesquisas do setor.

O método analítico de reconstrução de imagem, FBP, atualmente já não é mais utilizado, por mais que o contraste entre as estruturas seja bom e, numericamente até supere o contraste calculado entre as estruturas nas imagens reconstruídas através dos métodos iterativos MLEM e OSEM, o alto índice de ruído na imagem a degrada, fazendo com que perca seu poder preditivo para um diagnóstico preciso.

Os métodos iterativos de reconstrução de imagens, MLEM e OSEM, apresentaram resultados semelhantes de contraste e de SNR. Os métodos iterativos destacam-se por permitir a implementação da correção não uniforme de atenuação, diferentemente dos métodos analíticos, que não a prevêem e a correção de atenuação é dependente apenas da correção uniforme de atenuação. O método MLEM, apresentou contraste ligeiramente mais elevado e melhor relação sinal ruído. Em contrapartida, uma análise qualitativa através da observação das imagens geradas traz o método OSEM como método de reconstrução que menos falso negativos apresenta. Portanto, fica a critério clínico a decisão de qual filtro utilizar para a reconstrução das imagens.

De acordo com a avaliação de imagens do simulador Jaszczak e análise do contraste entre de simulações de lesões frias e o background, o método e 
parâmetros utilizados como padrão para reconstrução das imagens dos estudos cerebrais, OSEM com 3 iterações, 8 subsets, filtro Butterworth com frequência de corte 0,34 e potencia 1 , apresentou resultados de contraste e SNR inferiores quando comparados à reconstrução utilizando o método OSEM com 3 iterações, 16 subsets,filtro Butterworth com frequência de corte 0,34 e potencia 1. Considerando que o método padrão de reconstrução é o OSEM, propõe-se análise observacional e qualitativa de imagens clínicas com os parâmetros testados e comparação com a imagem reconstruída com o atual padrão de parâmetros de reconstrução e posterior implementação do método OSEM com 3 iterações e 16 subsets como novo método padrão de reconstrução de imagens. 


\section{Referências Bibliográficas}

1. BUShBERG, J. T.; SEIBERT, J. A.; BOONE, J. M. The Essential Physics of Medical Imaging. 2 ed. Lippincott Williams and Wilkings, Philadelphia, 2002.

2. ChERRY, S. R.; SORRENSON, J. A.; PHELPS, M. E. Physics in Nuclear Medicine. 4. ed. Philadelphia, EUA: Saunders Elsevier, 2012.

3. PATTON, J. A. e TURKIMGTON, T. G. SPECT/CT Physical Principles and Attenuation Correction. Journal of Nuclear Medicine Technology. Vol 36. № 1, March, 2008.

4. OGAWA, K. et al. A practical method for position dependent comptonscatter correction in single photon emission CT. IEEE Transactions of Medical Imaging, vol. 10 no. 3, 1991.

5. GODOI, W. C. Disponível em

<http://www.walmorgodoi.com/arquivos/Palestra_Reconstrucao_Imagens.pdf> . Acesso em 15 set 2013.

6. JASZCZAK phantom. Imagem. Disponível em <http://www.biodex.com/nuclear-medicine/products/pet-positron-emissiontomography/pet-phantoms/jaszczak-spect-phantom>. Acesso em 20 mai 2012.

7. PEREIRA, R. Apostila de Tomografia Computadorizada. Disponível em <http://www.ebah.com.br/content/ABAAAAtZoAL/apostila-tomografiacomputadorizada?part=7>. Acesso em 12/11/2013.

8. CHORNOBOY, E. S., et al.An Evaluation of Maximum Likelihood Reconstruction for SPECT.IEEE Transactions On Medical Imaging. vol. 9. No. 1, 1990.

9. FARID, K; et al. CT Nonuniform Attenuation and TEW Scatter Corrections in Brain Tc-99m ECD SPECT. Clinical Nuclear Medicine. Vol 36, No. 8, Agosto, 2011.

10. DEWARAJA, Y. K. et al. MIRD Pamphlet No. 23: Quantitative SPECT for Patient-Specific 3-Dimensional Dosimetry in Internal Radionuclide 
Therapy. Journal of Nuclear Medicine. Vol. 53. No. 8. Agosto, 2012. 1310$1325 \mathrm{p}$.

11. FAHEY, F Het al. Sensitivity, Resolution and Image Quality with a tivity was determined by counting a small area source. Journal of Nuclear Medicine. Vol. 33. No. 10. Outubro, 1992. 1859-1863 p.

12.DELBEKE, D. et al. Procedure Guideline for SPECT/CT Imaging 1.0. Disponível em <http://www.snm.org/guidelines>. Acesso em 20 jun 2012.

13. HASHIMOTO, J. et al.Scatter and Attenuation Correction in Technetium99m Brain SPECT. Journal of Nuclear Medicine. Vol. 38. No. 1. Janeiro, 1997.

14.ISHII, K. et al.Impact of CT attenuation correction by SPECT/CT in brain perfusion images. Annals of Nuclear Medicine. Vol. 26. No. 3., Janeiro, 2012. 241-247 p.

15.BRUYANT, P. P. Analytic and iterative reconstruction algorithms in SPECT. Journal of Nuclear Medicine. Vol. 43. No. 10. Outubro, 2002. 1343$1358 \mathrm{p}$.

16.PHILIPS MEDICAL SYSTEMS. JETPack for JETStream Workspace Release 1.0. 2007. 254 p.

17. MOTOMURA, N. Evaluation of a SPECT Attenuation Correction Method Using CT Data Registered with Automatic Registration Software.Nuclear Science Symposium Conference Record, 2003 IEEE. Vol. 4. 19-25 outubro 2003.

18.ROSENTHAL, M S. et al. Quantitative SPECT imaging: a review and recommendations by the Focus Committee of the Society of Nuclear Medicine Computer and Instrumentation Council. Journal of Nuclear Medicine. Vol. 36. No. 8. Agosto, 1995. 1489-1513 p.

19.SIEGEL, J. A. et al. MIRD pamphlet no. 16: Techniques for quantitative radiopharmaceutical biodistribution data acquisition and analysis for use in human radiation dose estimates. Journal Of Nuclear Medicine. Vol. 40. No. 2. Fevereiro, 1999. 37S-61S p. 
20.SOARES, E.J.; BARRETT, H.H.; KRUPINSKI, E.A. Noise properties of attenuation correction methods for SPECT. IEEE Conference Record Nuclear Science Symposium and Medical Imaging Conference, 1993.

21. WIECZOREK, H. SPECT Image Quality and Quantification. IEEE Nuclear Science Symposium Conference Record, 2006. 2854-2858 p. 